\title{
Dynamic Transformation during the Simulated Hot Rolling of an API-X80 Steel
}

\author{
Nizia Mendes Fonseca
}

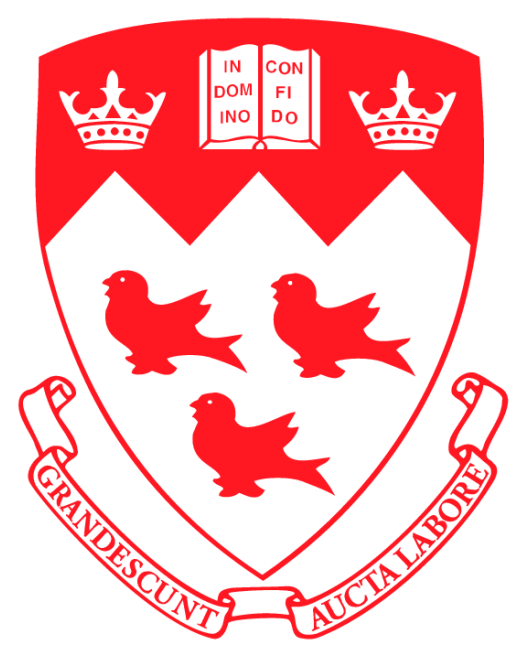

Department of Mining and Materials Engineering

McGill University, Montreal

April 2019

A thesis submitted to McGill University in partial fulfillment of the requirements of the degree of Masters of Engineering

(C) Nizia Mendes Fonseca 2019 


\begin{abstract}
Dynamic transformation (DT) is defined as the phase transformation that occurs during deformation. In steels, austenite can dynamically transform into ferrite above the equilibrium transformation temperature $\mathrm{Ae}_{3}$. The occurrence of DT during the simulated hot rolling of an API$\mathrm{X} 80$ steel is described in the present study. Torsion tests were carried out under continuous cooling conditions over the temperature range 920 to $830{ }^{\circ} \mathrm{C}$, all of which are above the calculated $\mathrm{Ae}_{3}$ temperature. Interpass times of 1, 8 and $20 \mathrm{~s}$ were examined. Samples were water quenched before and after the odd-numbered passes and the volume fractions of ferrite and martensite (prior austenite) were determined. The formation of DT ferrite was observed under all conditions, the volume fraction of which increased with strain. As a result of DT, the increase in flow stress with strain was less than expected under all conditions. When longer interpass times were employed, the stress levels were higher because ferrite transforms back into the harder austenite during holding after deformation. The critical strains for the onset of DT and dynamic recrystallization (DRX) were determined using the double differentiation method. The driving forces and energy barriers for DT were also calculated, indicating that the occurrence of DT is thermodynamically possible during hot rolling.
\end{abstract}




\section{RÉSUMÉ}

La transformation dynamique (TD) est définie comme la transformation de phase qui a lieu pendant la déformation. Dans l'acier, l'austénite peut transformer de manière dynamique en ferrite au-dessus de la température de transformation à l'équilibre $\mathrm{Ae}_{3}$. La présente étude analyse l'occurrence de la TD lors du laminage à chaude simulé d'un acier oléoduc X80. Des essais de torsion ont été réalisés dans des conditions de refroidissement continu à travers la gamme de température $920-830{ }^{\circ} \mathrm{C}$, c'est-à-dire au-dessus de la température $\mathrm{Ae}_{3}$ calculée. Des temps d'interpassage de 1,8 et $20 \mathrm{~s}$ ont été examinés. Les échantillons ont été trempés à l'eau avant et après les passes de nombre impair et les fractions volumiques de ferrite et martensite (austénite antérieure) ont été déterminés. La formation de ferrite TD a été observée sous toutes les conditions et sa fraction volumique a augmenté avec la déformation. Comme une preuve de la TD, l'augmentation de la contrainte avec la déformation a été inférieure aux prévisions sous toutes les conditions. Lorsque les temps d'interpassage plus longs étaient utilisés, les niveaux de contrainte ont été plus élevés car la ferrite se reconvertit en austénite lors du temps de maintien après la déformation. Les déformations critiques pour l'apparition de TD et de la recristallisation dynamique (RD) ont été déterminées à l'aide de la méthode de différentiation double. La force motrice et l'énergie d'activation de la TD ont également été calculées, indiquant que l'occurrence de la TD est thermodynamiquement possible lors du laminage à chaude. 


\section{Contributions of THE Authors}

This thesis was prepared according to the guidelines of the Graduate and Postdoctoral Studies Office for a manuscript-based thesis. The present document is based on the following manuscript:

Nizia Mendes-Fonseca, Samuel F. Rodrigues, Baoqi Guo and John J. Jonas, "Dynamic transformation during the simulated hot rolling", submitted to Steel Research International, $\operatorname{srin} .201900091$.

The manuscript was co-authored with Prof. John J. Jonas, who actively supervised my research. Dr. Samuel F. Rodrigues trained me on using the torsion machine and helped me during the torsion tests, metallography and analysis of the results. Baoqi Guo helped me with the thermodynamic calculations. 


\section{ACKNOWLEDGMENTS}

First and foremost, I would like to express my sincerest gratitude to my supervisor, Prof. Jonas, for his guidance, expertise, enthusiasm, patience and financial support during my journey at McGill. I would also like to acknowledge my co-supervisor Prof. Yue for his assistance and for providing a good environment for research.

I am thankful to my colleagues for the great time we spent together, especially to Dr. Samuel Rodrigues for being a good friend and for his valuable help in every step of my project. His support was essential for successfully completing this thesis.

I acknowledge with gratitude the financial assistance from the Natural Sciences and Engineering Research Council of Canada (NSERC).

Finally, I thank my mother sincerely for her unconditional love and constant encouragement throughout my years of study. 


\section{TABLE OF CONTENTS}

Abstract

Résumé

Contributions of the Authors

Acknowledgments $\quad$ iv

List of Figures $\quad$ viii

List of Tables $\quad$ xiii

$\begin{array}{ll}\text { Chapter 1: Introduction } & 1\end{array}$

1.1 Introduction 1

$\begin{array}{ll}1.2 \text { References } & 2\end{array}$

Chapter 2: Literature Review $\quad 5$

2.1.1 Mean Flow Stress (MFS) 9

$\begin{array}{lll}2.1 .2 & \text { Recovery } & 10\end{array}$

$\begin{array}{lll}2.1 .3 & \text { Recrystallization } & 10\end{array}$

2.2 Iron-Carbon Phase Diagram 13

$\begin{array}{lll}2.3 & \text { Phase Transformations of Austenite } & 15\end{array}$

2.3.1 Reconstructive Transformations 16

2.3.2 Displacive Transformations 19

2.4 Dynamic Transformation 22 
2.4.2 Thermodynamics of Dynamic Transformation

2.4.3 Critical Stress for Dynamic Transformation

$\begin{array}{lll}2.4 .4 & \text { Reverse Transformation } & 38\end{array}$

$\begin{array}{lll}2.5 & \text { Torsion Testing } & 39\end{array}$

$\begin{array}{llr}2.6 & \text { References } & 40\end{array}$

Chapter 3: Dynamic Transformation during the Simulated Hot Rolling of an API-X80 Steel 44

3.1 Abstract 45

$\begin{array}{lll}3.2 & \text { Introduction } & 45\end{array}$

3.3 Experimental Section 46

$\begin{array}{llr}\text { 3.4.1 Torsion Testing } & 47\end{array}$

$\begin{array}{lll}\text { 3.4.2 Metallography } & 48\end{array}$

3.4 Results 49

3.4.1 Stress-Strain Curves $\quad 49$

3.4.2 Dynamic Transformation Microstructures $\quad 50$

3.5 Discussion $\quad 53$

3.5.1 Mean Flow Stress $\quad 53$

3.5.2 Critical Strain for the initiation of dynamic transformation 55

$\begin{array}{lll}\text { 3.5.3 } & \text { Ferrite Volume Fractions } & 57\end{array}$

3.5.4 Thermodynamics of Dynamic Transformation 59 
3.6 Conclusions

3.7 Acknowledgments

3.8 References

Chapter 4: Summary 


\section{LIST OF FIGURES}

Figure 2.1: Layout of a plate rolling mill [2.1]. $\quad 6$

Figure 2.2: Layout of a hot strip rolling mill [2.2].

Figure 2.3: Schematic representation of deformation above the $T_{n r}$, with the complete recrystallization of austenite between passes [2.4]. $\quad 8$

Figure 2.4: Schematic representation of deformation below the $\mathrm{T}_{\mathrm{nr}}$, with partial recrystallization between passes and the formation of "pancaked" austenite grains [2.4]. 8

Figure 2.5: Mean flow stress behaviour during deformation of a microalloyed steel from 1200 to $720{ }^{\circ} \mathrm{C}[2.5]$.

Figure 2.6: Effect of DRX on the stress-strain curve at high strain rates [2.7].

Figure 2.7: Flow curves of a plain steel $(0.25 \% \mathrm{C})$ deformed at $1100{ }^{\circ} \mathrm{C}$ and at different strain rates [2.8].

Figure 2.8: The Fe-C phase diagram [2.9].

Figure 2.9: Schematic illustration of the displacive and reconstructive mechanisms of transformation. The parent crystal (left) contains two types of atoms. On the right, the figures represent partially transformed samples with the parent and product unit cells outlined [2.10]. 16

Figure 2.10: Formation mechanisms of allotriomorphic and idiomorphic ferrite [2.13].

Figure 2.11: Schematic representation of pearlite formation from austenite, showing the lamellar structure of ferrite plates and cementite [2.9].

Figure 2.12: Colonies of pearlite [2.9].

Figure 2.13: Schematic time-temperature-transformation (TTT) diagram for a steel [2.10]. 20

Figure 2.14: Martensite morphology of a medium C steel [2.14]. 20

Figure 2.15: Schematic representation of the formation of upper and lower bainite [2.10]. 21 
Figure 2.16: Schematic representation of the nucleation of primary and secondary Widmanstätten ferrite [2.15].

Figure 2.17: Stress-strain curves and corresponding microstructural changes of a plain steel during deformation above and below the $\mathrm{Ae}_{3}$ temperature [2.17].

Figure 2.18: Volume change during isothermal holding after deformation [2.16,2.17].

Figure 2.19: X-ray diffraction patterns. a) Before heating; b) after full austenitization and before deformation; c) deformed at a strain rate of $0.09 \mathrm{~s}^{-1}$ above the $\mathrm{Ae}_{3}$ temperature [2.18].

Figure 2.20: Dilatation curves of the specimen during isothermal holding after deformation at various temperatures above $\mathrm{Ae}_{3}[2.21]$.

Figure 2.21: Microstructures of the specimens quenched (a) immediately after deformation at $850{ }^{\circ} \mathrm{C}\left(\mathrm{Ae}_{3}+15^{\circ} \mathrm{C}\right)$, (b) after $1200 \mathrm{~s}$ of isothermal holding after deformation [2.21].

Figure 2.22: Micrographs of the specimens deformed at $856{ }^{\circ} \mathrm{C}\left(\mathrm{Ae}_{3}+20{ }^{\circ} \mathrm{C}\right)$ at $0.4 \mathrm{~s}^{-1}$ and held isothermally after deformation for: a) $0 \mathrm{~s}$, b) $200 \mathrm{~s}$, c) $400 \mathrm{~s}$. The arrows indicate martensite needles [2.22].

Figure 2.23: SEM and TEM images of the $0.79 \% \mathrm{C}$ steel deformed to a strain of 4.0 at $763{ }^{\circ} \mathrm{C}$ $\left(\mathrm{Ae}_{3}+30^{\circ} \mathrm{C}\right)$. a) SEM image, b) and c) TEM images (with diffraction patterns inserted) showing the presence of ferrite and cementite [2.23].

Figure 2.24: EBSD maps of the $0.21 \% \mathrm{C}$ steel deformed to 0.25 at $862{ }^{\circ} \mathrm{C}\left(\mathrm{Ae}_{3}+30{ }^{\circ} \mathrm{C}\right)$. a) Orientation image map of the ferrite phase (radial direction), black regions are martensite. b) Orientation image map of the ferrite phase (longitudinal direction). c) Orientation image map of the martensite phase (radial direction), black regions are ferrite. d) Misorientations measured along the line in (a) [2.23]. 
Figure 2.25: Schematic illustration of the microstructural evolution as a function of strain and temperature at temperatures above the $\mathrm{Ae}_{3}[2.25]$. 31

Figure 2.26: Schematic illustration of the stored energy model [2.28]. 33

Figure 2.27: Schematic illustration of the stress activation model [2.28]. 34

Figure 2.28: Geometries associated with the dilatation and shear accommodation work during the formation of Widmanstätten ferrite from austenite [2.28]. 34

Figure 2.29: Transformation softening model [2.30]. 36

Figure 2.30: a) Experimental flow curve obtained from torsion test of a steel containing $0.79 \% \mathrm{C}$ at $763{ }^{\circ} \mathrm{C}\left(\mathrm{Ae}_{3}+30^{\circ} \mathrm{C}\right)$ together with the fitted curve using the polynomial of order $\left.8 . \mathrm{b}\right) \theta$ versus $\sigma$ plot derived from the fitted curve in (a), the inset shows the $-(\partial \theta / \partial \sigma)$ versus $\sigma$ curve [2.33]. 37 Figure 2.31: TTRT curves for a Nb microalloyed steel. The solid lines cover the temperature range of the study and the broken lines are projections of the behaviour outside this range. The actual results are plotted by points. [2.34]. 38

Figure 2.32: Schematic illustration of the torsion machine. 39

Figure 3.1: Thermomechanical schedule for the torsion tests under continuous cooling conditions. Two roughing passes were applied at $1100{ }^{\circ} \mathrm{C}$ (strain of 0.4 at a strain rate of $1.0 \mathrm{~s}^{-1}$ and seven finishing passes were applied at $920,905,890,875,860,845$ and $830{ }^{\circ} \mathrm{C}$ (strain of 0.2 at a strain rate of $\left.1.0 \mathrm{~s}^{-1}\right)$. Interpass times of 1,8 and $20 \mathrm{~s}$ were employed, which corresponds to cooling rates of $15,1.88$ and $0.75^{\circ} \mathrm{C} \mathrm{s}^{-1}$, respectively.

Figure 3.2: Stress-strain curves of the finishing passes using the thermomechanical schedule of Figure 1 when employing interpass times of a) $1 \mathrm{~s}$, b) $8 \mathrm{~s}$ and c) $20 \mathrm{~s}$.

Figure 3.3: Optical micrographs of the deformed samples with the interpass time of $1 \mathrm{~s}$. The samples were quenched a) before the $1^{\text {st }}$ pass, b) after the $1^{\text {st }}$ pass, c) before the $3^{\text {rd }}$ pass, d) after 
the $3^{\text {rd }}$ pass, e) before the $5^{\text {th }}$ pass, f) after the $5^{\text {th }}$ pass, g) before the $7^{\text {th }}$ pass and $\mathrm{h}$ ) after the $7^{\text {th }}$ pass.

Figure 3.4: Optical micrographs of the deformed samples with the interpass time of $20 \mathrm{~s}$. The samples were quenched a) before the $1^{\text {st }}$ pass, b) after the $1^{\text {st }}$ pass, c) before the $3^{\text {rd }}$ pass, d) after the $3^{\text {rd }}$ pass, e) before the $5^{\text {th }}$ pass, f) after the $5^{\text {th }}$ pass, g) before the $7^{\text {th }}$ pass and $h$ ) after the $7^{\text {th }}$ pass.

Figure 3.5: SEM image of the sample quenched after the $5^{\text {th }}$ pass when employing the interpass time of $1 \mathrm{~s}$, showing the nucleation of DT ferrite at the austenite grain boundaries. F represents the ferrite phase and $\mathrm{M}$ is martensite (prior austenite).

Figure 3.6: MFS's curves obtained from the stress-strain curves of Figure 2. The decrease in the slope of the MFS is evidence of the formation of DT ferrite.

Figure 3.7: The double differentiation method used to identify the critical strains for the onset of DT and DRX of the $5^{\text {th }}$ pass with the interpass time of $1 \mathrm{~s}$. a) Actual flow curve and polynomial fit from the yield stress up to the peak. b) $\theta-\sigma$ plot with the two inflection points related to the critical stresses for DT and DRX identified. c) Plot of the derivative of $\theta$ against $\sigma$, with the two minima corresponding to the critical stresses.

Figure 3.8: Critical strains for the onset of DT and DRX. Interpass times of a) $1 \mathrm{~s}, \mathrm{~b}) 8 \mathrm{~s}$ and c) $20 \mathrm{~s}$.

Figure 3.9: Dependence of the volume fraction of ferrite on the cumulative strain obtained for interpass times of a) $1 \mathrm{~s}, \mathrm{~b}) 8 \mathrm{~s}$ and c) $20 \mathrm{~s}$.

Figure 3.10: Driving force calculation at each pass when employing the interpass time of $1 \mathrm{~s}$. The driving force is given by the difference between the austenite flow stress at the critical strain and 
the Widmanstätten ferrite yield stress, which is $18 \%$ higher than the polygonal ferrite yield stress.

Figure 3.11: Driving force and total energy barrier obtained for each finishing pass with $1 \mathrm{~s}$ of interpass time. The total energy barrier is composed by the Gibbs free energy difference between austenite and ferrite $\left(\Delta \mathrm{G}_{\gamma-\alpha}\right)$, and the work due to shear accommodation $\left(\mathrm{W}_{\mathrm{SA}}\right)$ and dilatation $\left(\mathrm{W}_{\mathrm{D}}\right)$ that arise from the transformation. 


\section{LIST OF TABLES}

Table 2.1: Comparison of hot rolling mills in terms of their ranges of strain rate and interpass time [2.3].

Table 3.1: Chemical composition [wt \%] and orthoequilibrium transformation temperature. 47 


\section{CHAPTER 1: INTRODUCTION}

\subsection{Introduction}

Hot rolling is the most widely used and efficient process for primary forming used in the steel industry. Knowledge regarding microstructure evolution during hot rolling is essential to improve the mechanical properties of the final product and for the development of new steel grades. Generally, the hot rolling process is carried out in the austenite phase field and both hardening and softening phenomena are observed. Hardening takes place due to the increase in dislocation density when straining the material. Traditionally, the softening mechanisms taken into account are recovery (static and dynamic) and recrystallization (static, dynamic and metadynamic), with recrystallization playing a major role in the hot rolling of austenite. However, another softening method should also be considered: dynamic transformation (DT).

In steels, DT refers to the transformation of austenite into ferrite during hot deformation. This phenomenon can occur above the equilibrium transformation temperature $\mathrm{Ae}_{3}$, where austenite is normally the only stable phase. The occurrence of DT above the $\mathrm{Ae}_{3}$ temperature was first reported by Yada et. al. in 1988 [1.1,1.2]. However, this topic gained attention again in 2000, when Yada and co-workers carried out an in situ x-ray diffraction study during hot torsion experiments and confirmed the formation of ferrite above the $\mathrm{Ae}_{3}$ temperature [1.3]. Since then, this topic has been widely studied [1.4-1.8] and it has since been reported that ferrite can be formed dynamically over the entire austenite phase field, up to the $\delta$-ferrite formation temperature [1.9].

The dynamically formed ferrite is Widmanstätten in type, formed through a displacive (diffusionless) mechanism. The Widmanstätten ferrite plates are only 200-300 $\mu \mathrm{m}$ wide, much 
finer than the plates formed below the $\mathrm{Ae}_{3}$ temperature. With increasing strain, these plates coalesce into polygonal grains [1.10]. After unloading, the dynamically formed ferrite, which is a metastable phase, transforms back into austenite through a diffusional process [1.11] that is considerably more sluggish than the displacive mechanism.

A thermodynamic model was proposed by Aranas Jr. and Jonas to explain DT at high temperatures, providing an accurate quantitative description of the phenomenon [1.12]. In their transformation softening model, the driving force for DT is given by the softening resulting from the transformation, since the freshly formed ferrite grains are softer than the prior strain hardened austenite structure. This driving force provides the energy to overcome the Gibbs free energy barrier, the shear accommodation work and the dilatation work.

Previous workers have extensively studied DT in plain carbon, Nb-microalloyed steels [1.7-1.10,1.13,1.14] and an API-X70 steel [1,15-1.18]. Therefore, the aim of the present study is to explore this phenomenon in an API-X80 steel through torsion tests.

This thesis follows the manuscript-based structure and consists of four chapters. In Chapter 2, an extensive literature review is presented on dynamic transformation in steels. In Chapter 3, the results of the present investigation are described and discussed in detail in the form of a manuscript that has been submitted for publication. Finally, Chapter 4 summarizes the main conclusions of this study.

\subsection{References}

[1.1] Y. Matsumara and H. Yada, "Evolution of ultrafine-grained ferrite in hot successive deformation", Trans. Iron Steel Inst. Jpn., vol. 27, pp. 492-498, 1987. 
[1.2] H. Yada, Y. Matsumara and T. Senuma, "A new thermomechanical heat treatment for grain refining in low carbon steels", in Proc. Int. Conf. Physical Metallurgy of Thermomech. Process. Steels Other Metals, THERMEC-88, 1988, pp. 200-207.

[1.3] H. Yada, C. M. Li and H. Yamagata, "Dynamic $\gamma \rightarrow \alpha$ transformation during hot deformation in iron-nickel-carbon alloys", ISIJ Int., vol. 40, pp. 200-206, 2000.

[1.4] Y. Chen and Q. A. Chen, "Dilatometric investigation on isothermal transformation after hot deformation", J. Iron Steel Res. Int., vol. 10, pp. 46 48, 2003.

[1.5] Z. Liu, D. Li, S. Lu and G. Qiao, “Thermal stability of high temperature deformation induced ferrite in low carbon steel”, ISIJ Int., vol. 47, pp. 289-293, 2007.

[1.6] X. Sun, H. Luo, H. Dong, Q. Liu and Y. Weng, "Microstructural evolution and kinetics for post-dynamic transformation in a plain low carbon steel”, ISIJ Int., vol. 48, pp. 994-1000, 2008.

[1.7] V. Basabe and J. J. Jonas, “The ferrite transformation in hot deformed $0.036 \% \mathrm{Nb}$ austenite at temperatures above the Ae3”, ISIJ Int., vol. 50, pp. 1185-1192, 2010.

[1.8] C. Ghosh, V. V. Basabe, J. J. Jonas, Y. M. Kim, I. H. Jung and S. Yue, "The dynamic transformation of deformed austenite at temperatures above the Ae3", Acta Mater., vol. 61, pp. 2348-2362, 2013.

[1.9] R. Grewal, C. Aranas Jr., K. Chadha, D. Shahriari, M. Jahazi and J. J. Jonas, "Formation of Widmanstätten ferrite at very high temperatures in the austenite phase field", Acta Mater., vol. 109, pp. 23-31, 2016.

[1.10] V. Basabe, J. J. Jonas and C. Ghosh, "Formation of Widmanstätten ferrite in a $0.036 \% \mathrm{Nb}$ low carbon steel at temperatures above the Ae3", Steel Res. Int., vol. 85, pp. 8-15, 2014.

[1.11] C. Ghosh, C. Aranas Jr. and J. J. Jonas, "Dynamic transformation of deformed austenite at temperatures above the Ae 3 , Prog. Mater. Sci., vol. 82, pp. 151-233, 2016.

[1.12] C. Aranas Jr. and J. J. Jonas, "Effect of Mn and Si on the dynamic transformation of austenite above the Ae3 temperature”, Acta Mater., vol. 82, pp. 1-10, 2015. 
[1.13] J. J. Jonas, C. Ghosh and V. V. Basabe, "Dynamic transformation during simulated hot rolling”, Mater. Sci. Forum, vol. 762, pp. 1-8, 2013.

[1.14] J. J. Jonas, C. Ghosh and V. V. Basabe, "Effect of dynamic transformation on the mean flow stress", Steel Res. Int., vol. 84, pp. 253-258, 2013.

[1.15] S. F. Rodrigues, C. Aranas Jr., T. Wang, and J. J. Jonas, "Dynamic transformation of an X70 steel under plate rollong conditions", ISIJ Int., vol. 57, pp. 162-169, 2017.

[1.16] S. F. Rodrigues, C. Aranas Jr., F. Siciliano, and J. J. Jonas, "Dynamic transformation during the simulation of plate rolling in an X70 steel”, Steel Res. Int,, vol. 88, pp. 1-9, 2017.

[1.17] S. F. Rodrigues, C. Aranas Jr., and J. J. Jonas, "Dynamic transformation during the simulated plate rolling of a $0.09 \% \mathrm{Nb}$ steel”, ISIJ Int., vol. 57, pp. 1102-1111, 2017.

[1.18] S. F. Rodrigues, C. Aranas Jr., and J. J. Jonas, "Retransformation behaviour of dynamically transformed ferrite during the simulated plate rolling of a low C and an X70 Nb steel", ISIJ Int., vol. 57, pp. 929-936, 2017. 


\section{CHAPTER 2: LITERATURE REVIEW}

In order to withstand higher pressures and use thinner walls, it is mandatory to use steels with high strength and good toughness at low temperatures. The mechanical properties of a steel pipe are a consequence of its microstructure, which is determined partly by the chemical composition and partly by thermomechanical processing during rolling and heat treatment after rolling. Therefore, the knowledge of the microstructural changes which occur during the hot rolling process is fundamental to improve the mechanical properties of the final products or even to reduce the alloying elements and eliminate some heat treatments, contributing to cost reduction.

\subsection{Hot Rolling}

Hot rolling is the most efficient process of primary forming used for the mass production of steel. The three main purposes of hot rolling are:

- Elimination of the structural casting defects in the ingot;

- Obtaining the required shape, dimensions and surface quality of products;

- Achieving the desired mechanical properties.

The principal hot-rolled product groups are flat products, long products, seamless tubes and specialty products such as wheels, rings, bars with periodically varying profile, etc. The hot-rolled flat products can have the form of plates or strip, and the strip products can further be cut in sheets or slit strip.

A schematic layout of the plate rolling process is shown in Figure 2.1. The slab is reheated in a furnace to a temperature typically between 1150 and $1270{ }^{\circ} \mathrm{C}$, at which it is fully austenitic and 
the most of the alloying elements are in solid solution. The extraction temperature depends on the steel chemical composition and the heating time should be long enough to ensure a uniform temperature through the entire volume of the slab. After reheating, the oxide layer (scale) formed on the outer surfaces of the slab is removed by means of a high-pressure water descaler. Plate rolling can be carried out in a reversing four-high mill or in a two-stand tandem arrangement for higher outputs. In both cases, edge stands can be used for obtaining a significant improvement of dimensional accuracy in the width direction. Once the desired dimensions are reached in the mill, the plate undergoes cooling by water jets. The cooling path is very important to the final mechanical properties, with faster cooling rates leading to greater grain refinement.

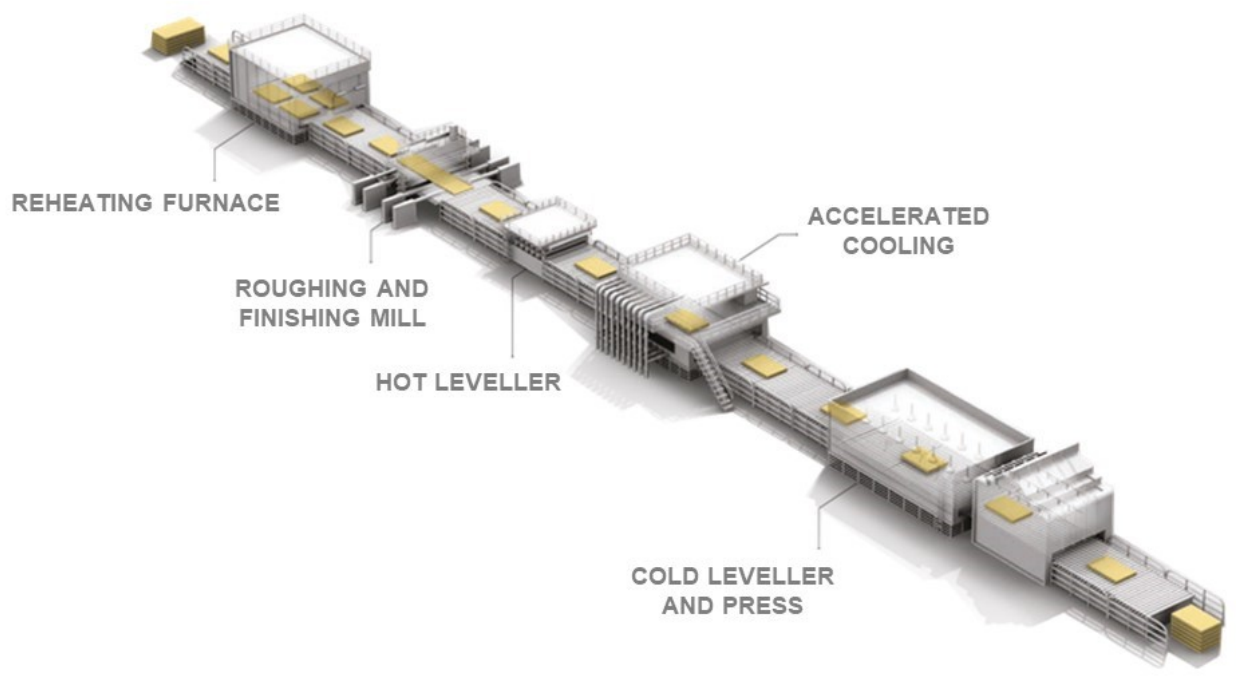

Figure 2.1: Layout of a plate rolling mill [2.1].

In hot strip rolling (Figure 2.2), as in the plate rolling process, the slab is reheated and then its scale formed during reheating is removed by means of a high-pressure water descaler. The rolling process can be preceded by sizing the slab width on a sizing press in order to increase production flexibility. Roughing passes are carried out in reversing universal mills and the slab is reduced to a transfer bar with a thickness of approximately $40 \mathrm{~mm}$. The transfer bar is then rolled in a six or 
seven-stand finishing train, achieving the final thickness. Finally, the rolled strip is water-cooled to the appropriate temperature for coiling.

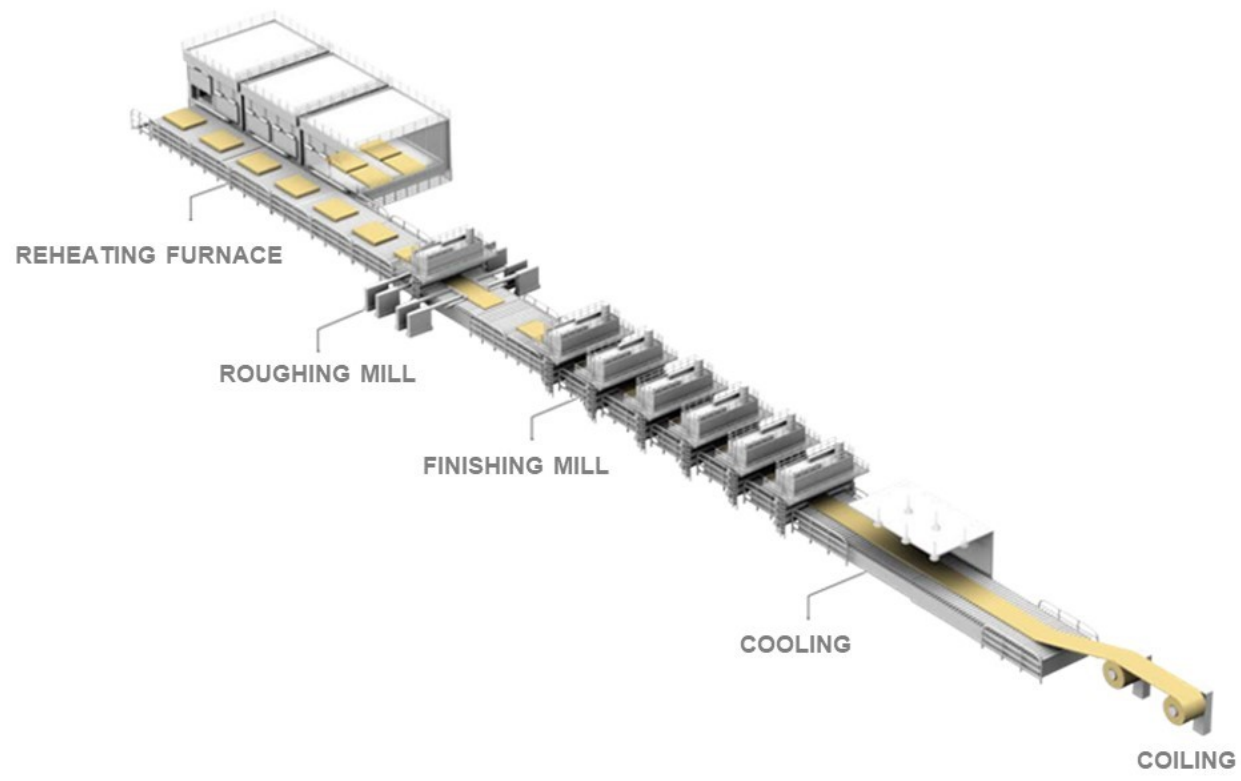

Figure 2.2: Layout of a hot strip rolling mill [2.2].

The typical ranges of interpass time and strain rate for reversing mills (roughing and plate mills), hot strip mills and wire rod mills are summarized in Table 2.1.

Table 2.1: Comparison of hot rolling mills in terms of their ranges of strain rate and interpass time [2.3].

\begin{tabular}{lll}
\hline Mill Type & Strain Rate $\left.\mathbf{( s}^{-\mathbf{1}}\right)$ & Interpass Time (s) \\
\hline Reversing Mills (plate, roughing, etc.) & $1-30$ & $8-20$ \\
Hot Strip Mills & $10-200$ & $0.4-4$ \\
Wire Rod Mills & $10-1000$ & $0.010-1$ \\
\hline
\end{tabular}

For both plate and hot strip rolling, the rolling process itself consists of roughing and finishing rolling, the former taking place above the non-recrystallization temperature $\left(\mathrm{T}_{\mathrm{nr}}\right)$ and the latter below the $\mathrm{T}_{\text {nr. }}$ Figures 2.3 and 2.4 show schematically the deformation processes above and below 
the $\mathrm{T}_{\mathrm{nr}}$. During rough rolling, the recrystallization of austenite occurs rapidly, which can lead to an eventual and limited grain refinement. In order to achieve further grain refinement, finishing rolling takes place between the $\mathrm{T}_{\mathrm{nr}}$ and the start of the austenite to ferrite transformation temperature. In this condition, recrystallization is no longer complete during the interpass time, which leads to the accumulation of strain hardening and results in elongated austenite grains ("pancaked" grains) and in the development of deformation bands within the grains. These deformation bands can also act as nucleation sites during the austenite to ferrite transformation, and the higher nucleus density leads to a finer ferrite grain size.

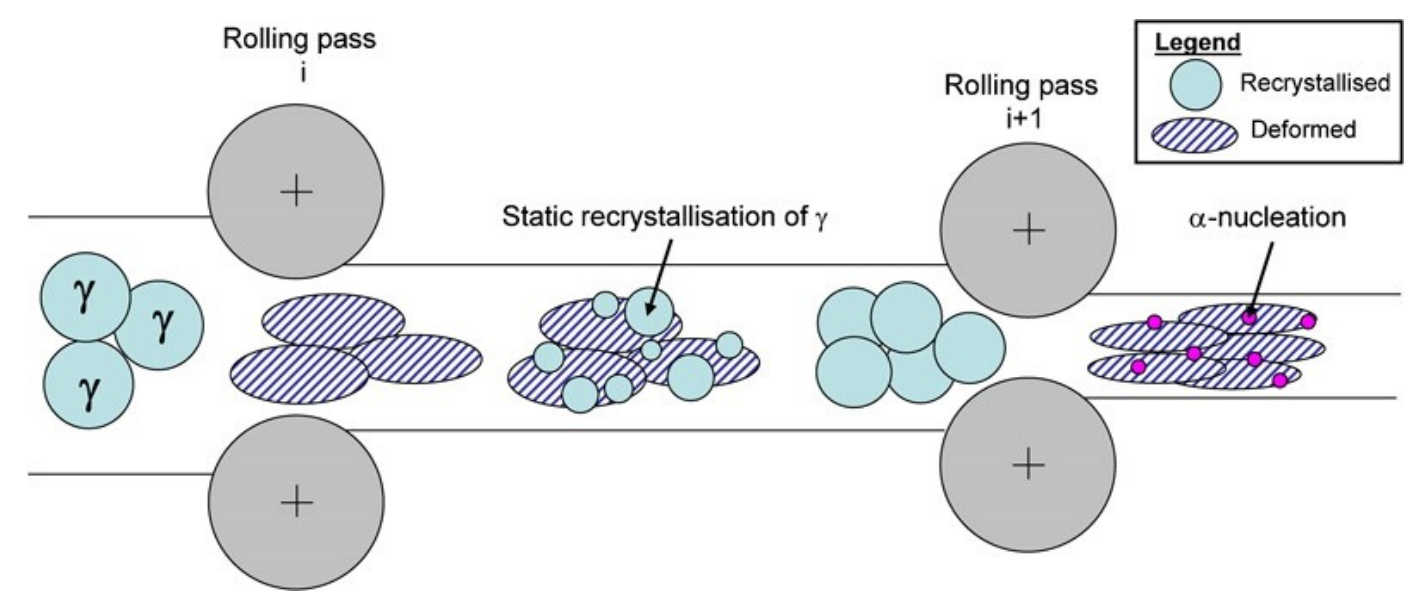

Figure 2.3: Schematic representation of deformation above the $T_{n r}$, with the complete recrystallization of austenite between passes [2.4].

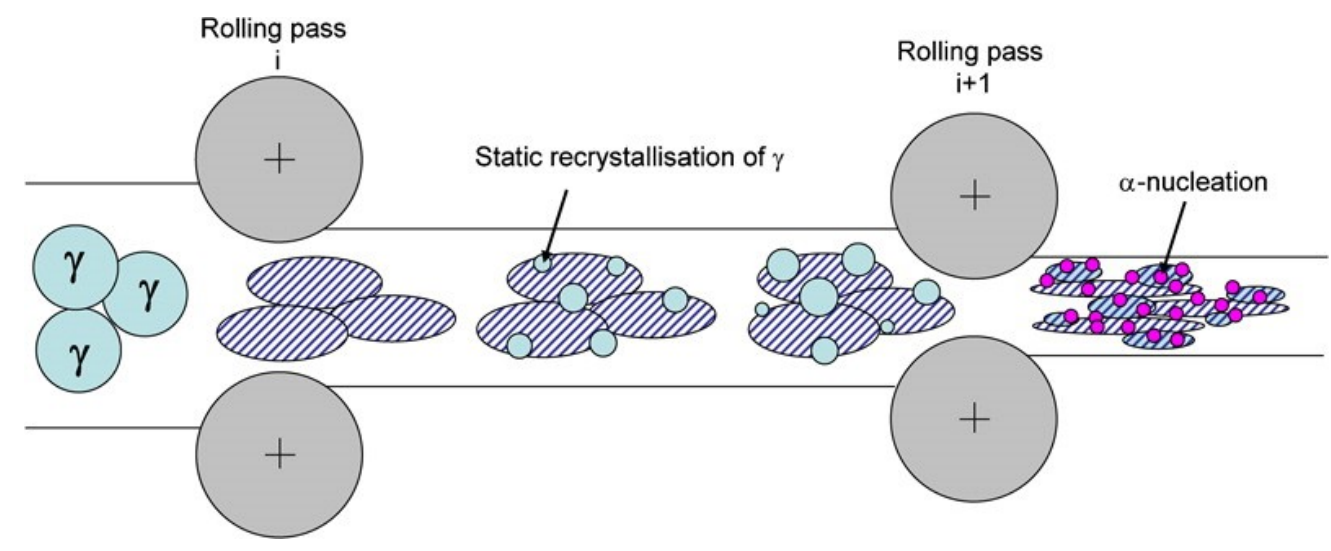

Figure 2.4: Schematic representation of deformation below the $T_{n r}$, with partial recrystallization between passes and the formation of "pancaked" austenite grains [2.4]. 
During hot rolling, both hardening and softening phenomena are observed. Hardening occurs by increasing the dislocation density when straining the material. Softening phenomena occur by means of recovery (static and dynamic) and recrystallization (static, dynamic and metadynamic). The following sections review the softening mechanisms and their effects on the mean flow stress.

\subsubsection{Mean Flow Stress (MFS)}

The mean flow stress (MFS) represents the metal's resistance to deformation in each pass and can be computed by integrating the area under the stress-strain curve for a given strain interval and then normalizing by the corresponding strain, according to Equation 2.1.

$$
\mathrm{MFS}=\frac{1}{\varepsilon_{\mathrm{f}}-\varepsilon_{\mathrm{i}}} \int_{\varepsilon_{\mathrm{i}}}^{\varepsilon_{\mathrm{f}}} \sigma \mathrm{d} \varepsilon
$$

Here $\varepsilon_{\mathrm{i}}$ and $\varepsilon_{\mathrm{f}}$ are the start and end of the strain interval, respectively.

When plotting the MFS as a function of the inverse of the absolute temperature, it is possible to identify the microstructural changes such as recrystallization, strain accumulation and phase transformation which take place during deformation. Figure 2.5 shows the curve of MFS versus 1/T (with $\mathrm{T}$ being the temperature in Kelvin) for a microalloyed steel specimen deformed in a torsion machine from $1200^{\circ} \mathrm{C}$ to $720^{\circ} \mathrm{C}$. The curve presents four different behaviours. In region I the MFS increases with decreasing temperature but with lower slope, indicating that recrystallization takes place at high temperatures leading to softening of the steel between passes. In region II the MFS increases with a higher slope, because of the strain accumulation as $T_{n r}$ is reached. Region III is characterized by a decrease in the MFS with decreasing temperature, indicating the transformation of austenite to ferrite, which is softer than austenite. In region IV all the austenite has already been transformed and only the ferrite phase is deformed [2.5]. 


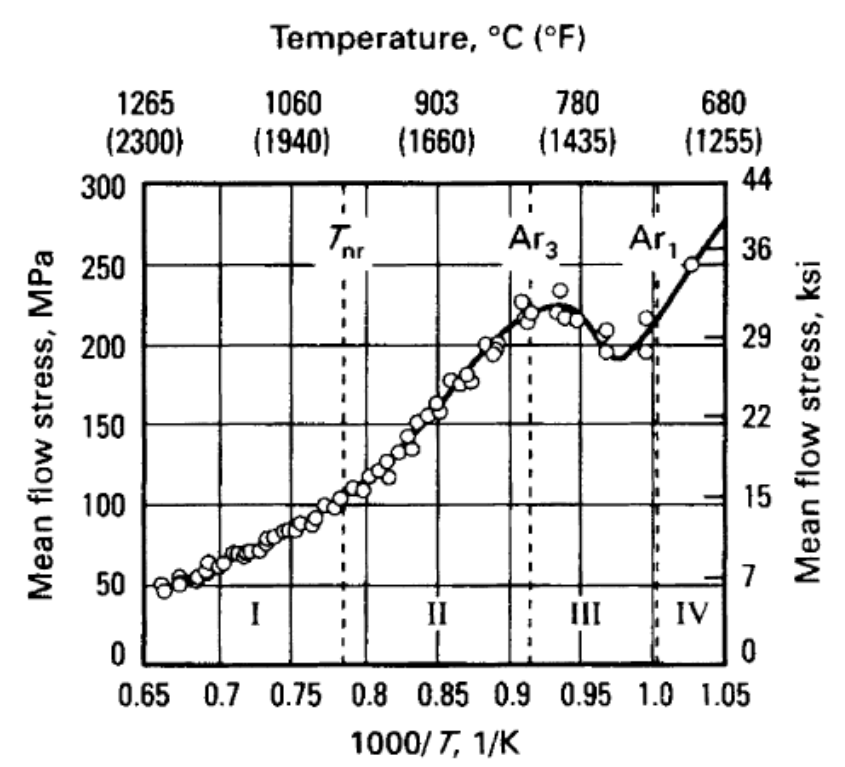

Figure 2.5: Mean flow stress behaviour during deformation of a microalloyed steel from 1200 to $720{ }^{\circ} \mathrm{C}[2.5]$.

\subsubsection{Recovery}

Recovery is the restoration process that takes place before the beginning of recrystallization and in which the strain energy is released by the annihilation and rearrangement of dislocations and defects, without the migration of high angle grain boundaries. Consequently, there is little change in the size and shape of the grains. The primary mechanism involved in dynamic recovery is thermally activated cross-slip [2.6]. Thus, the recovery rate increases with increasing temperature and it is higher in metals and alloys with high stacking fault energy (SFE), where the partial dislocations are closer to each other. Recovery can be divided in two categories: dynamic (when it occurs during deformation) and static (when it occurs after deformation).

\subsubsection{Recrystallization}

Recrystallization is the softening mechanism in which the nucleation and growth of new equiaxed grains with much lower dislocation densities occurs. The driving force for recrystallization is the stored energy of the dislocations. In metals with high SFE, the rapid recovery of the deformed 
grains leads to a decrease in the driving force for recrystallization and, if the driving force is sufficiently reduced, recovery can even prevent recrystallization. Austenite can be considered as a low to medium SFE phase [2.7], thus the recovery rate is low and the recrystallization process prevails. Recrystallization can be divided into three categories: static, dynamic and metadynamic.

\section{a) Static Recrystallization (SRX)}

Static recrystallization (SRX) occurs commonly during the rough rolling of steels, after deformation and during the interpass time. Critical values of strain and temperature are required for SRX to take place, and these values are characteristic of each material. The driving force is the stored energy of the dislocations, thus it depends on the strain and strain rate. As the SRX involves grain nucleation and growth, it also depends on the temperature and grain size and its kinetics follow the Avrami type of equation [2.7]:

$$
X_{\text {rex }}=1-\exp \left[-A\left(\frac{t}{t_{f}}\right)^{n}\right]
$$

Here $\mathrm{X}_{\mathrm{rex}}$ is the fraction recrystallized at a given time $\mathrm{t}, \mathrm{t}_{\mathrm{f}}$ is the time to reach a specific fraction of recrystallization $\mathrm{f}$, A is defined by $-\ln (1-\mathrm{f})$ and $\mathrm{n}$ is a constant. Siciliano Jr. [2.7] presented a review of some equations that have been fitted for $\mathrm{X}_{\mathrm{rex}}$ and $\mathrm{t}_{0.5}$ to data obtained on plain and $\mathrm{Nb}$ microalloyed steels.

b) Dynamic Recrystallization (DRX)

Dynamic recrystallization (DRX) takes place during hot deformation when the applied strain exceeds the critical strain $\left(\varepsilon_{c}\right)$ for the initiation of DRX. Figure 2.6 exhibits a characteristic stressstrain curve showing the effect of DRX at high strain rates. Due to DRX, the flow stress rises to a 
maximum at the peak strain $\left(\varepsilon_{\mathrm{p}}\right)$ followed by a drop to an intermediate level between the yield stress and the peak stress. After a certain strain, an equilibrium between the generation and annihilation of dislocations is reached and a steady state stress is attained.

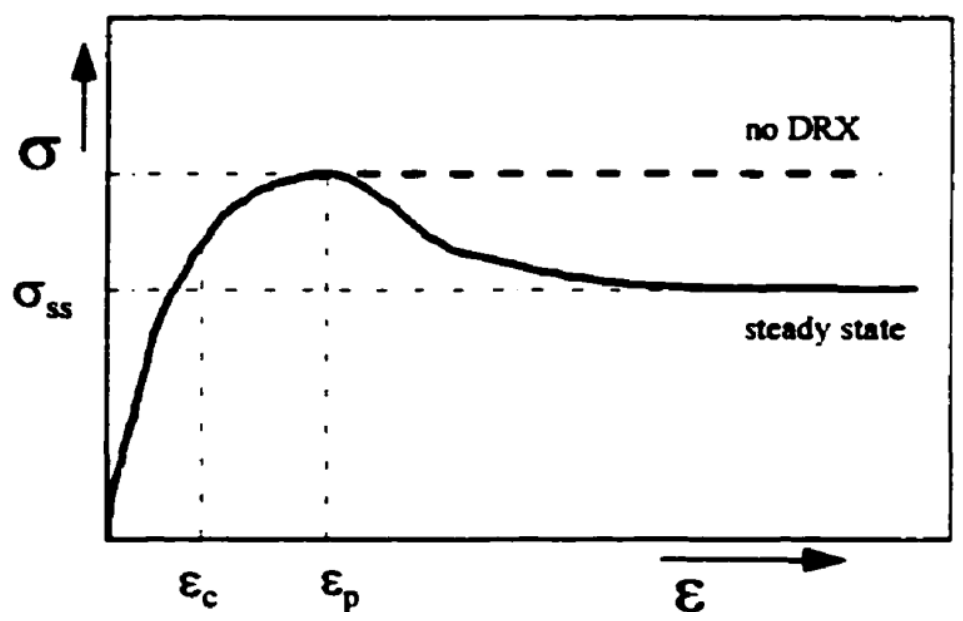

Figure 2.6: Effect of DRX on the stress-strain curve at high strain rates [2.7].

At lower strain rates, the stress-strain curve presents a multiple peak ("cyclic") behaviour as the softening due to DRX is followed by hardening. Figure 2.7, by Rossard (1960) and cited by Mc Queen and Jonas [2.8], shows the effect of strain rate on the stress-strain curve for a plain steel containing $0.25 \% \mathrm{C}$ and deformed at $1100{ }^{\circ} \mathrm{C}$.

c) Metadynamic Recrystallization (MDRX)

Metadynamic recrystallization (MDRX) is the result of the continued growth of the dynamically recrystallized nuclei after unloading; once deformation is interrupted, the nuclei formed dynamically grow statically during the interpass time. MDRX generally occurs when the applied strain exceeds or attains $\varepsilon_{\mathrm{p}}$. 


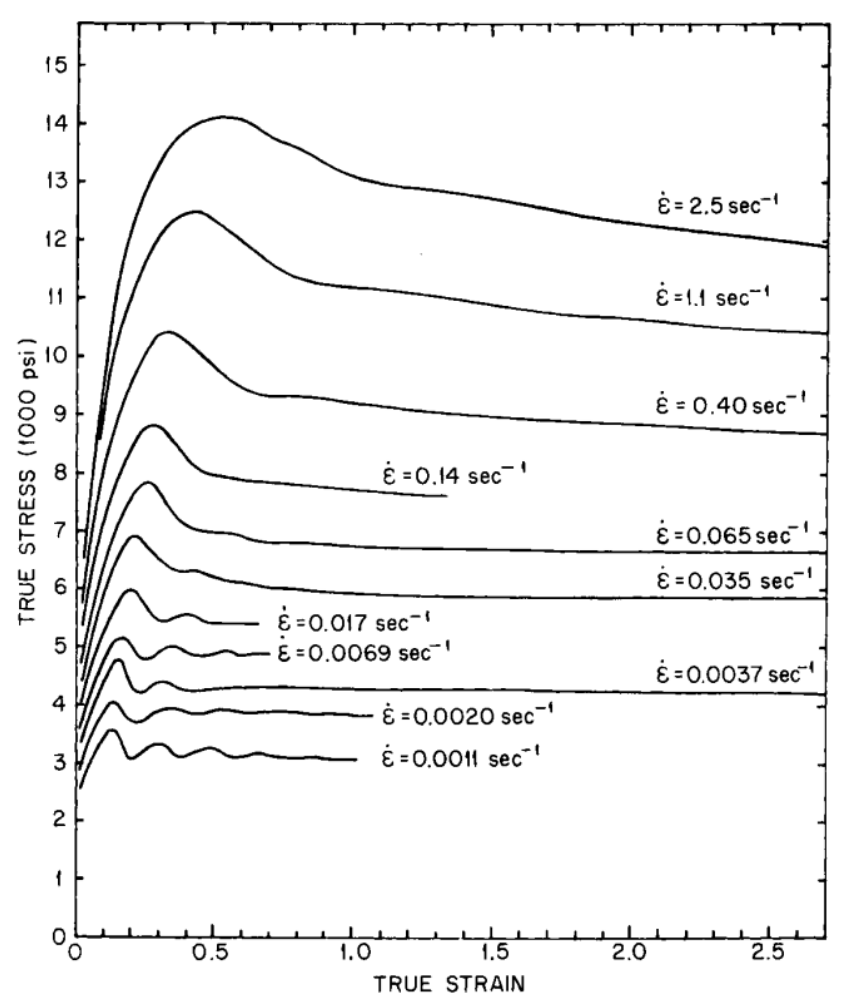

Figure 2.7: Flow curves of a plain steel $(0.25 \% \mathrm{C})$ deformed at $1100{ }^{\circ} \mathrm{C}$ and at different strain rates [2.8].

\subsection{Iron-Carbon Phase Diagram}

A portion of the Fe-C phase diagram is shown in Figure 2.8, with the composition ranging from pure iron to $6.70 \% \mathrm{C}$ (in weight) at which cementite $\left(\mathrm{Fe}_{3} \mathrm{C}\right)$ is formed. As all the steels present carbon content less than $6.70 \%$, only this part of the phase diagram will be considered.

In pure iron, from room temperature up to $912^{\circ} \mathrm{C}$, ferrite $(\alpha)$ is the stable phase and presents a BCC crystal structure. At $912^{\circ} \mathrm{C}$, ferrite undergoes a polymorphic transformation to austenite $(\gamma)$ which exhibits an FCC structure. Austenite is stable up to $1394{ }^{\circ} \mathrm{C}$, when it transforms back into a BCC phase known as $\delta$ ferrite. The melting point of pure iron is $1538^{\circ} \mathrm{C}$.

Carbon is an interstitial solute and when it is added as an alloying element, austenite is stabilized to lower temperatures, attaining a minimum at the eutectoid point $\left(0.76 \% \mathrm{C}\right.$ and $\left.727^{\circ} \mathrm{C}\right)$. The 
boundary line between the $\gamma$ and $\alpha+\gamma$ regions is known as the $\mathrm{Ae}_{3}$ temperature. Below the $\mathrm{Ae}_{3}$ temperature, ferrite starts to form from austenite and its volume fraction increases with decreasing temperature until the $\mathrm{Ae}_{1}$ temperature is reached $\left(727^{\circ} \mathrm{C}\right.$ for the $\mathrm{Fe}-\mathrm{C}$ system $)$, when all austenite is transformed into ferrite.

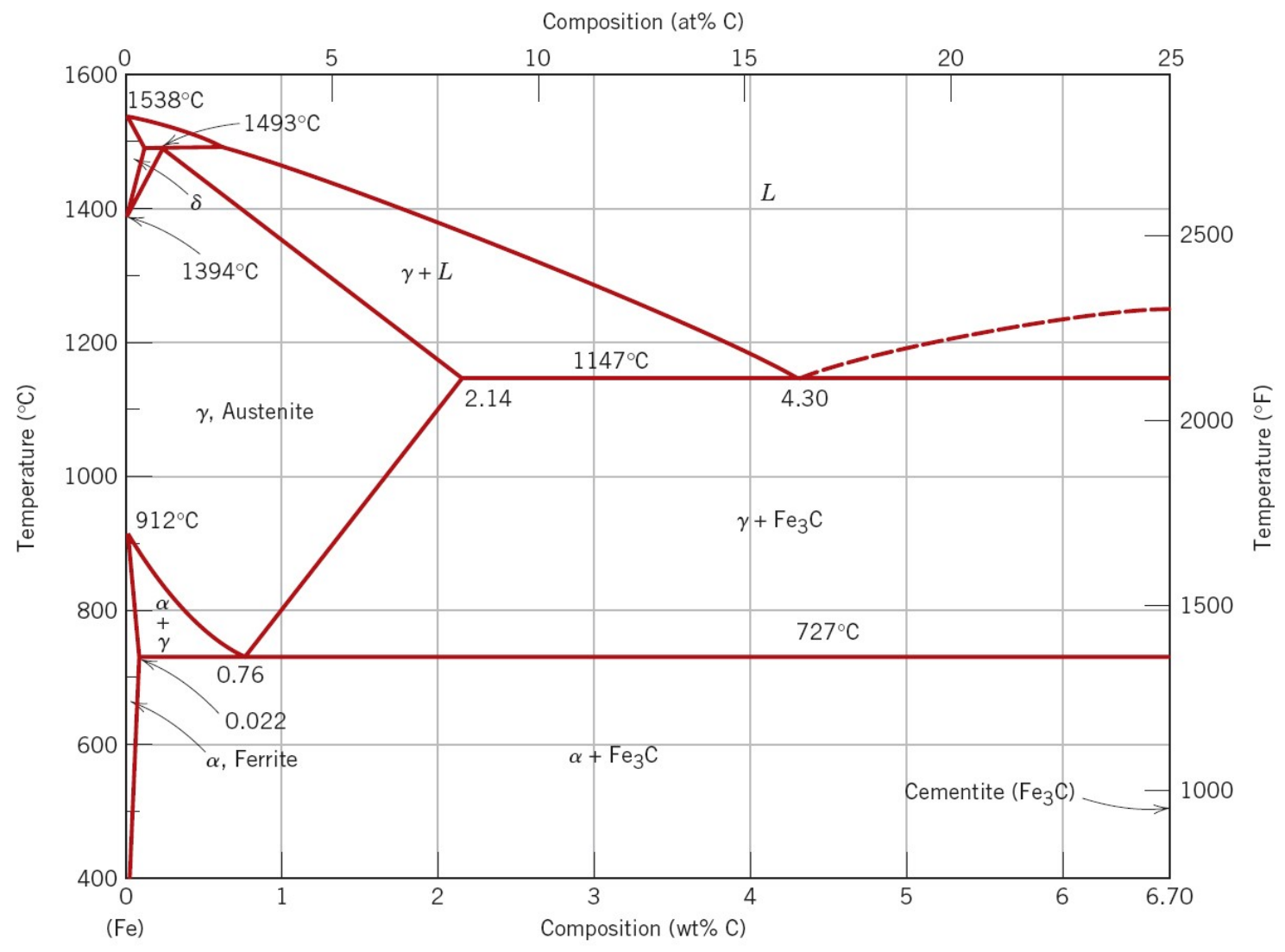

Figure 2.8: The Fe-C phase diagram [2.9].

The maximum solubility of carbon in austenite is $2.14 \%$ at $1147^{\circ} \mathrm{C}$, but it is much lower in ferrite, with a maximum of $0.022 \%$ at $727^{\circ} \mathrm{C}$. This difference in solubility arises from the crystal structures of austenite and ferrite; in austenite, the FCC interstitial positions are larger and thus the strains imposed on the structure by an atom of carbon are lower. At carbon contents higher than its solubility in ferrite, during the austenite to ferrite transformation, the excess carbon is rejected 
into the austenite phase. Below the $\mathrm{Ae}_{1}$ temperature, the remaining austenite transforms into a lamellar structure consisting of ferrite and cementite, named pearlite.

The addition of other alloying elements can affect the Fe-C phase diagram, especially the stability of the austenite and ferrite phases, and the effects depend on the alloying element and its concentration. The austenite-stabilizers, such as carbon, nitrogen, manganese, nickel, cobalt and copper, expand the austenite field and encourage the formation of austenite over wider compositional limits. The ferrite-stabilizers, such as silicon, aluminum, phosphorus, titanium, vanadium, niobium, molybdenum and chromium, contract the austenite-field and encourage the formation of ferrite over wider compositional limits [2.10].

In general, the phase diagrams are determined based on orthoequilibrium conditions, which involves the diffusion of both the interstitial and substitutional solutes. Conversely, paraequilibrium is a constrained equilibrium which occurs when the diffusion of substitutional solutes is not possible within the considered time scale, but the interstitial elements can diffuse. In a steel under paraequilibrium conditions, for example, manganese and other substitutional elements do not partition between ferrite and austenite, their contents remain the same as in the parent austenite, but carbon redistributes until it has the same chemical potential in both phases $[2.10,2.11]$. The paraequilibrium temperatures are lower than the orthoequilibrium ones and the difference between them depends on the alloying elements.

\subsection{Phase Transformations of Austenite}

The austenite transformation can occur by two different mechanisms: reconstructive (or diffusional) transformation and displacive (or shear or diffusionless) transformation. Figure 2.9 schematically illustrates these two mechanisms. In the reconstructive transformation, the atoms 
are rearranged into an alternative pattern. On the other hand, in the displacive transformation the original pattern is homogenously deformed into a new crystal structure. This variety of means in which the crystal structure can be changed is one of the reasons why there is a large variety of microstructures in steel.

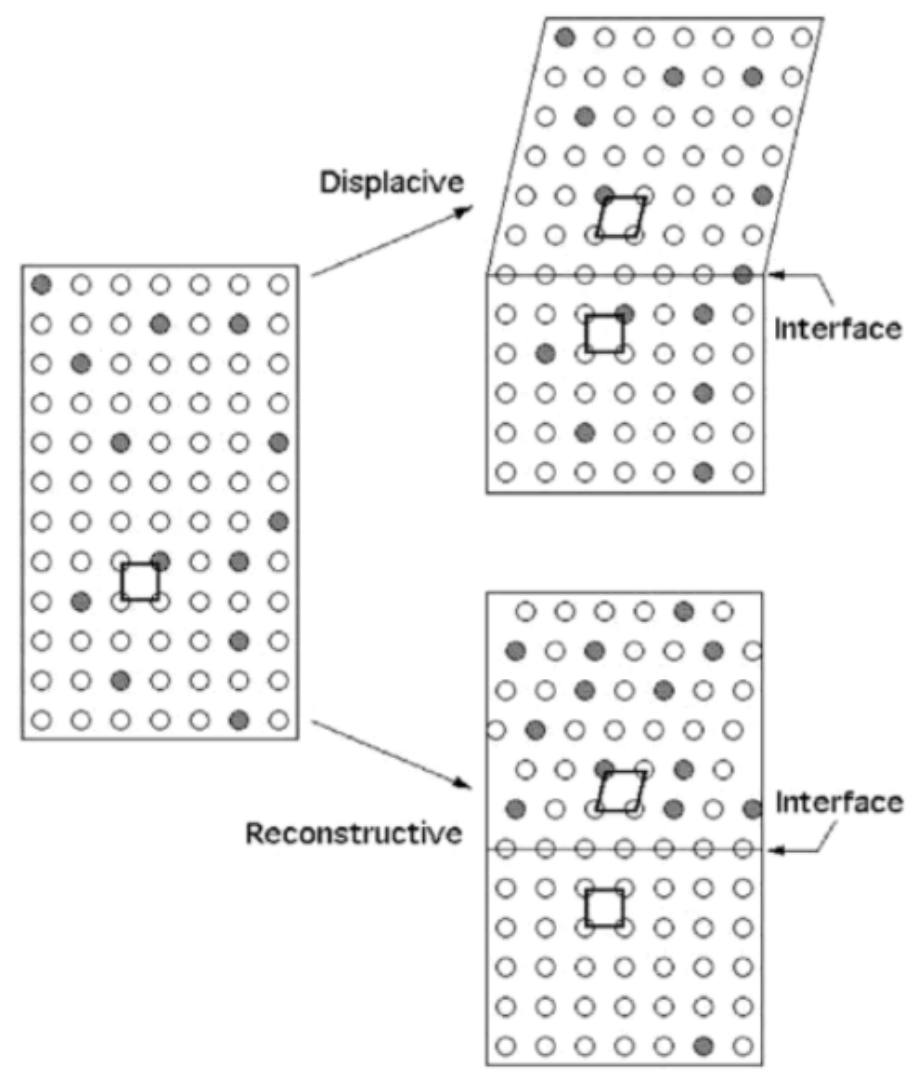

Figure 2.9: Schematic illustration of the displacive and reconstructive mechanisms of transformation. The parent crystal (left) contains two types of atoms. On the right, the figures represent partially transformed samples with the parent and product unit cells outlined [2.10].

\subsubsection{Reconstructive Transformations}

In reconstructive transformations, the new crystal structure is attained by means of the diffusion of all atoms. As a result, there are no shear components of the shape deformation, only the effects of volume change and the solutes are redistributed between the phases in order to reduce the overall free energy. Therefore, this kind of mechanism requires low cooling rates from the austenite field 
to temperatures below $\mathrm{Ae}_{3}$ and $\mathrm{Ae}_{1}$ and the phases formed are allotriomorphic and idiomorphic ferrite and pearlite.

a) Ferrite

The ferrite transformed through a diffusional mechanism can be classified into two main forms: allotriomorphic and idiomorphic ferrite. The allotriomorphic ferrite is the first morphology to come up and it tends to nucleate at the austenite grain surface, forming layers that follow the grain boundary. For this reason, it has an external shape that does not reflect its internal crystalline structure. The idiomorphic ferrite nucleates inside the austenite grains, usually on non-metallic inclusions or other heterogeneous nucleation sites, and presents as equiaxed grains [2.12]. Figure 2.10 illustrates schematically the formation mechanism of these two types of ferrite.

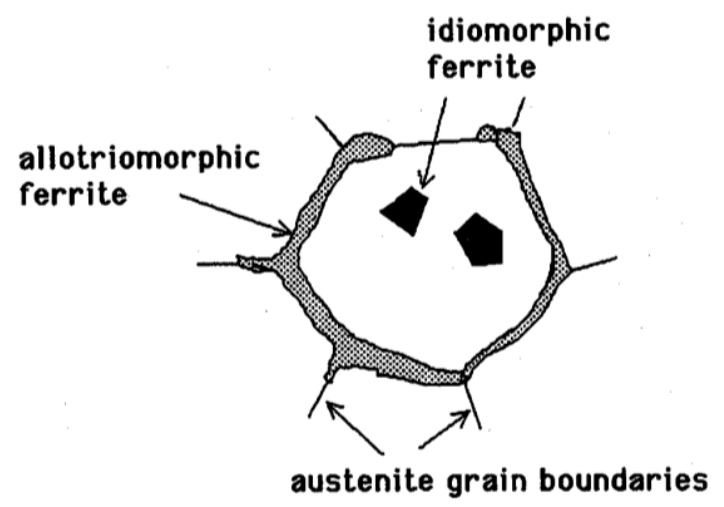

Figure 2.10: Formation mechanisms of allotriomorphic and idiomorphic ferrite [2.13].

b) Pearlite

Pearlite consists of lamellar structures of ferrite and cementite that form simultaneously during transformation. This lamellar structure arises because the austenite composition is different from both of the product phases $(0.022 \% \mathrm{C}$ in ferrite and $6.7 \% \mathrm{C}$ in cementite), and then the phase transformation requires a redistribution of carbon by diffusion. To form the layered structure, 
carbon atoms need to diffuse only minimal distances. Figure 2.11 schematically represents the pearlite formation from austenite and shows the direction of carbon diffusion.

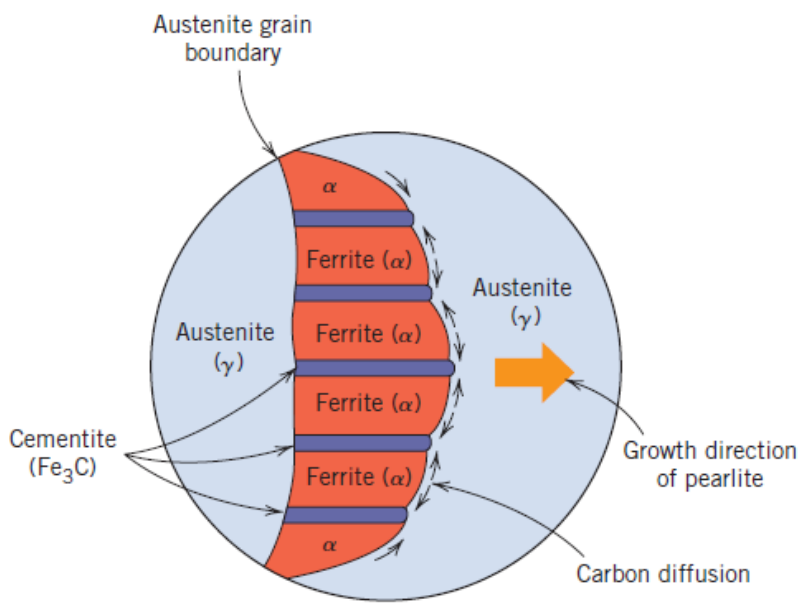

Figure 2.11: Schematic representation of pearlite formation from austenite, showing the lamellar structure of ferrite plates and cementite [2.9].

Pearlite nucleates at an austenite grain boundary, but it can also nucleate at a ferrite grain boundary or cementite, depending on whether the steel is hypo or hyper-eutectoid. The pearlite grows as "colonies", which have different lamellae orientations, but within each colony the layers are oriented in the same direction, as shown in Figure 2.12.

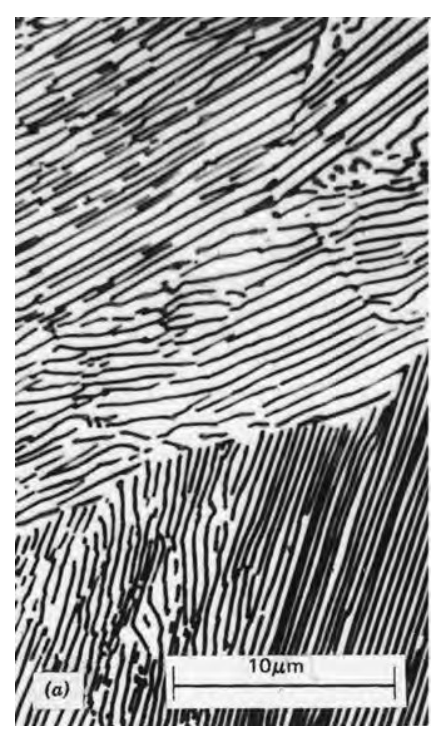

Figure 2.12: Colonies of pearlite [2.9]. 


\subsubsection{Displacive Transformations}

Displacive transformations can occur at low temperatures or during rapid cooling, that is, when the time is insufficient for diffusion to take place. During displacive transformations, the new crystal structure is obtained by shear, with a coordinated motion of the atoms into their new positions, since the atomic bonds are not broken and individual atomic movements are less than one interatomic spacing. Martensite, bainite, and Widmanstätten ferrite are formed through this mechanism.

\section{a) Martensite}

Martensite is formed through a diffusionless mechanism when austenite is quenched to a temperature below the martensite-start $\left(\mathrm{M}_{\mathrm{S}}\right)$ temperature of the time-temperature-transformation (TTT) diagram of Figure 2.13. As the transformation occurs at very low temperatures, diffusion even of interstitial atoms does not take place and then martensite forms with the same composition as the parent austenite. The change of the crystal structure from the FCC austenite to the bodycentered tetragonal (BCT) martensite is achieved by a homogenous deformation with volume expansion and, to minimize the strain energy, martensite forms as thin plates, or needles, on particular crystallographic planes (habit planes). The transformation of a whole grain may occur in approximately $10^{-7} \mathrm{~s}[2.14]$. The martensitic transformation normally occurs athermally, the volume fraction of formed martensite depends only on the temperature below $\mathrm{M}_{\mathrm{S}}$ to which the steel is cooled. Figure 2.14 shows the martensite plates of a medium C steel.

b) Bainite

Bainite is composed of non-lamellar fine clusters of ferrite plates (or laths), called sheaves, and cementite particles, and it is formed at temperatures above $\mathrm{M}_{\mathrm{S}}$ but below the pearlite formation 
temperature, as shown in the TTT diagram of Figure 2.13. The plates of bainite are formed without any diffusion, in a similar manner to martensite, but just after nucleation carbon diffusion takes place. As the transformation temperature is lowered, the carbon partition becomes slower and then two types of bainite can be distinguished: upper and lower bainite, as shown schematically in Figure 2.15.

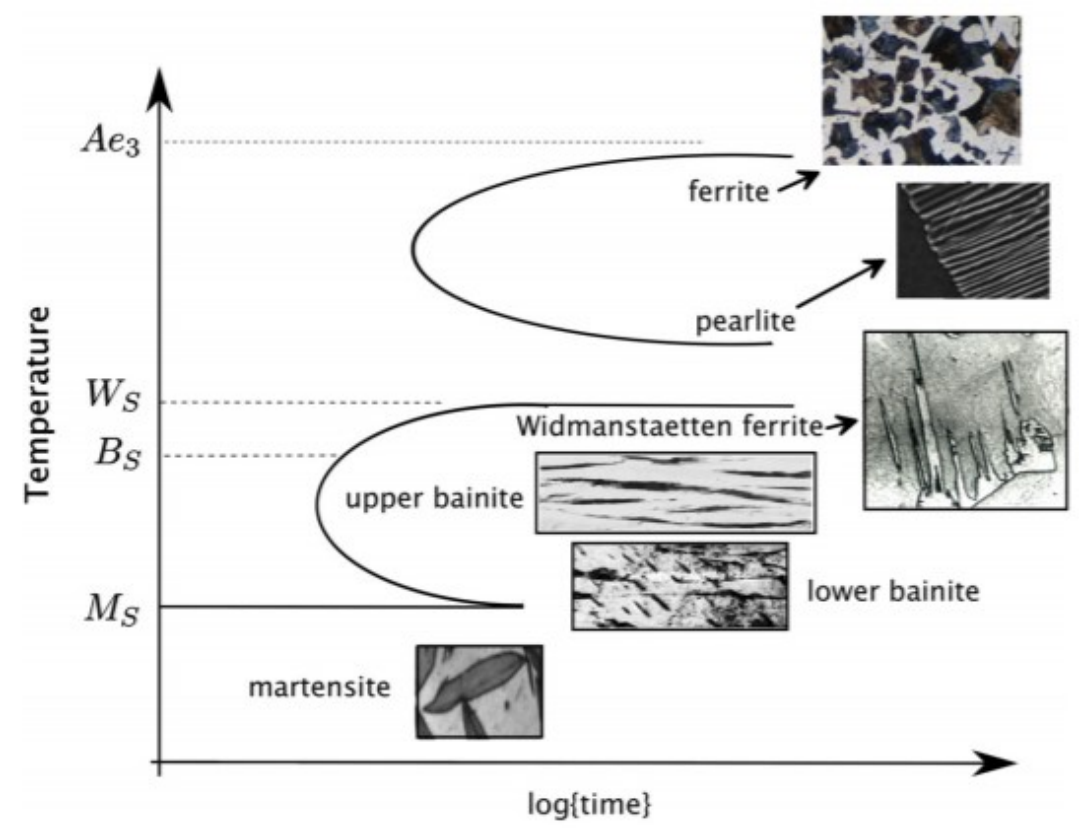

Figure 2.13: Schematic time-temperature-transformation (TTT) diagram for a steel [2.10].

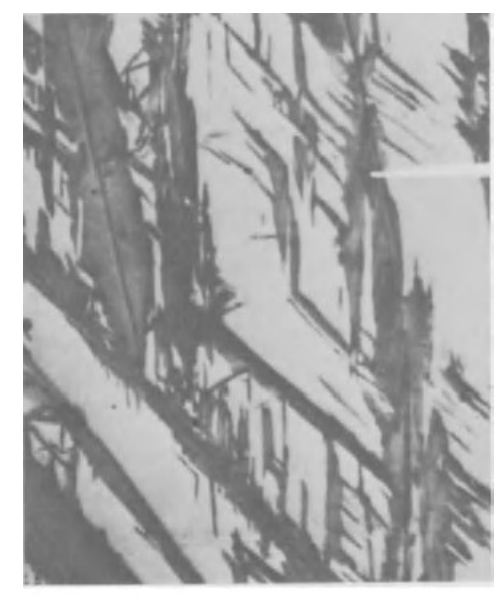

$.20 \mu \mathrm{m}$,

Figure 2.14: Martensite morphology of a medium C steel [2.14]. 


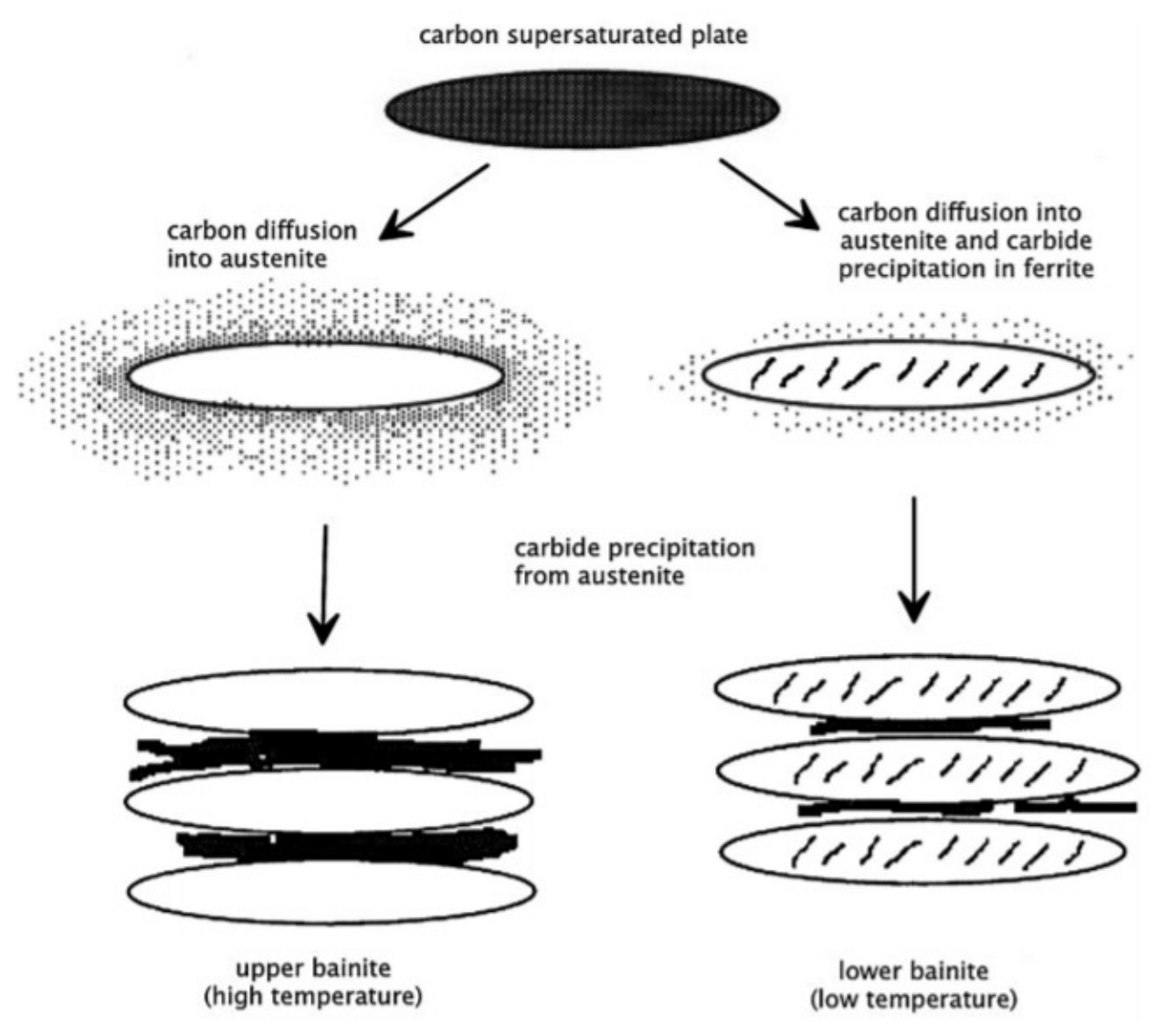

Figure 2.15: Schematic representation of the formation of upper and lower bainite [2.10].

Upper bainite is formed over the temperature range $550-400{ }^{\circ} \mathrm{C}$. After transformation, the carbon diffuses into the residual austenite and also precipitates as cementite between the ferrite plates. The transformation to lower bainite occurs at lower temperatures, between $400-250{ }^{\circ} \mathrm{C}$, and as the carbon partition is slower, some of the carbon can precipitate also inside the ferrite plates.

The bainite transformation occurs at higher temperatures than the martensitic transformation, and because the austenite strength decreases with increasing temperature, the adjacent austenite can no longer withstand the large strains associated with the shape change and it is then deformed plastically. The increase in dislocation density caused by the plastic deformation of austenite blocks the growth of the ferrite, leading to ferrite plates of about $0.2 \mu \mathrm{m}$ in thickness and $10 \mu \mathrm{m}$ in length [2.10]. 
c) Widmanstätten ferrite

Widmanstätten ferrite is formed just below the $\mathrm{Ae}_{3}$ temperature and it is composed of long and thin pointed plates of ferrite. Its formation involves a displacive mechanism and also carbon partition, with the carbon diffusion controlling the transformation rate. The ferrite plates can grow from the austenite grain boundaries (primary Widmanstätten ferrite) or from the allotriomorphic ferrite that may be present in the microstructure (secondary Widmanstätten ferrite), as shown in Figure 2.16.

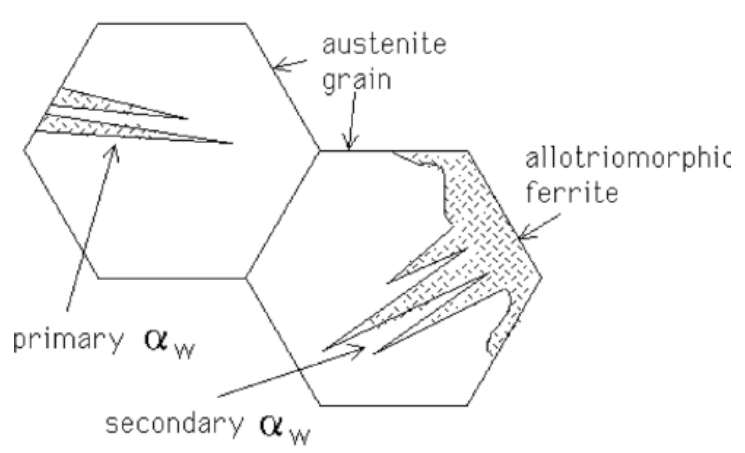

Figure 2.16: Schematic representation of the nucleation of primary and secondary Widmanstätten ferrite [2.15].

As the transformation occurs at high temperatures, the driving force is much lower than that required to support the strain energy associated with the displacive transformation. Therefore, Widmanstätten ferrite formation involves the simultaneous growth of two adjacent plates which accommodate each other's shape deformation, leading to a reduction of the strain energy.

\subsection{Dynamic Transformation}

Dynamic transformation above the $\mathrm{Ae}_{3}$ temperature was first reported by Yada and co-workers in the 1980's [2.16,2.17]. In their work, they evaluated the extent of dynamic transformation and the final ferrite grain size of two plain steels containing $0.11 \% \mathrm{C}, 1.0 \% \mathrm{Mn}$ and $0.02 \% \mathrm{Si}$ and $0.14 \%$ 
C, $1.06 \% \mathrm{Mn}$ and $0.33 \% \mathrm{Si}$ through compression tests and hot rolling simulations in a pilot mill. One evidence of dynamic transformation they found was that the actual stress during hot deformation was much lower than that expected for austenite. The various metallographic analyses of the deformed samples after rapid quenching similarly showed the presence of ferrite, which could not be formed during quenching. Figure 2.17 shows the stress-strain curves and the corresponding microstructures obtained after hot compression tests above and below the $\mathrm{Ae}_{3}$ temperature of the steel containing $0.14 \% \mathrm{C}, 1.06 \% \mathrm{Mn}$ and $0.33 \% \mathrm{Si}$. It can be seen that the critical strain for the dynamic transformation of ferrite is about $0.5 \%$ and the fraction of ferrite increases with increasing strain and decreasing temperature. The average ferrite grain size was about 1 to $2 \mu \mathrm{m}$ under all conditions.

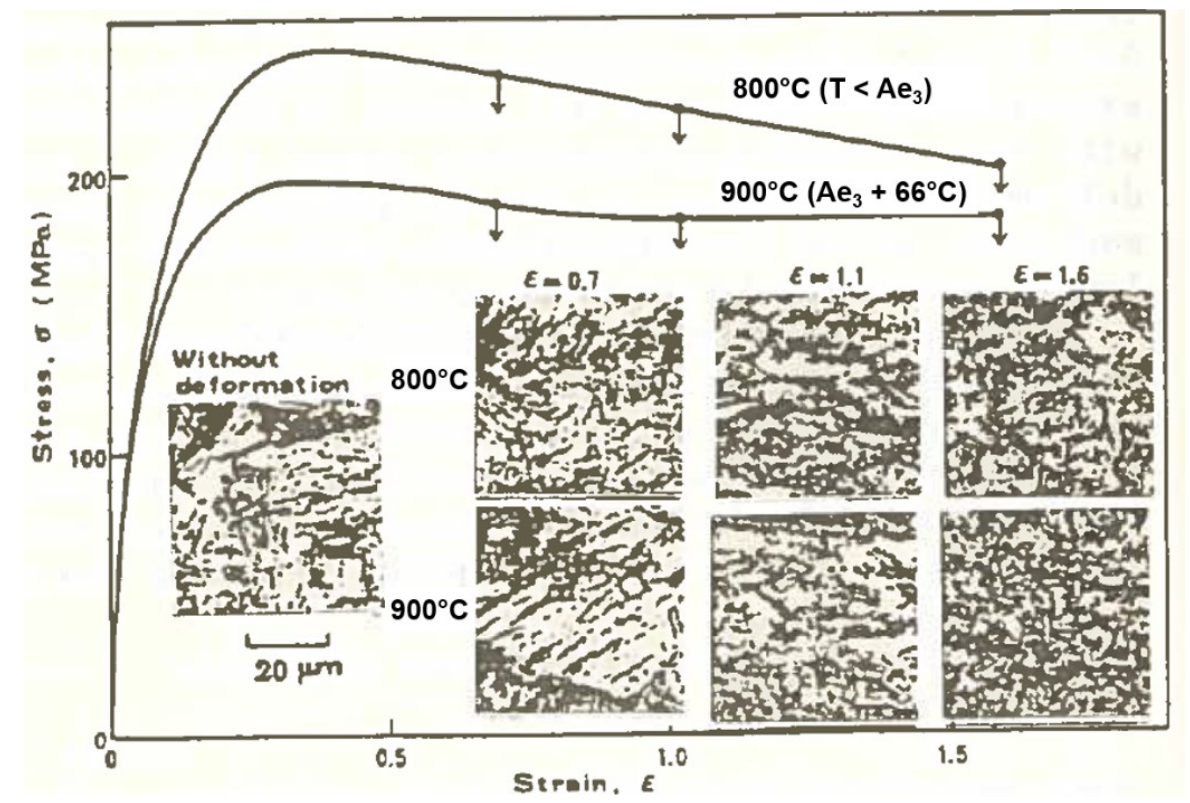

Figure 2.17: Stress-strain curves and corresponding microstructural changes of a plain steel during deformation above and below the $\mathrm{Ae}_{3}$ temperature [2.17].

By means of dilatometry measurements during isothermal holding after deformation of the steel containing $0.11 \% \mathrm{C}, 1.0 \% \mathrm{Mn}$ and $0.02 \% \mathrm{Si}$ they also showed that, as ferrite is unstable above the $\mathrm{Ae}_{3}$ temperature, the reverse transformation takes place, which could be expressed by the decrease 
in the volume of the specimens during holding after deformation above the $\mathrm{Ae}_{3}$ temperature, as shown in Figure 2.18.

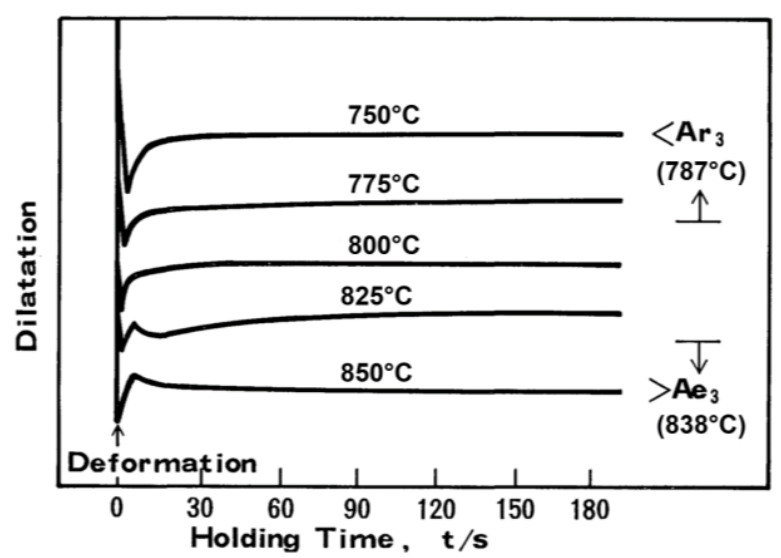

Figure 2.18: Volume change during isothermal holding after deformation [2.16,2.17].

Later in 2000, Yada et al. [2.18] carried out an in situ x-ray diffraction study during the hot deformation of Fe-Ni-C alloys with carbon contents varying from 0.0008 to $0.29 \%$ and containing approximately $6 \%$ of nickel. The latter was added to these alloys in order to reduce the transformation temperature to enable the in situ x-ray study above the $\mathrm{Ae}_{3}$ temperature. The specimens were exposed to the x-ray beam during deformation and the $\mathrm{x}$-ray diffraction lines were recorded on a film. The applied strain rate ranged between 0.01 to $0.09 \mathrm{~s}^{-1}$ during different deformation times of 1 to 5 min at temperatures up to $40{ }^{\circ} \mathrm{C}$ above the $\mathrm{Ae}_{3}$.

Some of the x-ray diffraction patterns obtained are shown in Figure 2.19 for the alloy containing 0.096\% C. In Figure 2.19a, the specimen was analyzed before heating, and only the diffraction line corresponding to $(110)_{\alpha-F e}$ is present. After fully austenitization and before deformation (Figure 2.19b), the line corresponding to (111) $\gamma$-Fe can be seen together with some oxide lines. After deformation at $40^{\circ} \mathrm{C}$ above the $\mathrm{Ae}_{3}$ temperature, Figure $2.19 \mathrm{c}$, a line corresponding to $(110)_{\alpha-\mathrm{Fe}}$ appeared together with the (111) $\gamma$-Fe line (some oxide lines are also present). Similar results were obtained at different temperatures and for other alloys with different contents of 
carbon. The authors suggested that because the deformation energy of ferrite is smaller than that of austenite, dynamic transformation occurs in order to reduce the total energy of the deformed material. In addition, the difference in energy between the deformed ferrite and the deformed austenite is greater than the chemical energy required for transformation at the test temperatures [2.18].
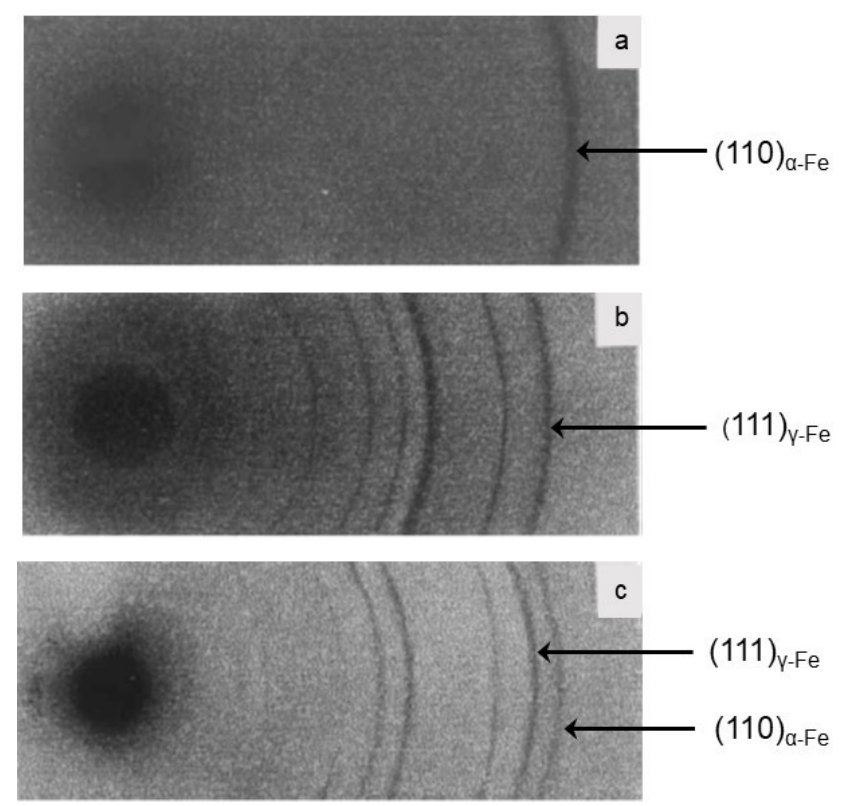

Figure 2.19: X-ray diffraction patterns. a) Before heating; $b$ ) after full austenitization and before deformation; c) deformed at a strain rate of $0.09 \mathrm{~s}^{-1}$ above the $\mathrm{Ae}_{3}$ temperature [2.18].

In 2003, Chen and Chen [2.19] performed dilatometry measurements during isothermal holding after deformation by compression of a plain steel $(0.18 \% \mathrm{C}, 0.60 \% \mathrm{Mn}$ and $0.21 \% \mathrm{Si})$. The experiments consisted of single and two pass deformations with strains of 0.3 and 0.6 over a temperature range both below and above the $\mathrm{Ae}_{3}$ and at a strain rate of 10 and $40 \mathrm{~s}^{-1}$. It was observed that a negative diameter variation occurred during holding for various temperatures and different deformations, which corresponds to the reverse transformation of ferrite into austenite.

In 2007, Liu et al. [2.20] performed several compression tests on a plain steel $(0.13 \% \mathrm{C}$ and $0.19 \% \mathrm{Mn}$ ) just above the $\mathrm{Ae}_{3}$ temperature in order to evaluate the effects of isothermal holding 
time after compression to a nominal strain of 0.8 at a strain rate of $20 \mathrm{~s}^{-1}$ by means of metallographic analysis. Cooling rates and annealing temperatures were also evaluated. It was observed that, as expected, an increase in holding time increased the grain size of the dynamically transformed ferrite and decreased the ferrite volume fraction. After about $7200 \mathrm{~s}$ all the ferrite was retransformed to austenite. Decreasing the cooling rate led to an increase in the grain size and decrease in ferrite volume fraction, as predictable.

Then in 2008, Sun et al. [2.21] studied, by means of microstructural analysis and dilatometry measurements, the forward transformation (austenite to ferrite) and reverse transformation (ferrite to austenite) that occur during isothermal holding after deformation applied below and above the $\mathrm{Ae}_{3}$ temperature of a plain steel containing $0.17 \% \mathrm{C}$ and $0.71 \% \mathrm{Mn}$. The specimens were deformed in compression to strains up to 0.69 at a strain rate of $1 \mathrm{~s}^{-1}$. At temperatures below $\mathrm{Ae}_{3}$, the specimen dilatations gradually reach a steady state, which indicates that the remaining austenite continues to transform to ferrite until the equilibrium fractions are attained, as expected. In order to investigate the reverse transformation, dilatometry measurements were conducted during isothermal holding after deformation at temperatures up to $115^{\circ} \mathrm{C}$ above the $\mathrm{Ae}_{3}$, as shown in Figure 2.20. At $950{ }^{\circ} \mathrm{C}, 115^{\circ} \mathrm{C}$ above the $\mathrm{Ae}_{3}$, no changes in the specimen diameter were observed, which suggests that no dynamic transformation took place. At 860 and $840{ }^{\circ} \mathrm{C}, 25$ and $5{ }^{\circ} \mathrm{C}$ above the $\mathrm{Ae}_{3}$ temperature respectively, a clear reduction in the specimen diameters can be observed in the first $200 \mathrm{~s}$ approximately of holding, suggesting the occurrence of reverse transformation. The authors did not report any test results between 25 and $115^{\circ} \mathrm{C}$ above the $\mathrm{Ae}_{3}$. These results were confirmed by microstructural analysis, as shown in Figure 2.21. The specimen quenched immediately after deformation (Figure 2.21a) presented a considerable amount of ferrite 
nucleated preferentially at the austenite grain boundaries, but in the specimen quenched after $1200 \mathrm{~s}$ of isothermal holding (Figure 2.21b) only martensite (previous austenite) can be observed.

The authors also determined by means of Thermo-Calc that the required austenite deformation stored energy for orthoequilibrium transformation at $860^{\circ} \mathrm{C}$ is $35 \mathrm{~J} / \mathrm{mol}$, higher than the calculated deformation stored energy $(22 \mathrm{~J} / \mathrm{mol})$. They suggested that this inconsistency arises because the actual deformation stored energy is not homogeneously distributed in the specimen as the calculation assumes it to be, and locally this stored energy may be raised to the required value [2.21].

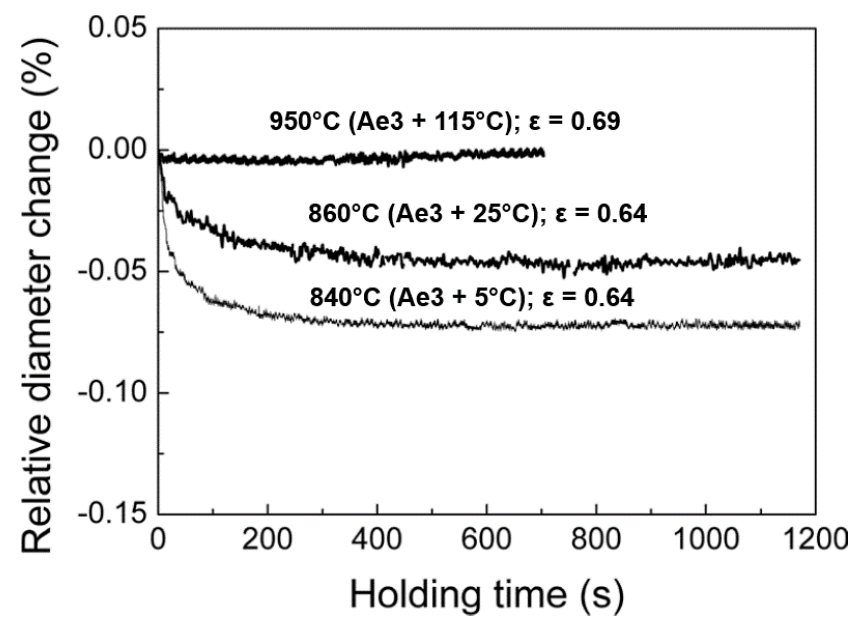

Figure 2.20: Dilatation curves of the specimen during isothermal holding after deformation at various temperatures above $\mathrm{Ae}_{3}[2.21]$.
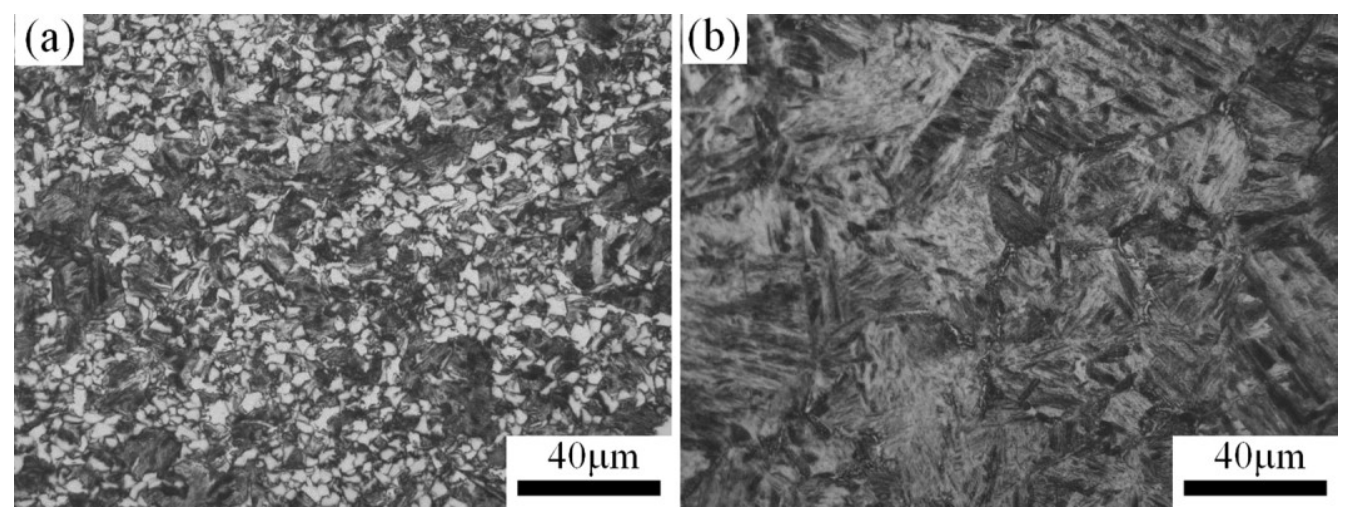

Figure 2.21: Microstructures of the specimens quenched (a) immediately after deformation at $850{ }^{\circ} \mathrm{C}\left(\mathrm{Ae}_{3}+15^{\circ} \mathrm{C}\right)$, (b) after $1200 \mathrm{~s}$ of isothermal holding after deformation [2.21]. 
In 2010, Basabe and Jonas [2.22] investigated the effects of temperature, strain and strain rate on the dynamic transformation of austenite into ferrite above the $\mathrm{Ae}_{3}$ temperature and the reverse transformation of a microalloyed steel containing $0.09 \% \mathrm{C}, 1.3 \% \mathrm{Mn}, 0.02 \% \mathrm{Si}$ and $0.036 \% \mathrm{Nb}$ by means of hot torsion tests. The specimens were strained from 0.5 to 5.0, at strain rates of 0.04 and $0.4 \mathrm{~s}^{-1}$ and at temperatures up to $60{ }^{\circ} \mathrm{C}$ above the $\mathrm{Ae}_{3}$. In order to evaluate the retransformation, some specimens were isothermally held for 50 to $400 \mathrm{~s}$. It was observed that ferrite was dynamically formed up to $60^{\circ} \mathrm{C}$ above the $\mathrm{Ae}_{3}$ (highest temperature employed in this study). The average ferrite grain size increased with increasing temperature and decreasing strain rate. The critical strain for ferrite formation was 0.5 and the ferrite volume fraction increased with strain and slightly with strain rate. The reverse transformation began only after about $200 \mathrm{~s}$ of isothermal holding, a considerable delay compared to a plain carbon steel, and reached saturation at $400 \mathrm{~s}$, as shown in Figure 2.22. They suggested that this delay in the reverse transformation is due to dislocation pinning by $\mathrm{Nb}(\mathrm{C}, \mathrm{N})$ precipitation and to the solute drag effect of niobium in solution, as both effects can retard the motion of interphase boundaries. Therefore, niobium can play a useful role in preventing reverse transformation during hot rolling.

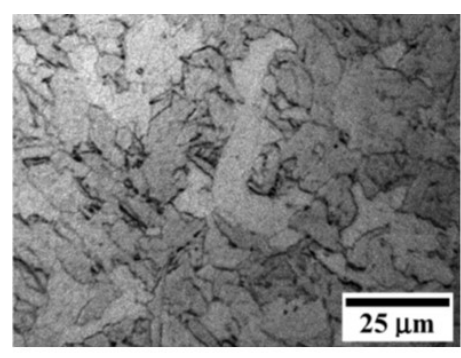

(a)

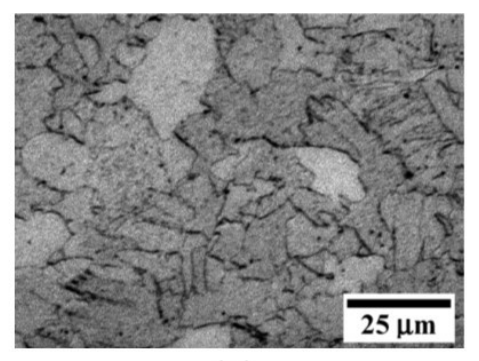

(b)

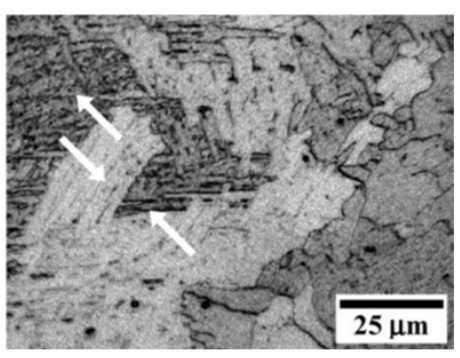

(c)

Figure 2.22: Micrographs of the specimens deformed at $856{ }^{\circ} \mathrm{C}\left(\mathrm{Ae}_{3}+20^{\circ} \mathrm{C}\right)$ at $0.4 \mathrm{~s}^{-1}$ and held isothermally after deformation for: a) $0 \mathrm{~s}, \mathrm{~b}) 200 \mathrm{~s}$, c) $400 \mathrm{~s}$. The arrows indicate martensite needles [2.22].

In 2013, Ghosh et al. [2.23] studied the occurrence of dynamic transformation above the $\mathrm{Ae}_{3}$ temperature by means of torsion tests on four different steels, with the following range of chemical 
compositions: $0.06-0.79 \% \mathrm{C}, 0.30-1.30 \% \mathrm{Mn}, 0.01-0.24 \% \mathrm{Si}$, where one of these steels contained $0.036 \% \mathrm{Nb}$. Dynamic transformation was observed to take place up to $130{ }^{\circ} \mathrm{C}$ above the $\mathrm{Ae}_{3}$, with an increase in the volume fraction of transformed ferrite as the strain was increased. The microstructures of the deformed specimens were analyzed by scanning electron microscopy (SEM), electron backscatter diffraction (EBSD) and transmission electron microscopy (TEM), which showed that the transformed ferrite is Widmanstätten in form and relatively thin (about $200 \mathrm{~nm}$ ). The microstructure was also characterized by a small value of the misorientation between the ferrite plates, which contributes to the rapid coalescence into grains. Figure 2.23 shows the SEM and TEM images obtained in the $0.79 \% \mathrm{C}$ steel and Figure 2.24 presents the EBSD maps obtained for the $0.21 \% \mathrm{C}$ steel, both deformed above the $\mathrm{Ae}_{3}$ temperature.

The authors also showed that the time available during the experiments and during hot rolling is insufficient for the occurrence of substitutional diffusion, but is enough for interstitial diffusion. Thus, it was suggested that the Widmanstätten ferrite is nucleated by a displacive mechanism followed by growth and carbon diffusion at lower carbon levels and accompanied by carbon diffusion at higher carbon levels. By calculating the driving forces, considering the inhomogeneous dislocation density and assuming that the austenite continues to work harden after the onset of transformation, it was shown that Gibbs energy contributions $\left(197 \mathrm{~J} \mathrm{~mol}^{-1}\right)$ are sufficient to promote transformation around $100^{\circ} \mathrm{C}$ above the Ae3 temperature [2.23].

More recently, Grewal et al. [2.24] reported on the dynamic transformation of austenite to ferrite in a steel containing $0.06 \% \mathrm{C}, 0.3 \% \mathrm{Mn}$ and $0.01 \% \mathrm{Si}$ by means of compression tests up to $480{ }^{\circ} \mathrm{C}$ above the $\mathrm{Ae}_{3}$ temperature. It was observed that the volume fraction of transformed ferrite first decreased with temperature but then increased when moving toward the $\delta$ ferrite formation temperature. 


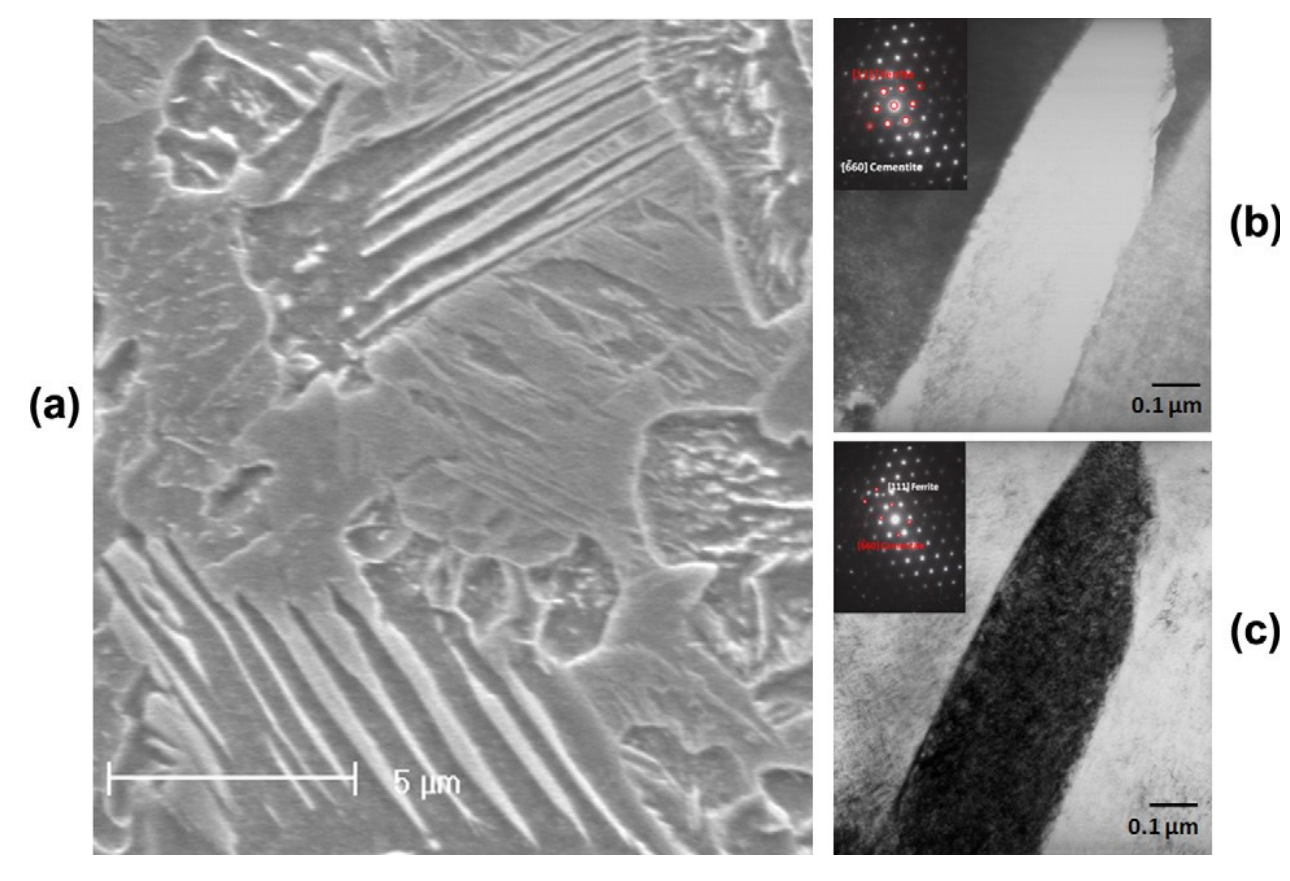

Figure 2.23: SEM and TEM images of the $0.79 \% \mathrm{C}$ steel deformed to a strain of 4.0 at $763{ }^{\circ} \mathrm{C}$ $\left(\mathrm{Ae}_{3}+30^{\circ} \mathrm{C}\right)$. a) SEM image, b) and c) TEM images (with diffraction patterns inserted) showing the presence of ferrite and cementite [2.23].

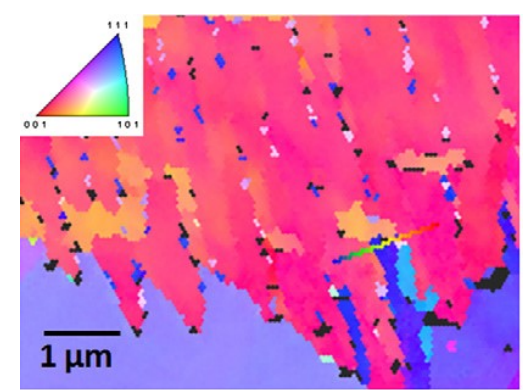

(a)

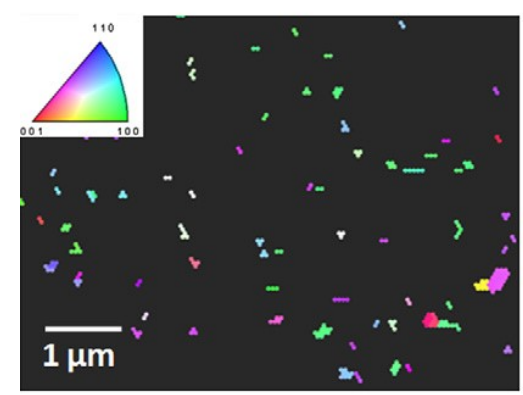

(c)

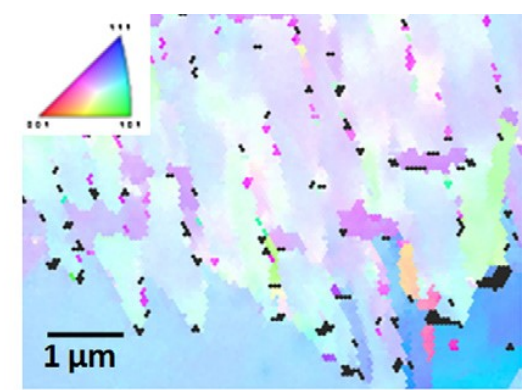

(b)

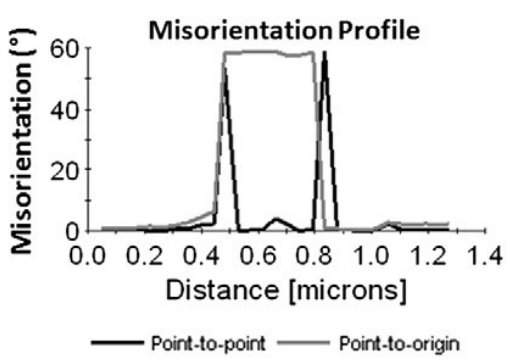

(d)

Figure 2.24: EBSD maps of the $0.21 \% \mathrm{C}$ steel deformed to 0.25 at $862{ }^{\circ} \mathrm{C}\left(\mathrm{Ae}_{3}+30{ }^{\circ} \mathrm{C}\right)$. a) Orientation image map of the ferrite phase (radial direction), black regions are martensite. b) Orientation image map of the ferrite phase (longitudinal direction). c) Orientation image map of the martensite phase (radial direction), black regions are ferrite. d) Misorientations measured along the line in (a) [2.23]. 


\subsubsection{Formation Mechanism of Dynamically Transformed Ferrite}

The formation of DT ferrite takes place in two consecutive steps, as shown schematically in Figure 2.25. First, at lower strains, Widmanstätten ferrite plates nucleate by a displacive mechanism at the austenite grain boundaries and also within the austenite grains. Later, at higher strains, the plates coalesce into polygonal grains [2.25]. The Widmanstätten ferrite plates are only about 200-300 $\mu \mathrm{m}$ wide, much finer than the plates formed below the $\mathrm{Ae}_{3}$ temperature. As shown in Figure 2.24, there is a similarity in orientation between the plates, which promotes the coalescence of the plates into grains when increasing the strain [2.23,2.25].

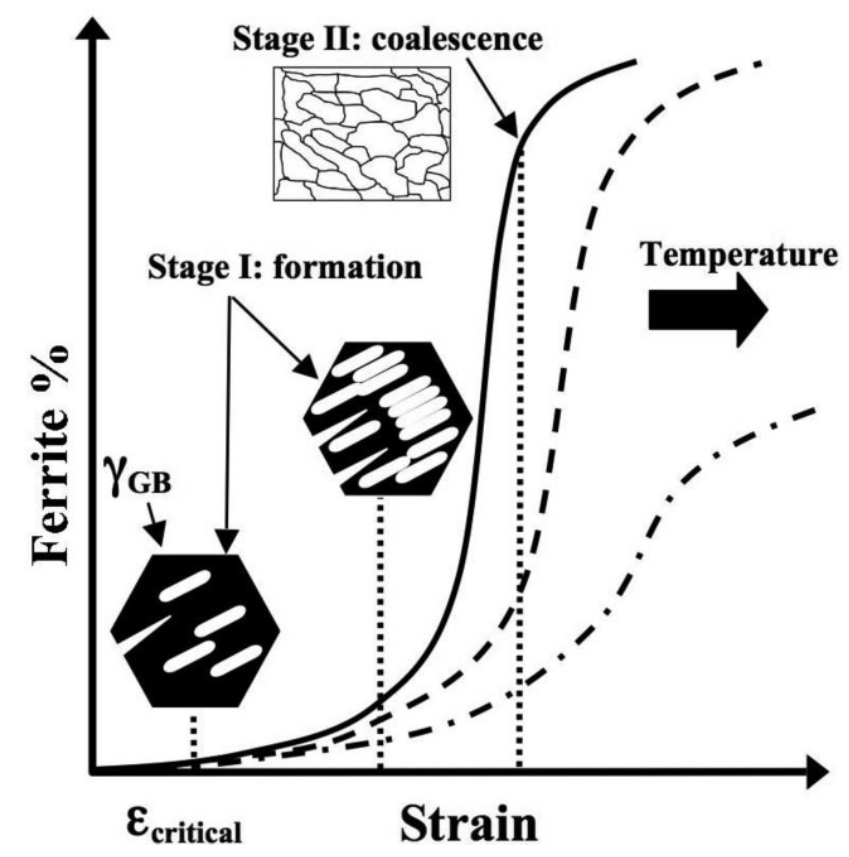

Figure 2.25: Schematic illustration of the microstructural evolution as a function of strain and temperature at temperatures above the $\mathrm{Ae}_{3}$ [2.25].

The Widmanstätten ferrite nucleated as a result of a displacive mechanism is supersaturated in carbon and, during or after growth of the plates, the carbon is rejected into the adjacent austenite phase or precipitated as cementite [2.23]. In Figure 2.23c, cementite particles of around $30 \mathrm{~nm}$ of diameter were identified. During hot rolling, the time available for DT was calculated as about 
$100 \mu \mathrm{s}$, which is sufficient for carbon to diffuse out of the Widmanstätten ferrite plates or to precipitate as cementite. During this time interval a substitutional atom can diffuse only for a distance of less than one atomic diameter. For torsion tests at strain rates of $1 \mathrm{~s}^{-1}$ and $10 \mathrm{~s}^{-1}$ the time for dynamic transformation was calculated as $10 \mathrm{~ms}$ and $1 \mathrm{~ms}$, respectively, and the previous considerations about diffusion also apply [2.23,2.26].

\subsubsection{Thermodynamics of Dynamic Transformation}

At temperatures above the $\mathrm{Ae}_{3}$, the transformation of underformed austenite into ferrite is not thermodynamically possible. However, as it was seen previously, the transformation of deformed austenite above the $\mathrm{Ae}_{3}$ temperature has been reported by many authors. In this section, three thermodynamic models which have been proposed to explain the dynamic transformation at high temperatures will be described: the stored energy, the stress activation and the transformation softening models.

\section{a) Stored Energy Model}

In the stored energy model proposed by Ghosh [2.23] based on Hanlon's work [2.27] and schematically illustrated on Figure 2.26, the mechanical energy stored in the austenite raises the Gibbs energy of the system, enabling the occurrence of the transformation of austenite into ferrite above the $\mathrm{Ae}_{3}$ temperature. This stored energy includes the dislocation, the grain boundary and the vacancy formation energies, but it was shown that the dislocation and grain boundary energies are much lower than the dislocation energy and thus they can be neglected [2.23]. According to his model, Hanlon could explain the occurrence of transformation at $10^{\circ} \mathrm{C}$ above the $\mathrm{Ae}_{3}$ temperature [2.27]. By considering the dislocation distribution to be inhomogeneous, Ghosh 
extrapolated the occurrence of DT to $100{ }^{\circ} \mathrm{C}$ above the $\mathrm{Ae}_{3}$ temperature. However, this model requires the application of high strains in order to increase the Gibbs energy of the system at high temperatures, and thus it is not able to explain the fact that the critical strain for the onset of DT can be as low as 0.1 . Additionally, the model fails in explaining the reason for the forward transformation being faster than the reverse [2.26].

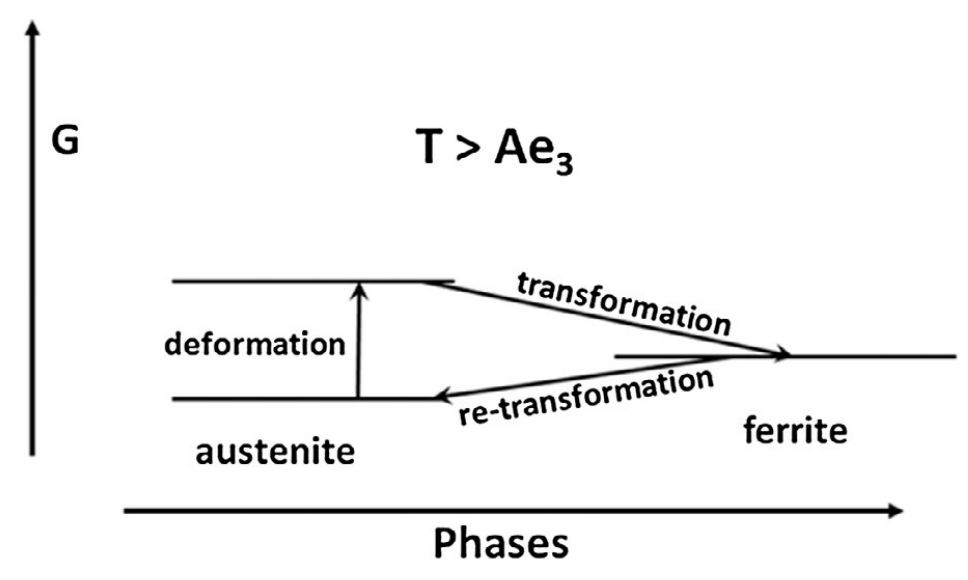

Figure 2.26: Schematic illustration of the stored energy model [2.28].

b) Stress Activation Model

To eliminate these discrepancies of the stored energy model, Jonas and Ghosh [2.28] proposed a model in which the driving force for DT is provided mainly by the applied stress. The stress activation model, illustrated in Figure 2.27, considers that the applied stress therefore must provide the energy to overcome three energy barriers: the Gibbs free energy, the dilatation work and the shear accommodation work.

The dilatation and shear accommodation geometries are shown schematically in Figure 2.28. Dilatation is considered to take place in a direction perpendicular to the habit plane, which forces the austenite adjacent to the ferrite upper surface to shear along with the ferrite, leading to the dilatation work (Figure 2.28a). According to the geometry of the formation of a pair of self- 
accommodating plates (Figure 2.28b), the austenite above and below the plates is not displaced laterally, but the austenite to the right and left of the plates has to accommodate the associated shear.

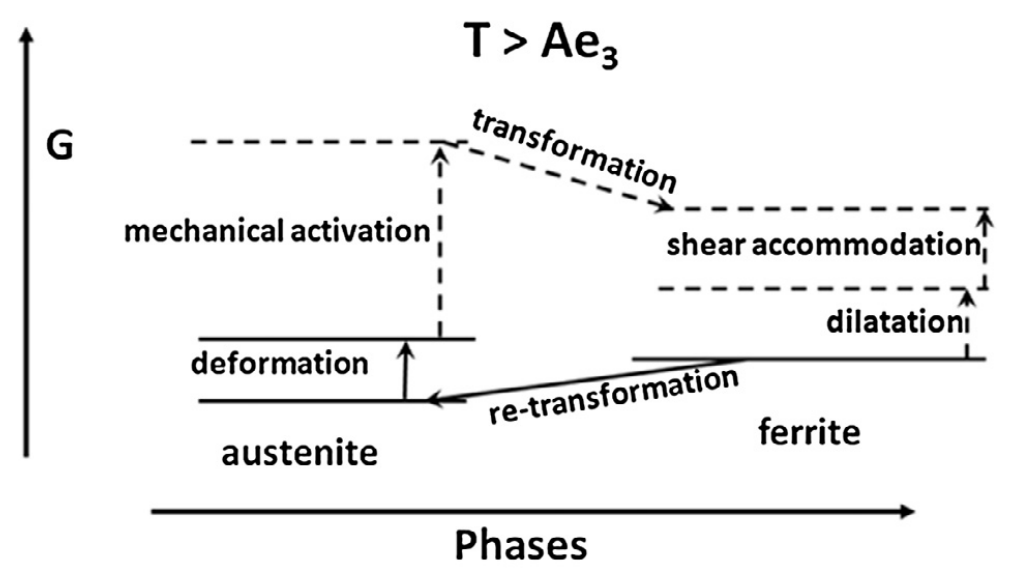

Figure 2.27: Schematic illustration of the stress activation model [2.28].

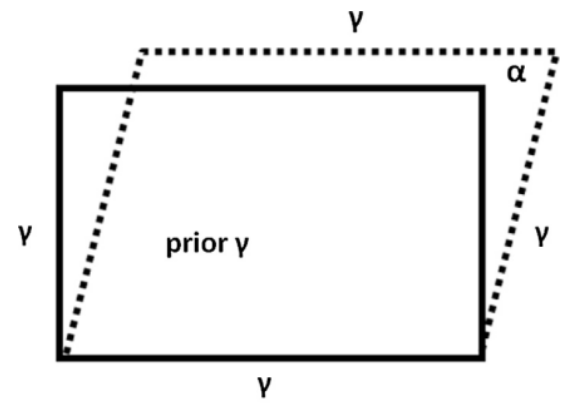

(a)

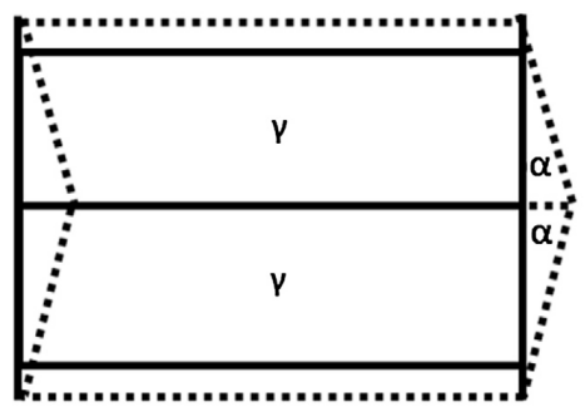

(b)

Figure 2.28: Geometries associated with the dilatation and shear accommodation work during the formation of Widmanstätten ferrite from austenite [2.28].

The dilatation work and the shear accommodation work per unit volume of transformed austenite, $\mathrm{W}_{\mathrm{D}} / \mathrm{V}$ and $\mathrm{W}_{\mathrm{A}} / \mathrm{V}$, were estimated by Equations 2.3 and 2.4 [2.28].

$$
\begin{gathered}
\frac{\mathrm{W}_{D}}{\mathrm{~V}}=\lambda \times \sigma_{0.1} \times \varepsilon \\
\frac{\mathrm{W}_{\mathrm{A}}}{\mathrm{V}}=\tau \times \gamma=\mathrm{m} \times \sigma_{0.1} \times \gamma
\end{gathered}
$$


Here $\sigma_{0.1}$ is the flow stress at the moment of nucleation of the Widmanstätten ferrite plate, $\varepsilon$ is the dilatation strain $(\varepsilon=0.03)$ [2.29], $\lambda$ is the orientation factor $\left(\lambda=\cos 54.7^{\circ}\right), \gamma$ is the average shear strain $(\gamma=0.18)$ and $\mathrm{m}$ is the Schmid factor $(\mathrm{m}=0.334)$ [2.28]. The shear strain for the austenite to Widmanstätten ferrite transformation is 0.36 [2.29], but the authors considered that only an average shear of $0.36 / 2=0.18$ have to be accommodate [2.28]. This dilatation work and shear accommodation work associated with the transformation are added to the chemical free energy difference between the austenite and ferrite to form the total energy barrier that must be overcome by the applied stress.

To explain the fact that the forward transformation is much faster than the reverse transformation, the authors suggested that as the forward transformation is mechanically activated, it does not require thermal activation and then can take place rapidly. In addition, it does not require an increase in the Gibbs energy of the austenite. After releasing the stress, reverse transformation takes place in the conventional manner, under a diffusional mechanism, which is thermally activated and thus is much slower [2.28].

\section{b) Transformation Softening Model}

The stress activation model does not provide an accurate quantitative description of the phenomenon. Thus, Aranas Jr. and Jonas [2.30] introduced the transformation softening model, illustrated in Figure 2.29. In this model, the driving force is considered to be the difference between the flow stress of the work-hardened austenite up to the critical strain and the flow stress of the newly formed Widmanstätten ferrite, and not the total applied stress. That is, the softening resulting from the transformation provides the energy to overcome the energy barriers. 
The flow stress of the Widmanstätten ferrite can be estimated from experimental data of the polygonal ferrite yield stress below the $\mathrm{Ae}_{1}$ temperature. For this, it is considered that the yield stress of both polygonal ferrite and Widmanstätten ferrite are linearly dependent on the inverse absolute temperature, according to the exponential stress law for creep, and the Widmanstätten flow stress is $18 \%$ higher than that of polygonal ferrite, as described in detail in reference [2.30].

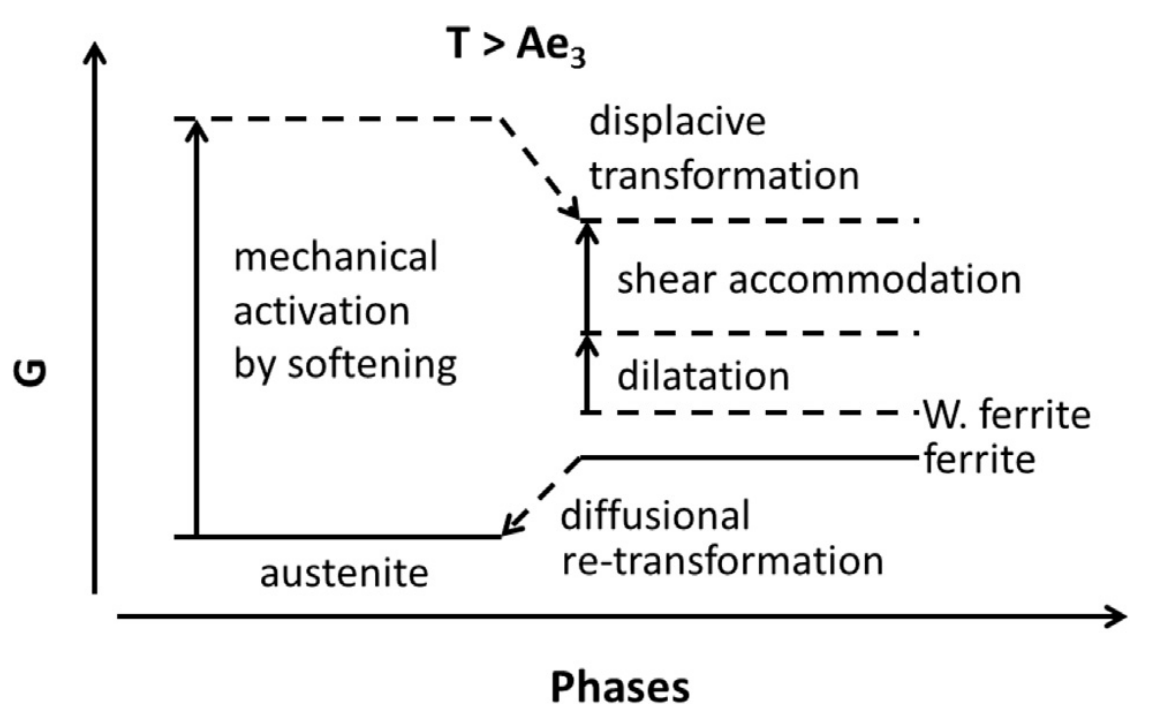

Figure 2.29: Transformation softening model [2.30].

\subsubsection{Critical Stress for Dynamic Transformation}

The strains at which DT and DRX begin are known as critical strains $\left(\varepsilon_{\mathrm{c}}\right)$. As the critical strains are located well before the peak strain, they cannot be estimated by the latter value. For this reason, Poliak and Jonas [2.31] developed the double differentiation method to accurately determine the onset of DRX. Later, Ghosh et al. [2.32] extended this method to determine the critical strain also for DT.

To apply the double differentiation method, first the loading transient of the experimental flow curve obtained from the torsion or compression tests (up to $0.2 \%$ offset in the total strain) is 
removed. Then, the curve is fitted to a polynomial and smoothened by using a software for numerical analysis, such as MATLAB ${ }^{\circledR}$. The smoothing process aims to eliminate the noise and fluctuations of the experimental data. The next step is to construct the curve of the conventional strain hardening rate $(\theta)$, defined by Equation 2.5, as a function of the stress $(\sigma)$. The onsets of DT and DRX are associated with inflection points in a $\theta$ versus $\sigma$ plot and hence the critical stresses obey the condition of Equation 2.6 (the critical stresses are associated with the minima of the $-(\partial \theta / \partial \sigma)$ versus $\sigma$ curve) [2.32]. An example of these curves constructed to determine the critical strains is displayed in Figure 2.30. When fitting the experimental flow curve to a polynomial of order less than 8 , it cannot be reproduced accurately and it is not possible to detect the onset of DT. Nevertheless, the order of the polynomial has only a slight effect on the obtained values for the critical strains [2.26].

$$
\begin{gathered}
\theta=\left(\frac{\partial \sigma}{\partial \varepsilon}\right)_{\dot{\varepsilon}} \\
\left(\frac{\partial}{\partial \sigma}\right)\left(-\frac{\partial \theta}{\partial \sigma}\right)=0
\end{gathered}
$$

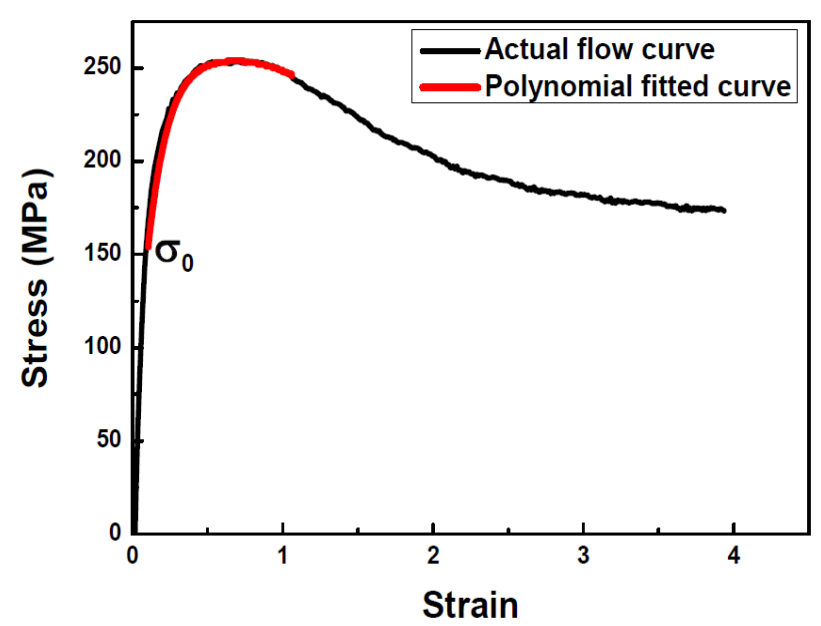

(a)

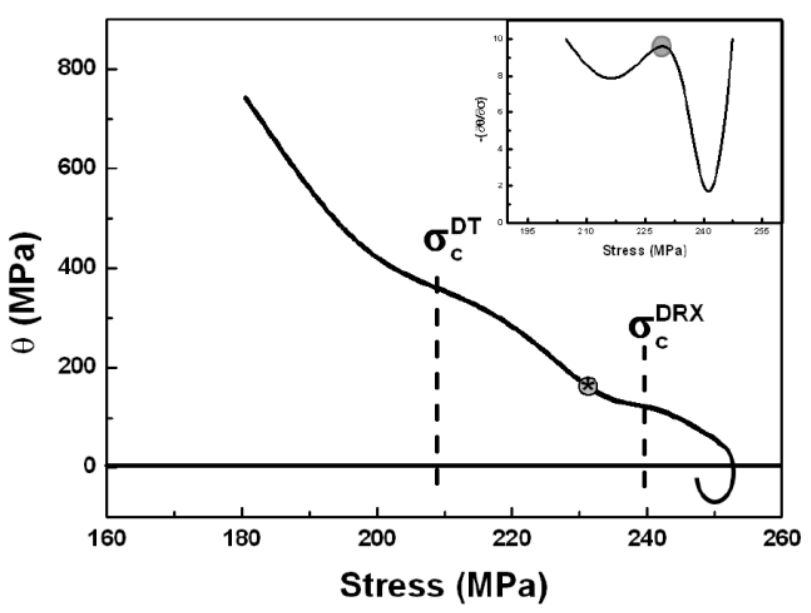

(b)

Figure 2.30: a) Experimental flow curve obtained from torsion test of a steel containing $0.79 \% \mathrm{C}$ at $763{ }^{\circ} \mathrm{C}\left(\mathrm{Ae}_{3}+30{ }^{\circ} \mathrm{C}\right)$ together with the fitted curve using the polynomial of order $\left.8 . \mathrm{b}\right) \theta$ versus $\sigma$ plot derived from the fitted curve in (a), the inset shows the $-(\partial \theta / \partial \sigma)$ versus $\sigma$ curve [2.33]. 


\subsubsection{Reverse Transformation}

At temperatures above the $\mathrm{Ae}_{3}$, the metastable DT ferrite transforms back into austenite during holding after deformation. This reverse transformation is thermally activated and occurs under a diffusional mechanism; thus it is time dependent [2.28]. The forward transformation has been extensively studied, but in order to completely understand the microstructural changes which take place during hot rolling to improve the mechanical properties and to have deep control of the process, it is necessary to know the rate of retransformation during the interpass time. In 2017, Aranas Jr. et al. [2.34] generated for the first time time-temperature-reverse transformation (TTRT) diagrams, a tool which enables predicting the amount of retransformed ferrite during holding after deformation. Figure 2.31 presents an example of this kind of diagram for a $\mathrm{Nb}$-microalloyed steel, constructed by means of hot compression tests at three different temperatures and applying different holding times after deformation. The fraction of retransformed ferrite was calculated by the difference between the ferrite volume fractions of the sample quenched just after deformation (no holding time) and after holding.

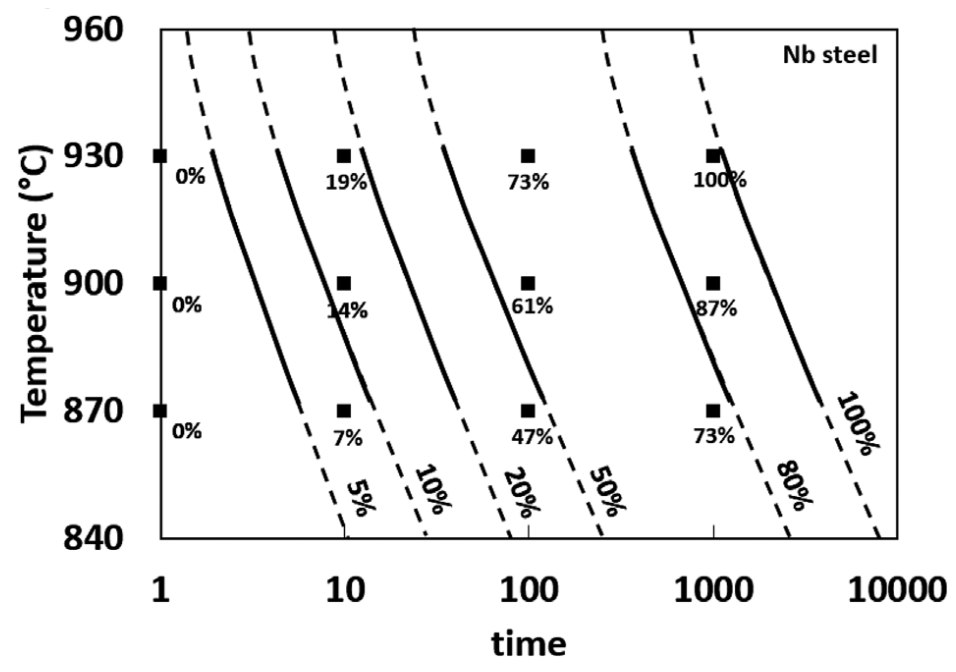

Figure 2.31: TTRT curves for a Nb microalloyed steel. The solid lines cover the temperature range of the study and the broken lines are projections of the behaviour outside this range. The actual results are plotted by points. [2.34]. 


\subsection{Torsion Testing}

Torsion tests are widely used to simulate the hot rolling process. The two main advantages of this method in relation to tension or compression tests are: large strains can be achieved without the torsion specimen undergoing significant shape change such as necking or barreling and a constant true strain rate can be imposed at a given radial position of the specimen by twisting at a constant rate. However, the interpretation of the torsion test data is more complex, because the strain and strain rate vary along the specimen radius [2.35]. A schematic illustration of a torsion machine is given in Figure 2.32.

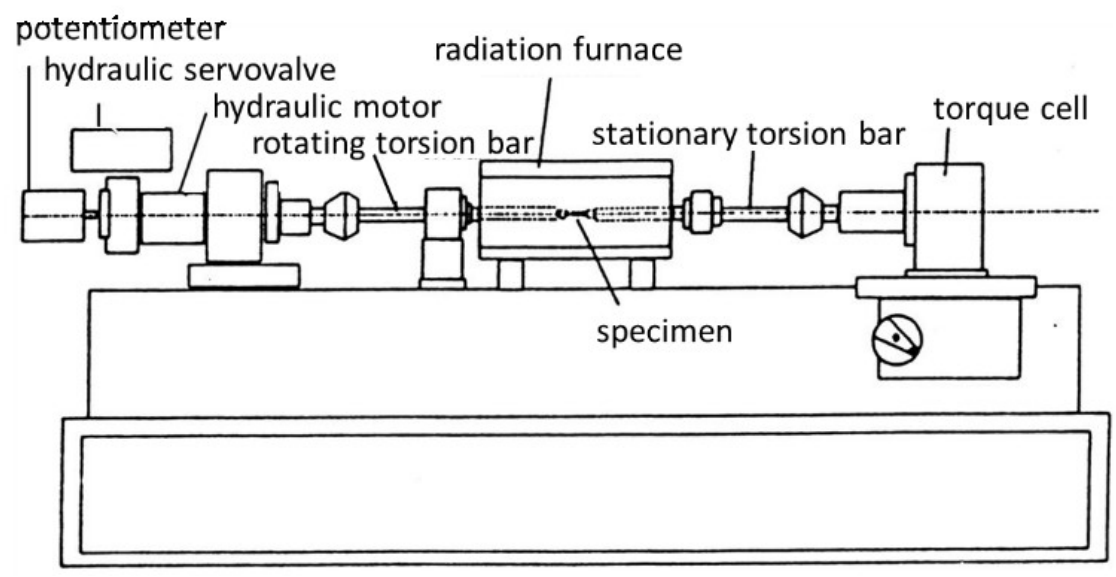

Figure 2.32: Schematic illustration of the torsion machine.

In a solid bar under torsion, the strain varies linearly from zero at the axis up to a maximum at the outer radius. The shear stress $(\tau)$ at the specimen surface can be evaluated by the Filds and Backofen equation below [2.35]:

$$
\tau=\frac{T}{2 \pi r^{3}}(3+N+M)
$$

Here $\mathrm{T}$ is the torque and $\mathrm{r}$ is the specimen radius. $\mathrm{N}$ is the twist sensitivity coefficient, defined by the slope of the curve $\log \mathrm{T}$ versus $\log \theta$ at a constant $\dot{\theta}$, with $\theta$ being the amount of twist in the 
specimen, in radians. $M$ is the twist rate sensitivity coefficient, defined by the slope of the curve $\log \mathrm{T}$ versus $\log \dot{\theta}$ at a constant $\theta$.

At temperatures above $500{ }^{\circ} \mathrm{C}, \mathrm{N}$ is negligible and $\mathrm{M}$ can be considered as 0.3 [2.33]. Thus, the shear stress can be calculated by Equation 2.8.

$$
\tau=\frac{3.3 \mathrm{~T}}{2 \pi r^{3}}
$$

Applying the von Mises criteria, the equivalent stress $(\sigma)$ and strain $(\varepsilon)$ are given by Equations 2.9 and 2.10 , respectively.

$$
\begin{gathered}
\sigma=\frac{3.3 \sqrt{3} \mathrm{~T}}{2 \pi r^{3}} \\
\varepsilon=\frac{r \theta}{\sqrt{3} \mathrm{~L}}
\end{gathered}
$$

Here $\mathrm{L}$ is the gage length.

\subsection{References}

[2.1] Usiminas, 2015. Available: http://www.usiminas.com/wp-content/uploads/2013/11/us0073-15g-cat-sincron-ing.pdf

[2.2] Usiminas, 2015. Available: http://www.usiminas.com/wp-content/uploads/2013/11/is0073-15h-cat-tiras-a-quente-ing.pdf

[2.3] J.J. Jonas, "Effect of interpass time on the hot rolling behaviour of microalloyed steels", Mater. Sci. Forum, vol. 284-286, pp. 3-14, 1998.

[2.4] S. Vervynckt, K. Verbeken, B. Lopez and J. J. Jonas, "Modern HSLA steels and role of nonrecrystallization temperature", Int. Mater. Rev., vol. 57, pp. 187-297, 2012. 
[2.5] J. J. Jonas, "The hot strip mill as an experimental tool”, ISIJ Int., vol. 40, pp. 731-738, 2000.

[2.6] R. E. Reed-Hill and R. Abbaschian, Physical Metallurgy Principles. Boston, USA: PWS Pub., 1994.

[2.7] F. Siciliano Jr., "Mathematical modeling of the hot strip rolling of Nb microalloyed steels", PhD Thesis, Dept. Min. Mater. Eng., McGill Univ., Montreal, Canada, 1999.

[2.8] H. J. McQueen and J. J. Jonas, "Recovery and recrystallization during high temperature deformation”, Treatise Mater. Sci. Technol., vol. 6, pp. 393-493, 1975.

[2.9] W. D. Callister, Materials Science and Engineering: an Introduction. New York, USA: John Wiley \& Sons, 2007.

[2.10] H. K. D. H. Bhadeshia and R. Honeycombe, Steels: Microstructure and Properties. Oxford, UK: Elsevier, 2017.

[2.11] M. Hillert and J. Agren, "On the definitions of paraequilibrium and orthoequilibrium", Scr. Mater., vol. 50, pp. 697-699, 2004.

[2.12] H. K. D. H. Bhadeshia, "Diffusional formation of ferrite in iron and its alloys", Prog. Mater. Sci., vol. 29, pp. 321-386, 1985.

[2.13] H. K. D. H. Bhadeshia, "Allotriomorphs and idiomorphs", Undergraduate Lecture Notes Metals and Alloys (year 3), University of Cambridge, 2000. Available: http://www.phase$\underline{\text { trans.msm.cam.ac.uk/2000/C9/lectures78.pdf }}$

[2.14] D. A. Porter and K. E. Easterling, Phase Transformations in Metals and Alloys, Boca Raton, USA: Taylor \& Francis Group, 2004.

[2.15] H. K. D. H. Bhadeshia, "Widmanstätten ferrite", Undergraduate Lecture Notes - Metals and Alloys (year 3), University of Cambridge, 2000. Available: http://www.phasetrans.msm.cam.ac.uk/2000/C9/lecture7.pdf 
[2.16] Y. Matsumara and H. Yada, "Evolution of ultrafine-grained ferrite in hot successive deformation", Trans. ISIJ, vol. 27, pp. 492-498, 1987.

[2.17] H. Yada, Y. Matsumara and T. Senuma, "A new thermomechanical heat treatment for grain refining in low carbon steels", in Proc. Int. Conf. Physical Metallurgy of Thermomech. Process. Steels Other Metals, THERMEC-88 1988, Tokyo, Japan, pp. 200-207.

[2.18] H. Yada, C. M. Li and H. Yamagata, "Dynamic $\gamma \rightarrow \alpha$ transformation during hot deformation in iron-nickel-carbon alloys", ISIJ Int., vol. 40, pp. 200-206, 2000.

[2.19] Y. Chen and Q. A. Chen, "Dilatometric investigation on isothermal transformation after hot deformation", J. Iron Steel Res. Int., vol. 10, pp. 46-48, 2003.

[2.20] Z. Liu, D. Li, S. Lu and G. Qiao, "Thermal stability of high temperature deformation induced ferrite in low carbon steel”, ISIJ Int., vol. 47, pp. 289-293, 2007.

[2.21] X. Sun, H. Luo, H. Dong, Q. Liu and Y. Weng, "Microstructural evolution and kinetics for post-dynamic transformation in a plain low carbon steel”, ISIJ Int., vol. 48, pp. 994-1000, 2008.

[2.22] V. Basabe and J. J. Jonas, "The ferrite transformation in hot deformed $0.036 \% \mathrm{Nb}$ austenite at temperatures above the $\mathrm{Ae}_{3}$ ", ISIJ Int., vol. 50, pp. 1185-1192, 2010.

[2.23] C. Ghosh, V. V. Basabe, J. J. Jonas, Y. M. Kim, I. H. Jung and S. Yue, "The dynamic transformation of deformed austenite at temperatures above the Ae $_{3}$ ", Acta Mater., vol. 61, pp. 2348-2362, 2013.

[2.24] R. Grewal, C. Aranas Jr., K. Chadha, D. Shahriari, M. Jahazi and J. J. Jonas, "Formation of Widmanstätten ferrite at very high temperatures in the austenite phase field", Acta Mater., vol. 109, pp. 23-31, 2016.

[2.25] V. Basabe, J. J. Jonas and C. Ghosh, "Formation of Widmanstätten ferrite in a $0.036 \% \mathrm{Nb}$ low carbon steel at temperatures above the Ae3”, Steel Res. Int., vol. 85, pp. 8-15, 2014.

[2.26] C. Ghosh, C. Aranas Jr. and J. J. Jonas, "Dynamic transformation of deformed austenite at temperatures above the Ae3”, Prog. Mater. Sci., vol. 82, pp. 151-233, 2016. 
[2.27] D. N. Hanlon, J. Sietsma and S. van der Zwaag, "The effect of plastic deformation of austenite on the kinetics of subsequent ferrite formation", ISIJ Int., vol. 41, pp. 1028-1036, 2001. [2.28] J. J. Jonas and C. Ghosh, "Role of mechanical activation in the dynamic transformation of austenite", Acta Mater., vol. 61, pp. 6125-6131, 2013.

[2.29] H. K. D. H. Bhadeshia, "Material factors", in Handbook of Residual Stress and Deformation of Steel, G. Totten, M. Howes, T. Inoue, Eds., Materials Park, USA: ASM International, 2002, pp. 3-10.

[2.30] C. Aranas Jr. and J. J. Jonas, "Effect of Mn and Si on the dynamic transformation of austenite above the $\mathrm{Ae}_{3}$ temperature", Acta Mater., vol. 82, pp. 1-10, 2015.

[2.31] E. I. Poliak and J. J. Jonas, "A one-parameter approach to determining the critical conditions for the initiation of dynamic recrystallization”, Acta Mater., vol. 44, pp. 127-136, 1996. [2.32] C. Ghosh, V. V. Basabe and J. J. Jonas, "Determination of the critical strains for the initiation of dynamic transformation and dynamic recrystallization in four steels of increasing carbon contents", Steel Res. Int., vol. 84, pp. 490-494, 2013.

[2.33] C. Ghosh, "The dynamic transformation of deformed austenite at temperatures above the Aes”, PhD Thesis, Dept. Min. Mater. Eng., McGill Univ., Montreal, Canada, 2013.

[2.34] C. Aranas Jr., S. F. Rodrigues, Y. J. Shen, Z. Zhang and J. J. Jonas, "Time-temperaturereverse transformation (TTRT) behaviours of a $\mathrm{C}-\mathrm{Mn}$ and $\mathrm{Nb}$ microalloyed steel after dynamic transformation above the $\mathrm{Ae}_{3}$ ”, Steel Res. Int., vol. 87, pp. 1-7, 2017.

[2.35] S. L. Semiatin and J. J. Jonas, "Torsion testing to assess bulk workability" in Handbook of Workability and Process Design, G. E. Dieter, H. A. Kuhn and S. L. Semiatin, Eds., Materials Park, USA: ASM International, 2003, ch. 8, pp. 86-121. 


\section{ChAPTER 3: DYNAMic TRANSFORMATION DURING THE SiMUlated Hot Rolling OF AN API-X80 STEEL}

This chapter concerns tthe phenomenon of dynamic transformation during the hot rolling of an API-X80 steel. For this purpose, the hot rolling process was simulated through torsion tests carried out under continuous cooling conditions. Seven deformation passes were applied above the transformation temperature and interpass times of 1,8 and $20 \mathrm{~s}$ were employed. Metallographic analysis showed that dynamic transformation took place under all conditions. The volume fraction of ferrite increased with cumulative strain and it was lower for longer interpass times due to the reverse transformation. The effect of dynamic transformation on the flow curves was also investigated. Thermodynamic calculations confirmed that this phenomenon is likely to occur during hot rolling.

- This chapter has been submitted to Steel Research International as: Nizia Mendes-Fonseca,

Samuel F. Rodrigues, Baoqi Guo and John J. Jonas, "Dynamic Transformation during the Simulated Hot Rolling of an API-X80 Steel', 2019. 


\subsection{Abstract}

The occurrence of dynamic transformation was investigated during the simulated hot rolling of an API-X80 steel. Torsion tests were carried out under continuous cooling conditions, with all deformation passes applied above the equilibrium transformation temperature. Three different interpass times were investigated: 1, 8 and $20 \mathrm{~s}$. Samples were water-quenched before and after the odd-numbered passes, and the volume fraction of ferrite was evaluated metallographically. Dynamic transformation took place under all conditions and the volume fraction of retained ferrite increased with the retained strain. The increase in flow stress during simulated rolling was less than expected under all conditions, which is evidence for the dynamic formation of ferrite. The driving forces and energies barriers were evaluated, indicating that dynamic transformation is mechanically activated.

\subsection{Introduction}

Dynamic transformation (DT) is defined as a phase transformation that occurs during deformation. In steels, austenite can transform dynamically into ferrite above the transformation temperature $\mathrm{Ae}_{3}$. The occurrence of DT above the $\mathrm{Ae}_{3}$ temperature was first reported by Yada and co-workers in the 1980s [3.1,3.2]. However, as their evidence of the phenomenon was indirect, there were doubts as to whether the ferrite was formed during deformation or during quenching. Later in 2000, Yada et al. carried out an in situ x-ray diffraction study during hot deformation [3.3], and since then this topic has been widely studied [3.4-3.8]. More recently, it was shown that DT can occur over all the austenite phase field, up to the $\delta$-ferrite formation temperature [3.9]. The dynamically formed ferrite is Widmanstätten in type and forms displacively. With increasing strain, these Widmanstätten plates coalesce into polygonal grains [3.10]. During holding after deformation at 
temperatures above the $\mathrm{Ae}_{3}$, the metastable DT ferrite transforms back into austenite. This reverse transformation is thermally activated and occurs through a diffusional mechanism [3.11].

Rodrigues et. al. explored the occurrence of DT during the simulated plate rolling of an API-X70 steel, under both isothermal and continuous cooling conditions. They also investigated the reverse transformation of the dynamically formed ferrite during isothermal holding after deformation [3.12-3.15]. More recently, the higher strength API-X80 steel has been developed and is being produced on a large scale, gradually supplanting the API-X70 steel in pipeline projects. Here, a range of interpass times and temperatures are employed in keeping with the modified $\mathrm{Ae}_{3}$ temperature. Thus the present study represents an advance over the previous investigations and this phenomenon is characterized in an API-X80 steel for the first time.

The simulations were carried out by means of torsion tests, with seven finishing passes applied under continuous cooling conditions. Three different interpass times (1, 8 and $20 \mathrm{~s})$ were investigated. The extent of DT after each pass and the amount of ferrite retained during the interpass intervals were quantified on samples quenched before and after selected passes. The results obtained are described in detail below.

\subsection{Experimental Section}

The API X-80 steel was supplied in the form of a $12.5 \mathrm{~mm}$ thick pipe. The chemical composition and the orthoequilibrium $\mathrm{Ae}_{3}$ temperature are shown in Table 3.1. The transformation temperature was calculated using the FactSage software [3.16]. Cylindrical torsion specimens with diameters of $6.35 \mathrm{~mm}$ and gauge lengths of $12.7 \mathrm{~mm}$ were machined from this sample. 
Table 3.1: Chemical composition [wt \%] and orthoequilibrium transformation temperature.

\begin{tabular}{ccccccccc}
\hline $\mathbf{C}$ & $\mathrm{Mn}$ & $\mathrm{Si}$ & $\mathbf{C r}$ & $\mathrm{Ni}$ & $\mathbf{C u}$ & $\mathrm{Mo}$ & $\mathrm{Nb}$ & Orthoequilibrium Ae3 \\
\hline 0.07 & 2.02 & 0.10 & 0.02 & 0.15 & 0.26 & 0.17 & 0.049 & $813^{\circ} \mathrm{C}$ \\
\hline
\end{tabular}

\subsubsection{Torsion Testing}

The simulations were performed using a servo-hydraulic, computer-controlled MTS torsion machine, equipped with a radiation furnace and a temperature controller. A K-type thermocouple was attached to the sample for temperature control purposes. The specimens were enclosed in a quartz tube and a protective argon atmosphere was employed to prevent oxidation and decarburization. The amount of twist applied to the specimen was regulated by the servocontrolled software and the torque-twist data were registered in the server.

Continuous cooling conditions were employed with three different interpass times, as shown schematically in Figure 3.1. The specimens were heated at $1^{\circ} \mathrm{C} \mathrm{s}^{-1}$ from room temperature to $1200{ }^{\circ} \mathrm{C}$ and held for $10 \mathrm{~min}$ to allow full austenitization. They were then cooled at $1{ }^{\circ} \mathrm{C} \mathrm{s}^{-1}$ to $1100{ }^{\circ} \mathrm{C}$, and after holding for $60 \mathrm{~s}$ at this temperature, the first roughing pass was applied. The second roughing pass was applied after the specimens were held isothermally for $120 \mathrm{~s}$, to allow for recrystallization to take place. During each roughing pass, the specimens were strained to 0.4 at a strain rate of $1 \mathrm{~s}^{-1}$.

After the second roughing pass, the specimens were held at the roughing temperature for $60 \mathrm{~s}$ before cooling down to $920^{\circ} \mathrm{C}$. They were then held at this temperature for $60 \mathrm{~s}$ before beginning the finishing passes. A strain of 0.2 was employed for each pass at a strain rate of $1 \mathrm{~s}^{-1}$. The simulations were carried out using interpass times of 1,8 and $20 \mathrm{~s}$; in order to have a constant temperature difference of $15{ }^{\circ} \mathrm{C}$ between two consecutive passes, the cooling rates employed were 
$15,1.88$ and $0.75{ }^{\circ} \mathrm{C} \mathrm{s}^{-1}$, respectively. For the three simulations, the last pass was applied at $830{ }^{\circ} \mathrm{C}$ $\left(17^{\circ} \mathrm{C}\right.$ above the orthoequilibrium $\mathrm{Ae}_{3}$ temperature). Before and after the $1^{\text {st }}, 3^{\text {rd }}, 5^{\text {th }}$ and $7^{\text {th }}$ passes, specimens were water quenched with the aim of quantifying the volume fraction of ferrite formed dynamically and retained.

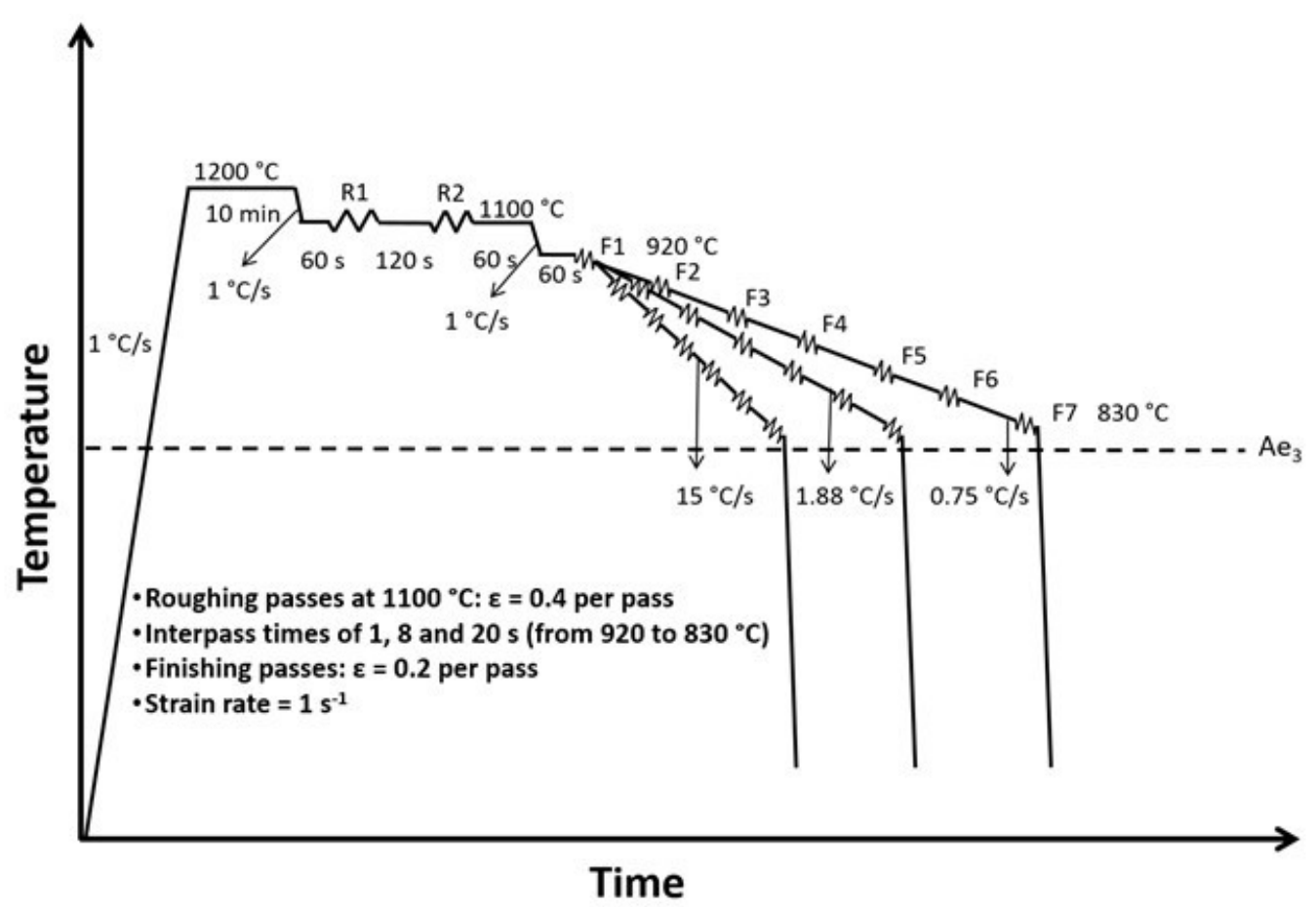

Figure 3.1: Thermomechanical schedule for the torsion tests under continuous cooling conditions. Two roughing passes were applied at $1100{ }^{\circ} \mathrm{C}$ (strain of 0.4 at a strain rate of $1.0 \mathrm{~s}^{-1}$ and seven finishing passes were applied at $920,905,890,875,860,845$ and $830^{\circ} \mathrm{C}$ (strain of 0.2 at a strain rate of $1.0 \mathrm{~s}^{-1}$ ). Interpass times of 1,8 and $20 \mathrm{~s}$ were employed, which corresponds to cooling rates of $15,1.88$ and $0.75^{\circ} \mathrm{C} \mathrm{s}^{-1}$, respectively.

\subsubsection{Metallography}

Sections of the torsion specimens were hot mounted longitudinally for metallographic analysis. A layer of about $200 \mu \mathrm{m}$ of the specimens' surface was removed by grinding in order to avoid the region oxidized during water quenching. The specimens were then polished using silicon carbide papers from 400 to 1200 grit while being lubricated with water. Final polishing was carried out with 3 and $1 \mu \mathrm{m}$ diamond pastes. Finally, the specimens were etched with a 3\% nital solution for 
approximately $15-20 \mathrm{~s}$ and treated with a $10 \%$ sodium metabisulfite $\left(\mathrm{Na}_{2} \mathrm{~S}_{2} \mathrm{O}_{5}\right)$ solution for around $10 \mathrm{~s}$ to improve the contrast between ferrite and martensite (prior austenite). Microstructural analysis was performed using optical microscopy and SEM. To quantify the ferrite volume fractions, about ten images at 200x magnification were analyzed for each condition using the ImageJ software [3.17].

\subsection{Results}

\subsubsection{Stress-Strain Curves}

In order to derive the stress-strain curves from the torque-twist data, the Fields and Backofen equation was employed [3.18]. It was observed that the specimen diameter increased during freeend torsion testing [3.19]; these changes in diameter were taken into account when computing the equivalent stress from the torque values.

The stress-strain curves obtained for the 7-pass simulations under continuous cooling conditions are displayed in Figure 3.2. Here the interpass times are $1 \mathrm{~s}$ (Figure 3.2a), $8 \mathrm{~s}$ (Figure 3.2b) and $20 \mathrm{~s}$ (Figure 3.2c). The temperature of each pass is also indicated on the flow curves, and it should be noted that all passes were carried out above the orthoequilibrium $\mathrm{Ae}_{3}$ temperature for this steel, see Table 3.1.

The stress level increases with strain for all interpass times, but this increase is less than expected solely from recrystallization and recovery. This effect on the flow curves can be attributed to the DT of austenite into ferrite since ferrite is a softer phase. During longer interpass times, more static restoration takes place and more ferrite transforms back into austenite. These two concurrent phenomena lead to higher stress levels at longer interpass times. 
a)

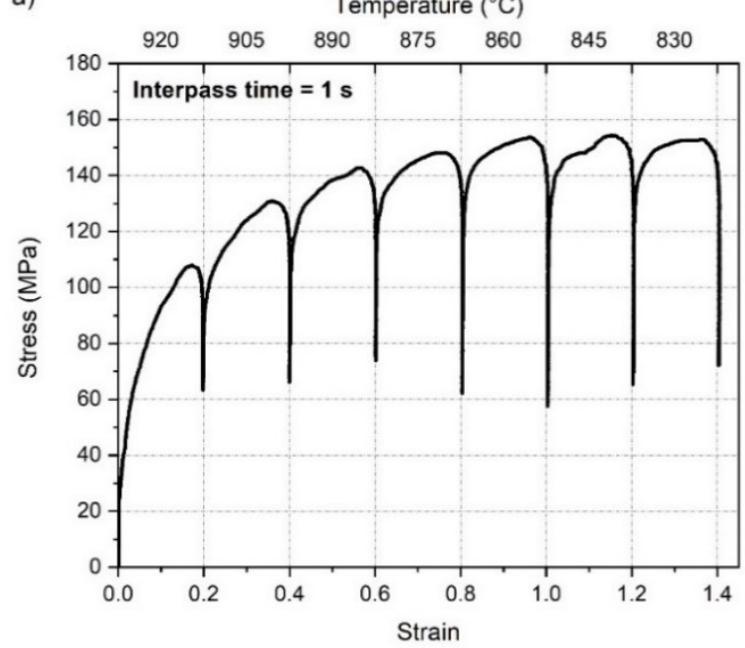

b)

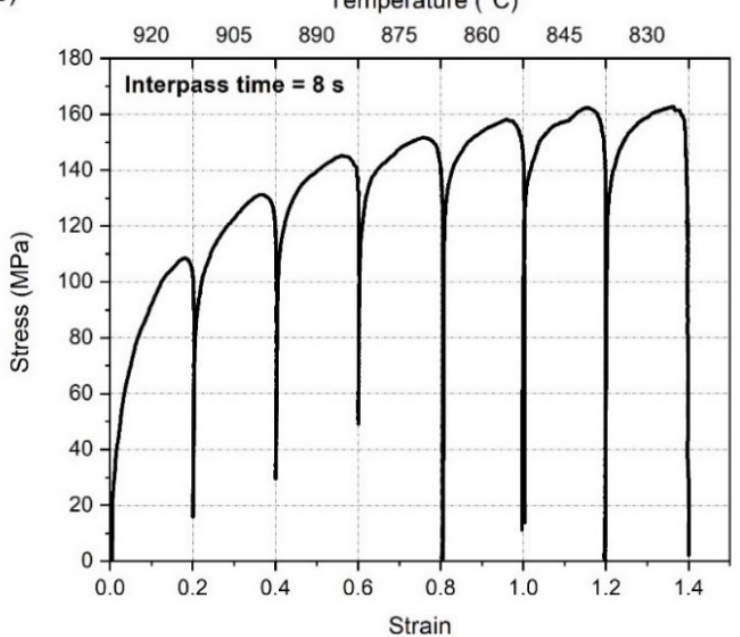

c)

Temperature $\left({ }^{\circ} \mathrm{C}\right)$

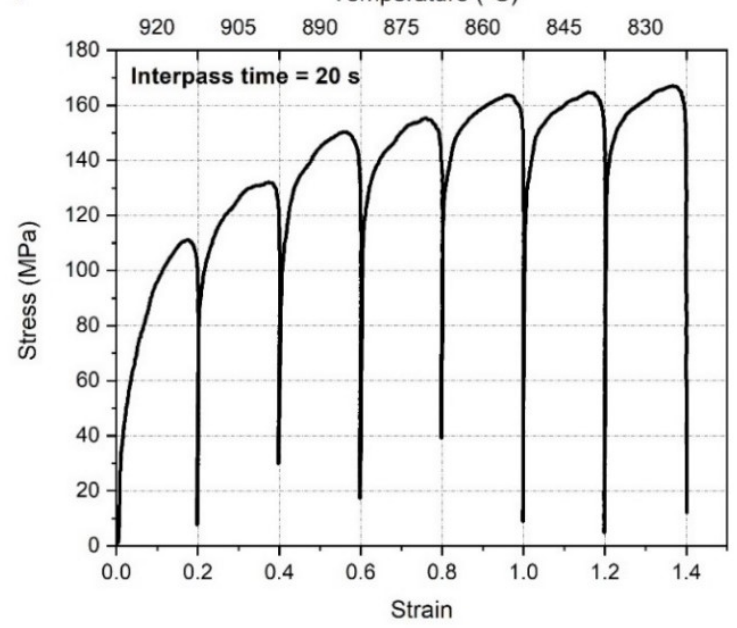

Figure 3.2: Stress-strain curves of the finishing passes using the thermomechanical schedule of Figure 1 when employing interpass times of a) $1 \mathrm{~s}$, b) $8 \mathrm{~s}$ and c) $20 \mathrm{~s}$.

\subsubsection{Dynamic Transformation Microstructures}

The optical micrographs of the samples quenched immediately before and after the odd-numbered passes are shown in Figures 3.3 and 3.4 for interpass times of $1 \mathrm{~s}$ and $20 \mathrm{~s}$, respectively. The microstructures were observed below approximately $300 \mu \mathrm{m}$ of the outer surface of the longitudinal sections, where the applied strain is at a maximum and the region is free of oxidation. In these micrographs, the uniformly light-colored regions correspond to ferrite and the darker ones to martensite (prior austenite). 

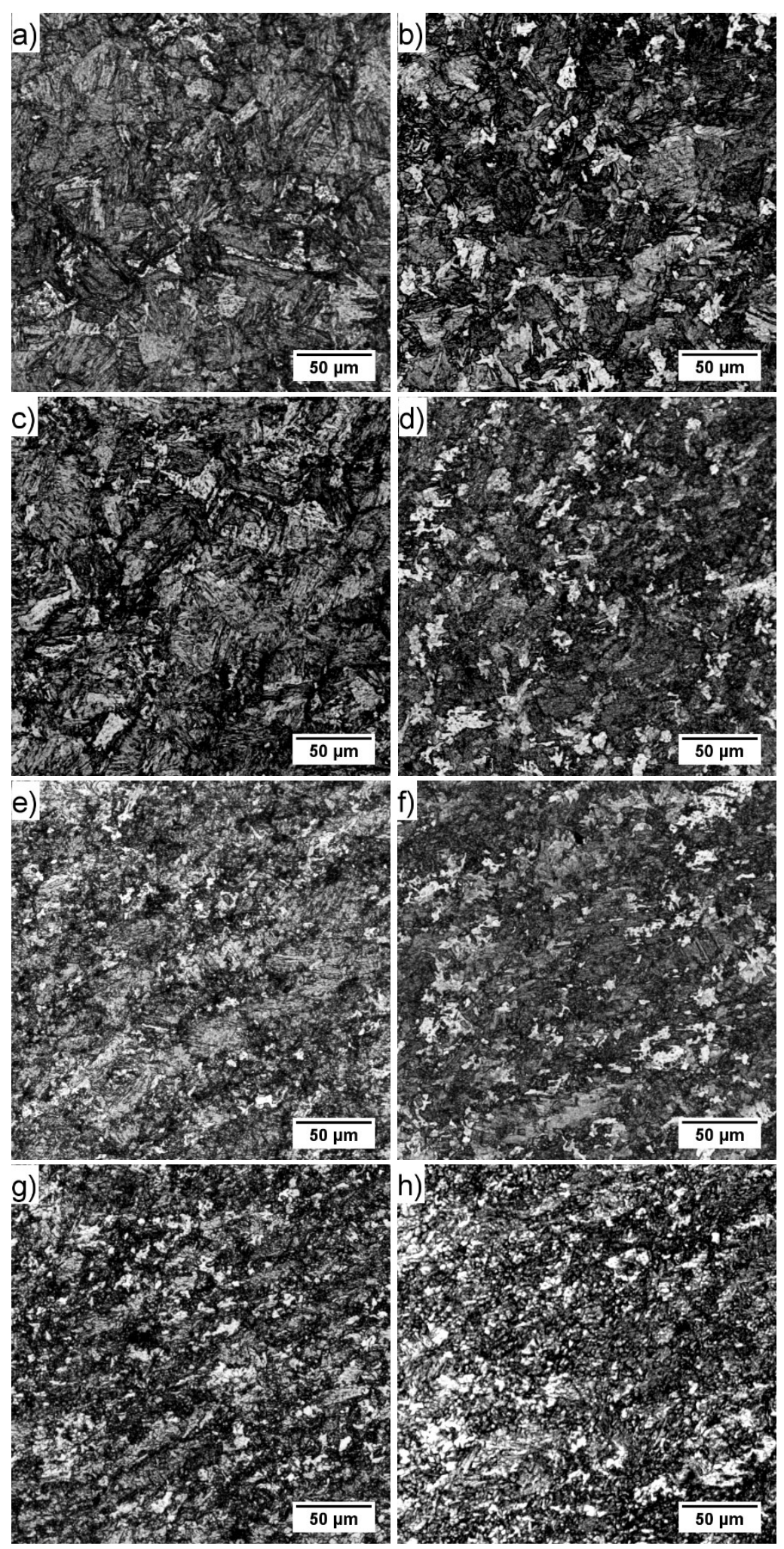

Figure 3.3: Optical micrographs of the deformed samples with the interpass time of $1 \mathrm{~s}$. The samples were quenched a) before the $1^{\text {st }}$ pass, b) after the $1^{\text {st }}$ pass, c) before the $3^{\text {rd }}$ pass, d) after the $3^{\text {rd }}$ pass, e) before the $5^{\text {th }}$ pass, f) after the $5^{\text {th }}$ pass, g) before the $7^{\text {th }}$ pass and $h$ ) after the $7^{\text {th }}$ pass. 

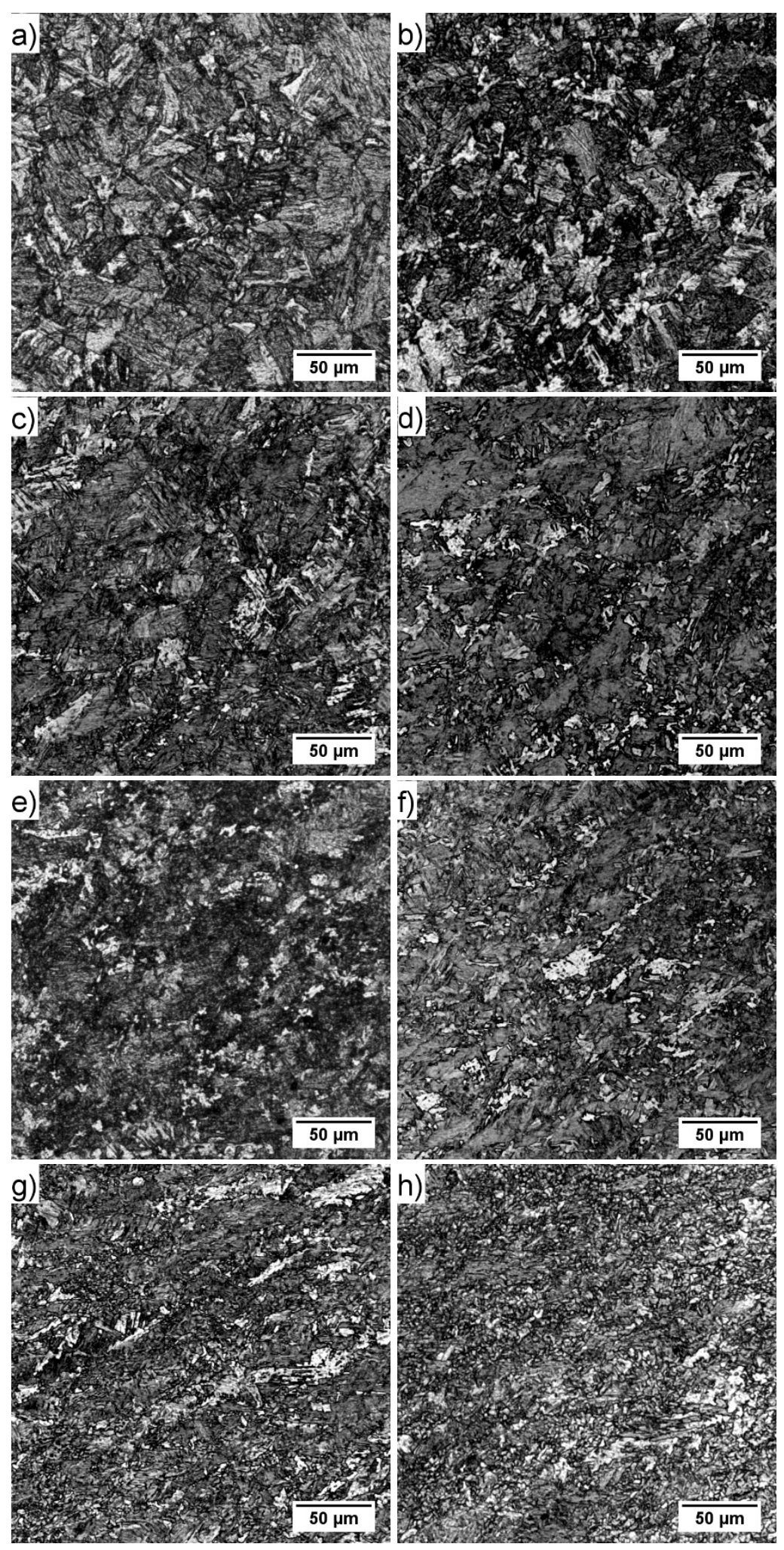

Figure 3.4: Optical micrographs of the deformed samples with the interpass time of $20 \mathrm{~s}$. The samples were quenched a) before the $1^{\text {st }}$ pass, b) after the $1^{\text {st }}$ pass, c) before the $3^{\text {rd }}$ pass, d) after the $3^{\text {rd }}$ pass, e) before the $5^{\text {th }}$ pass, f) after the $5^{\text {th }}$ pass, g) before the $7^{\text {th }}$ pass and $h$ ) after the $7^{\text {th }}$ pass. 
It can be seen that a small amount of ferrite is already present before the first pass (Figure 3a and 4a). This ferrite was formed during roughing and was retained to the beginning of the finishing passes. The amount of ferrite increases during each pass, for both interpass times, with a larger increase during the $7^{\text {th }}$ pass (compare for example Figures 3.3e and $\mathrm{f}$ with Figures $3.3 \mathrm{~g}$ and $\mathrm{h}$ and Figures 3.4e and $\mathrm{f}$ with Figures 3.4g and h). It can also be seen that an interpass time of $1 \mathrm{~s}$ produces more ferrite than an interpass time of $20 \mathrm{~s}$ (compare Figures 3.3h and 3.4h). This topic will be discussed further below. The DT ferrite is nucleated primarily at the austenite grain boundaries, as shown in the SEM image of Figure 3.5, but it can also nucleate within the austenite grains.

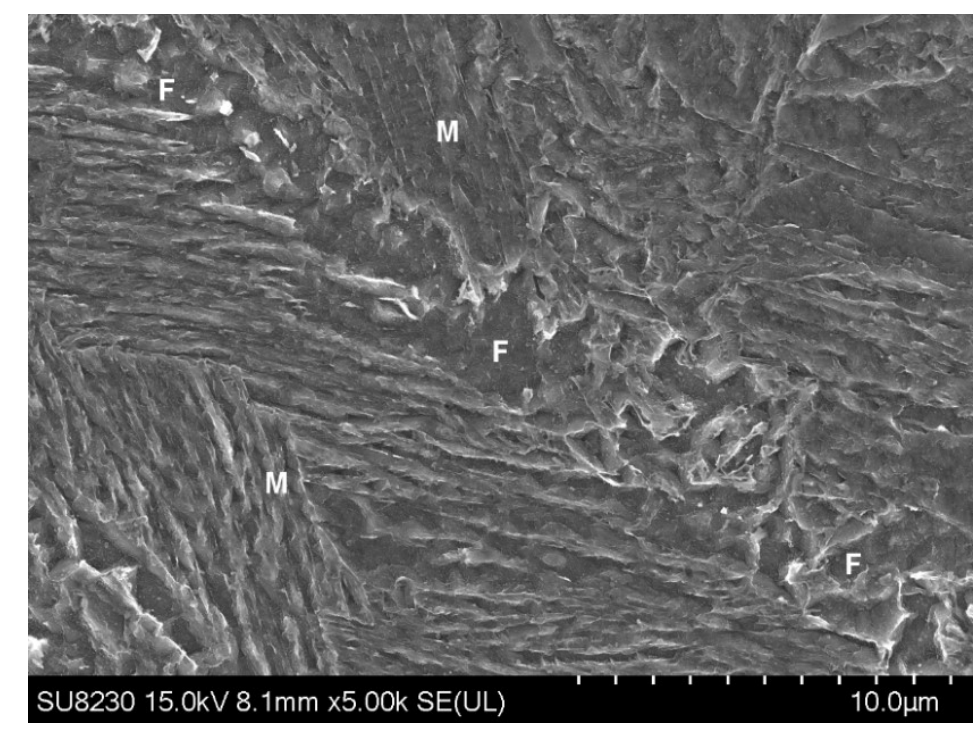

Figure 3.5: SEM image of the sample quenched after the $5^{\text {th }}$ pass when employing the interpass time of $1 \mathrm{~s}$, showing the nucleation of DT ferrite at the austenite grain boundaries. F represents the ferrite phase and $\mathrm{M}$ is martensite (prior austenite).

\subsection{Discussion}

\subsubsection{Mean Flow Stress}

The evolution of the mean flow stress (MFS) as a function of inverse absolute temperature for interpass times of 1,8 and $20 \mathrm{~s}$ is shown in Figure 3.6. For reference, the pass temperatures are 
also shown and the $\mathrm{Ae}_{3}$ orthoequilibrium temperature is represented by the vertical broken line. The MFS was computed by integrating the area under the stress-strain curves of Figure 3.2 and then normalizing by the corresponding strain of the given pass, according to Equation 3.1.

$$
\operatorname{MFS}=\frac{1}{\varepsilon_{\mathrm{f}}-\varepsilon_{\mathrm{i}}} \int_{\varepsilon_{\mathrm{i}}}^{\varepsilon_{\mathrm{f}}} \sigma \mathrm{d} \varepsilon
$$

Here $\varepsilon_{\mathrm{i}}$ and $\varepsilon_{\mathrm{f}}$ are the start and end of the strain interval pertaining to a given pass, respectively, and $\sigma$ is the equivalent stress.

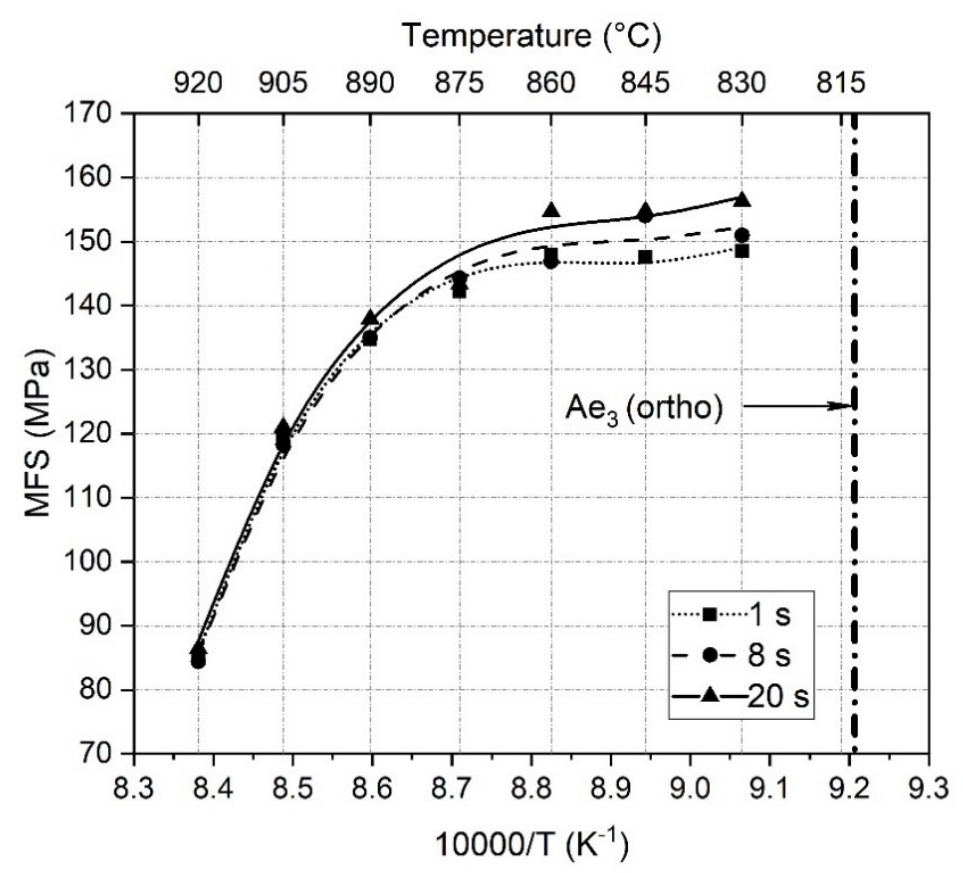

Figure 3.6: MFS's curves obtained from the stress-strain curves of Figure 2. The decrease in the slope of the MFS is evidence of the formation of DT ferrite.

The rate of increase of MFS decreases with successive passes under continuous cooling conditions. From the first to the second pass, there is a sharp increase in MFS (average of $40 \%$ for all interpass times) due to strain accumulation. From the second to the third pass, this increase falls to $14 \%$ and there is no increase in MFS from the sixth to the seventh pass. This decrease in the slope of the MFS curve is an indication of the formation of DT ferrite, which is softer than austenite, as shown in the micrographs of Figures 3.3 and 3.4. It should also be noted that shorter interpass times result 
in lower MFS values because smaller amounts of ferrite retransform into austenite since the reverse transformation takes place through a diffusional mechanism.

\subsubsection{Critical Strain for the initiation of dynamic transformation}

The critical strains for the onset of DT and dynamic recrystallization (DRX) were determined by the double differentiation method. This was originally developed to detect the critical strain for DRX and is employed here to determine the onset of DT [3.20,3.21]. This method is exhibited in Figure 3.7. First, the portions of the flow curves of Figure 2 from the yield stress up to the peak stress were fitted to a $10^{\text {th }}$ order polynomial using the MATLAB ${ }^{\circledR}$ software, as shown in Figure 3.7a. For more complex cases, higher-order polynomials were employed. Then, the strain hardening rate $(\theta)$, as defined by Equation 3.2, was plotted as a function of the stress $(\sigma)$ and the onsets of DT and DRX associated with inflection points of this curve (Figure 3.7b) were also determined. The two minima of Figure 3.7c correspond to the critical stresses for DT and DRX, respectively [3.21]. With these critical stress values, one can determine the critical strains for the onset of DT and DRX.

$$
\theta=\left(\frac{\partial \sigma}{\partial \varepsilon}\right)_{\dot{\varepsilon}}
$$

As mentioned earlier, the flow curves of Figure 3.2 were obtained from the torque-twist data by employing the Fields and Backofen equation [3.18]. This equation involves the coefficients M and $\mathrm{N}$ that specify the logarithmic dependences of the torque on twist and twist rate, respectively. In general, average values for these coefficients are used when computing the stress-strain curves during torsion testing. However, in the present case, the use of the average values led to overestimation of the critical strains for DT and DRX [3.22]. Therefore, instantaneous values of these coefficients were employed here.

The method described above was employed to calculate the critical strains for DT and DRX for the seven passes and the three conditions investigated, as shown in Figure 8. For all interpass times, 
the critical strains for DT and DRX are higher for the first pass. In the first pass, the austenite grains are fully recrystallized after the long holding time at high temperature after the roughing passes. This accounts for the high critical strain values. A peak in the critical strains is also observed in the $4^{\text {th }}$ pass for all conditions. It appears that static recrystallization takes place from pass to pass, decreasing the amount of retained strain. At the $4^{\text {th }}$ pass, the retained strain is so low that it is necessary to accumulate more strain in order to initiate both DT and DRX, causing an increase in the critical strain.

a)

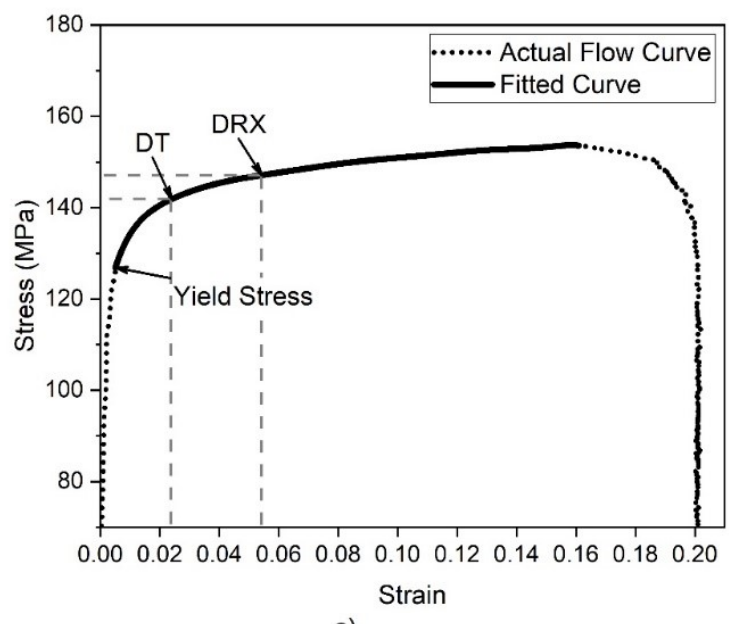

c) b)

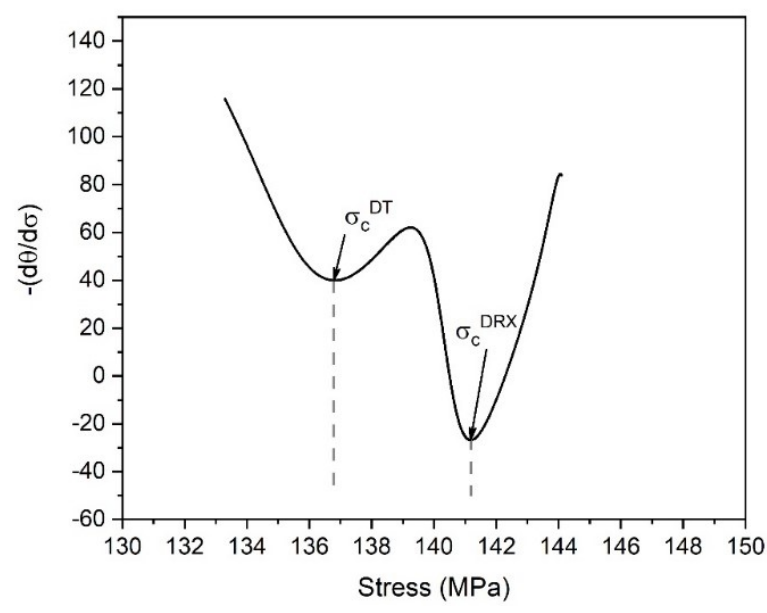

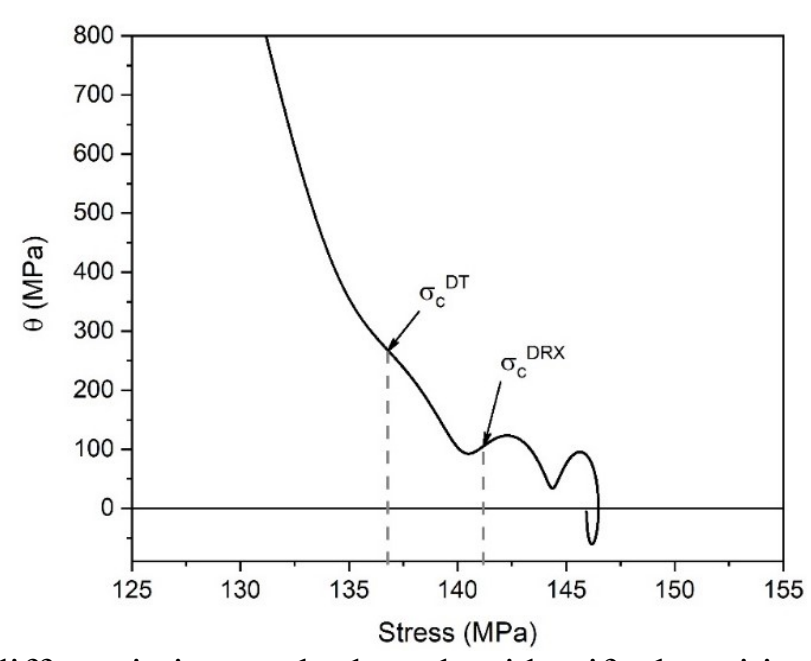

Figure 3.7: The double differentiation method used to identify the critical strains for the onset of DT and DRX of the $5^{\text {th }}$ pass with the interpass time of $1 \mathrm{~s}$. a) Actual flow curve and polynomial fit from the yield stress up to the peak. b) $\theta-\sigma$ plot with the two inflection points related to the critical stresses for DT and DRX identified. c) Plot of the derivative of $\theta$ against $\sigma$, with the two minima corresponding to the critical stresses. 
a)

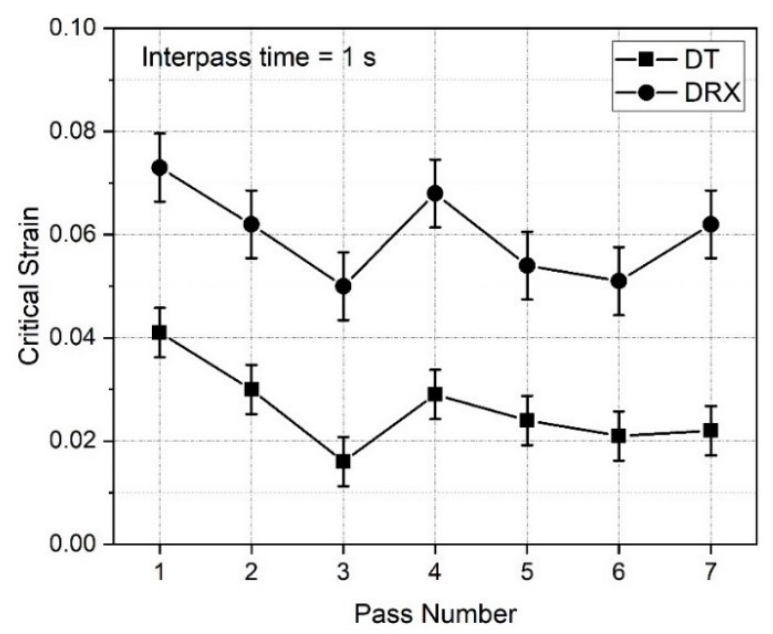

b)

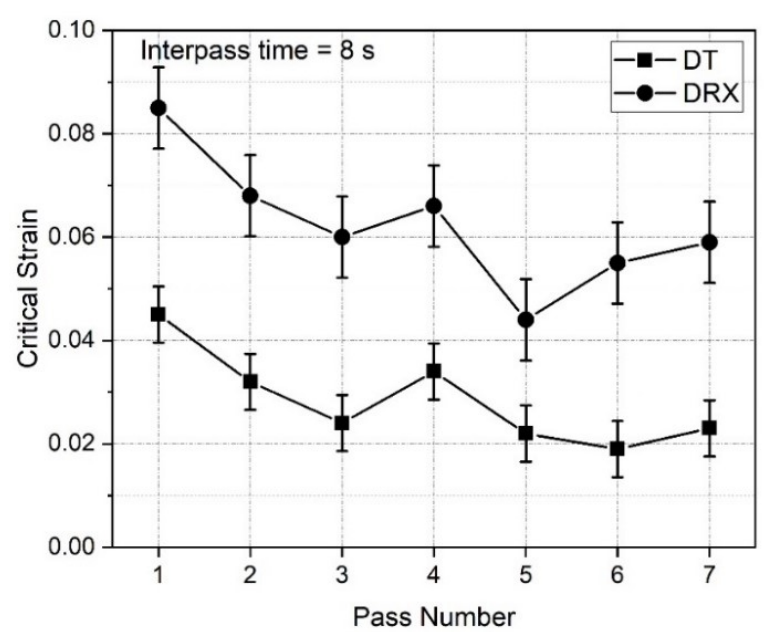

c)

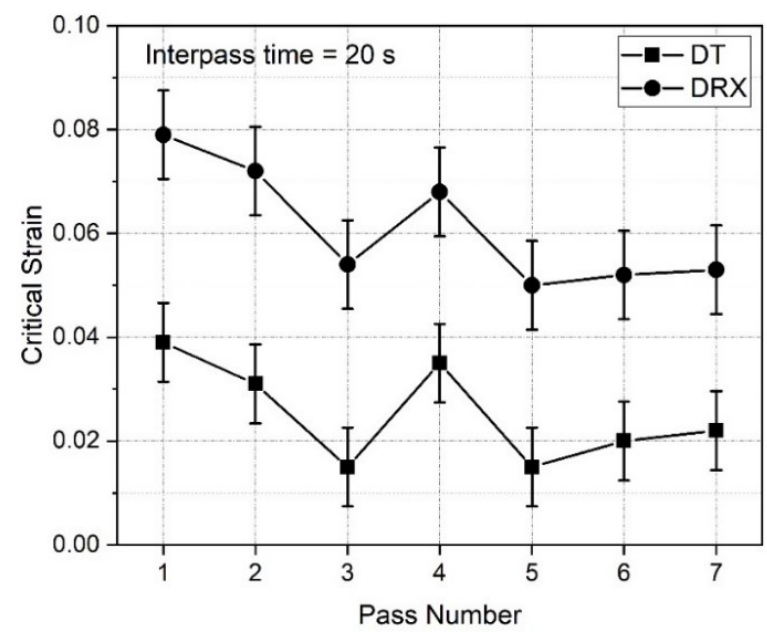

Figure 3.8: Critical strains for the onset of DT and DRX. Interpass times of a) $1 \mathrm{~s}$, b) $8 \mathrm{~s}$ and c) $20 \mathrm{~s}$.

\subsubsection{Ferrite Volume Fractions}

The volume fractions of ferrite present before and after the odd-numbered passes are shown in Figure 3.9 for interpass times of 1,8 and $20 \mathrm{~s}$. The cumulative strains and deformation temperatures are also shown. The ferrite formed during roughing and retained until the beginning of finishing corresponds to about $7 \%$ volume fraction. It can be seen that the amount of ferrite formed during a deformation pass increases as the cumulative strain increases, for all interpass times, due to the strain induced nature of DT. In addition, the temperature decreases and 
approaches the equilibrium transformation temperature, which decreases the energy barrier and facilitates the occurrence of DT. It should also be noted that the amount of ferrite formed and retained decreases at longer interpass times. After the $7^{\text {th }}$ pass, the ferrite volume fractions were $23 \%, 19 \%$ and $15 \%$ for interpass times of 1,8 and $20 \mathrm{~s}$, respectively. When longer interpass times are employed, there is considerably more retransformation, which occurs by a diffusional mechanism, and also more static recrystallization between passes, which reduces the dislocation density.

a)

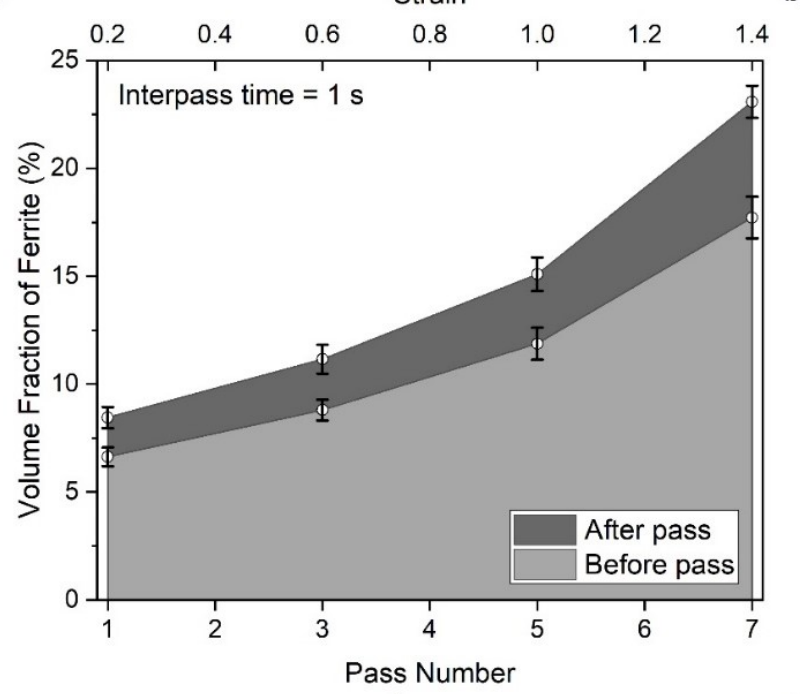

b)

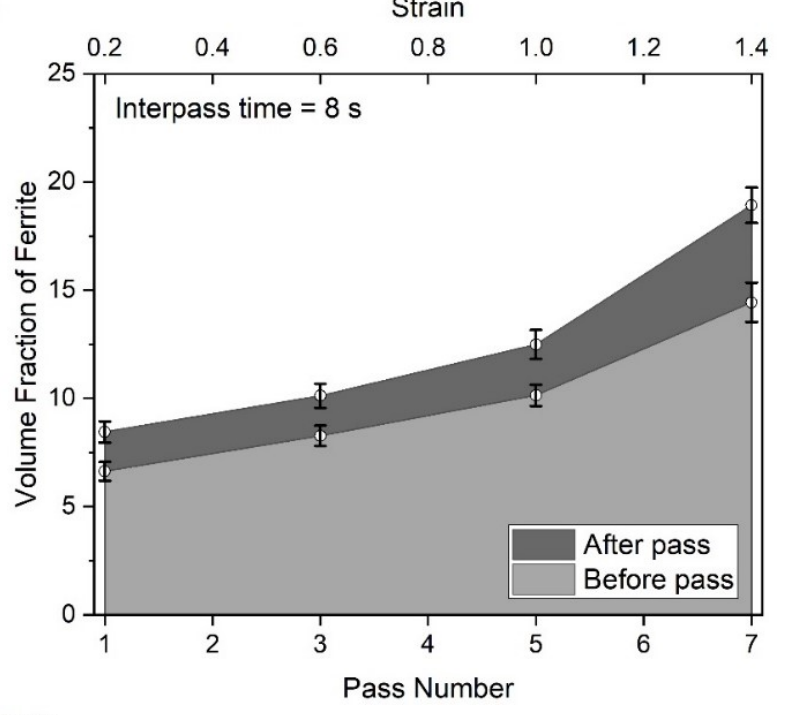

c)

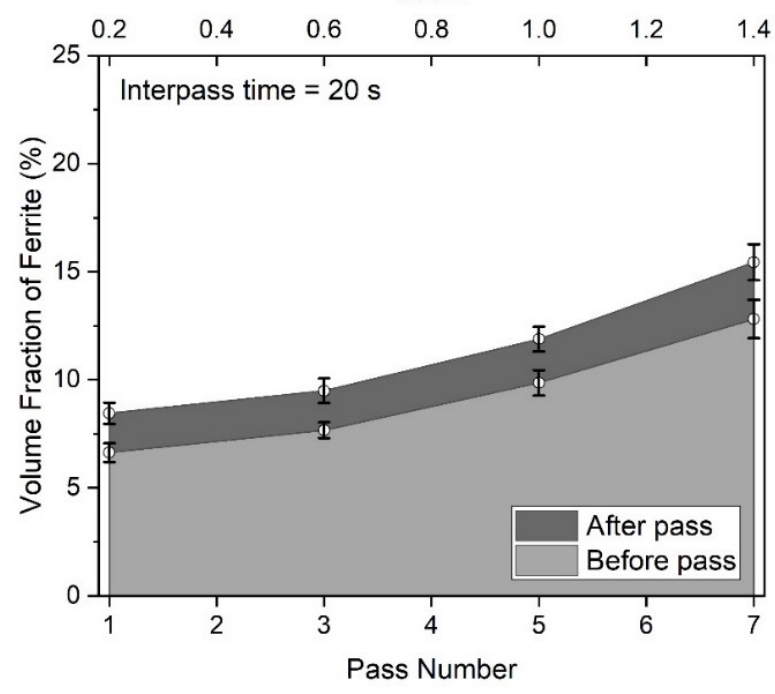

Figure 3.9: Dependence of the volume fraction of ferrite on the cumulative strain obtained for interpass times of a) $1 \mathrm{~s}$, b) $8 \mathrm{~s}$ and c) $20 \mathrm{~s}$. 


\subsubsection{Thermodynamics of Dynamic Transformation}

The driving force for DT is given by the difference between the flow stress of deformed austenite at the critical strain for DT and the flow stress of the freshly formed Widmanstätten ferrite [3.23]. The flow stress of austenite at the critical strain was considered here as the critical stress determined by the double differentiation method, as described in Figure 7. The yield stress of Widmanstätten ferrite was estimated by considering that this stress is $18 \%$ higher than that of polygonal ferrite [3.23]. This was in turn predicted at each pass temperature using the High Temperature Strength module of the JMatPro ${ }^{\circledR}$ software. This software calculates the flow stress of the material (or phase) at a given temperature, strain and strain rate by considering if the deformation mechanism is dominated by dislocation glide or dominated by dislocation climb under these conditions [3.24,3.25]. An alternative approach to evaluate the yield stress of polygonal ferrite is the one employed by Aranas Jr. et al [3.23,3.26]. In this method, the yield stress of polygonal ferrite at temperatures below the $\mathrm{Ae}_{1}$ is obtained from experimental curves. Then, these values are plotted against the inverse of the absolute temperature and, assuming a linear behavior based on the exponential stress law for creep, the yield stress can be estimated by extrapolating to higher temperatures.

The austenite flow stresses and the polygonal and Widmanstätten ferrite yield stresses at each finishing pass are illustrated in Figure 3.10 for an interpass time of $1 \mathrm{~s}$. The pass temperatures are also shown. Since the difference in the behavior of the critical strain when comparing different interpass times is not pronounced, as can be noted in Figure 8, the thermodynamic calculations are only shown here only for one condition. In the graph, the driving force at each pass is given by the vertical distance between the austenite flow stress at the critical strain for DT and the Widmanstätten ferrite yield stress. 


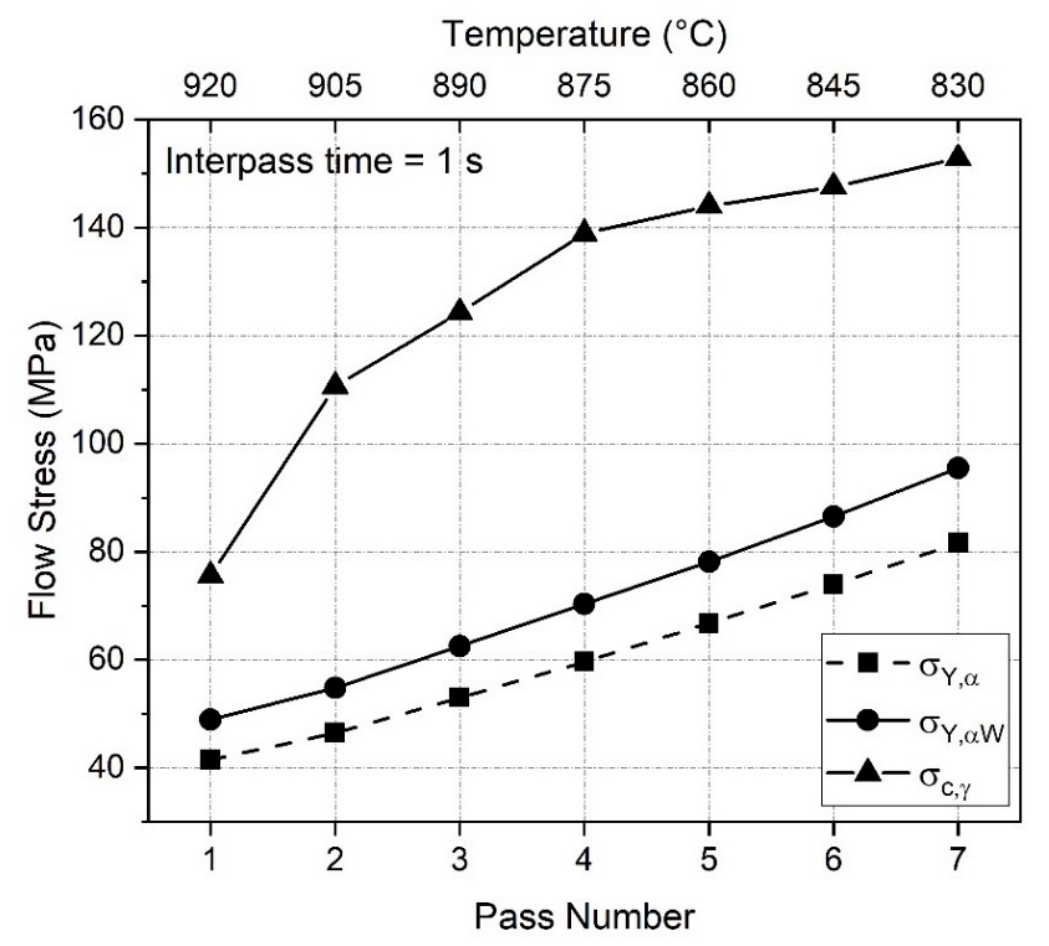

Figure 3.10: Driving force calculation at each pass when employing the interpass time of $1 \mathrm{~s}$. The driving force is given by the difference between the austenite flow stress at the critical strain and the Widmanstätten ferrite yield stress, which is $18 \%$ higher than the polygonal ferrite yield stress.

The total energy barrier (TEB) opposing to the driving force can be expressed as [3.23]:

$$
\mathrm{TEB}=\Delta \mathrm{G}_{\gamma \rightarrow \alpha}+\mathrm{W}_{\mathrm{SA}}+\mathrm{W}_{\mathrm{D}}
$$

where $\Delta \mathrm{G}_{\gamma-\alpha}$ is the chemical free energy barrier, $\mathrm{W}_{\mathrm{SA}}$ is the shear accommodation work, and $\mathrm{W}_{\mathrm{D}}$ is the dilatation work.

The chemical free energy barrier, i.e., the Gibbs energy difference between austenite and ferrite $\left(\Delta \mathrm{G}_{\gamma-\alpha}\right)$ was determined using the JMatPro ${ }^{\circledR}$ software. This Gibbs energy difference equals zero at the $\mathrm{Ae}_{3}$ temperature and increases with temperature until it reaches a maximum of $152.9 \mathrm{~J} \mathrm{~mol}^{-1}$ at $1080{ }^{\circ} \mathrm{C}$, when it starts to decrease with further increase in temperature as it approaches the delta ferrite phase field. 
It was assumed that the transformation of austenite into Widmanstätten ferrite implies a shear strain in the austenite lattice of 0.36 and a dilatation of $3 \%$ [3.27]. The work done per unit volume to accommodate the shearing process $\left(\mathrm{W}_{\mathrm{SA}}\right)$ can be calculated by the following equation [3.28]:

$$
\mathrm{W}_{\mathrm{SA}}=\mathrm{m} \times \sigma_{\mathrm{c}, \gamma} \times \gamma
$$

where $\sigma_{c, \gamma}$ is the austenite flow stress at the critical strain for each pass (critical stress), $\gamma=0.36$ is the shear strain, and $\mathrm{m}$ is the Schmid factor. The habit plane of the transformation of austenite into Widmanstätten ferrite in low alloy steels is $(0.506,0.452,0.735)$, and the shear direction is $[-0.867,0.414,0.277][3.27]$. On the assumption that these parameters are still valid for the steel used in this study and that the shear accommodation work takes place in the shear direction and along the habit plane, the Schmid factor works out to be $\mathrm{m}=0.334$ [3.28].

The dilatation work per unit volume $\left(\mathrm{W}_{\mathrm{D}}\right)$ can be estimated employing the following equation [3.28]:

$$
\mathrm{W}_{\mathrm{D}}=\lambda \times \sigma_{\mathrm{c}, \gamma} \times \varepsilon
$$

Here $\sigma_{c, \gamma}$ is the critical stress for DT, $\varepsilon=0.03$ is the dilatation strain, and $\lambda=\sqrt{\mathrm{m}}=0.578$ is the orientation factor for $\mathrm{m}=0.334$.

The driving force and energy barriers obtained for the seven finishing passes when employing $1 \mathrm{~s}$ of interpass time are shown in Figure 3.11. The driving force and the work done per unit volume has been converted into $\mathrm{J} \mathrm{mol}^{-1}$ by applying the conversion factor $1 \mathrm{MPa}=7.2 \mathrm{~J} \mathrm{~mol}^{-1}$. The driving force for DT, associated with the softening provided by the formation of ferrite, is higher than the total energy barrier for all passes, which indicates that the formation of ferrite through a displacive mechanism during deformation is thermodynamically possible. For the first pass, the driving force 
is only slightly higher than the total energy barrier. Thus, only those austenite grains that are most favorably oriented with respect to the applied stress will transform dynamically into ferrite during the first pass.

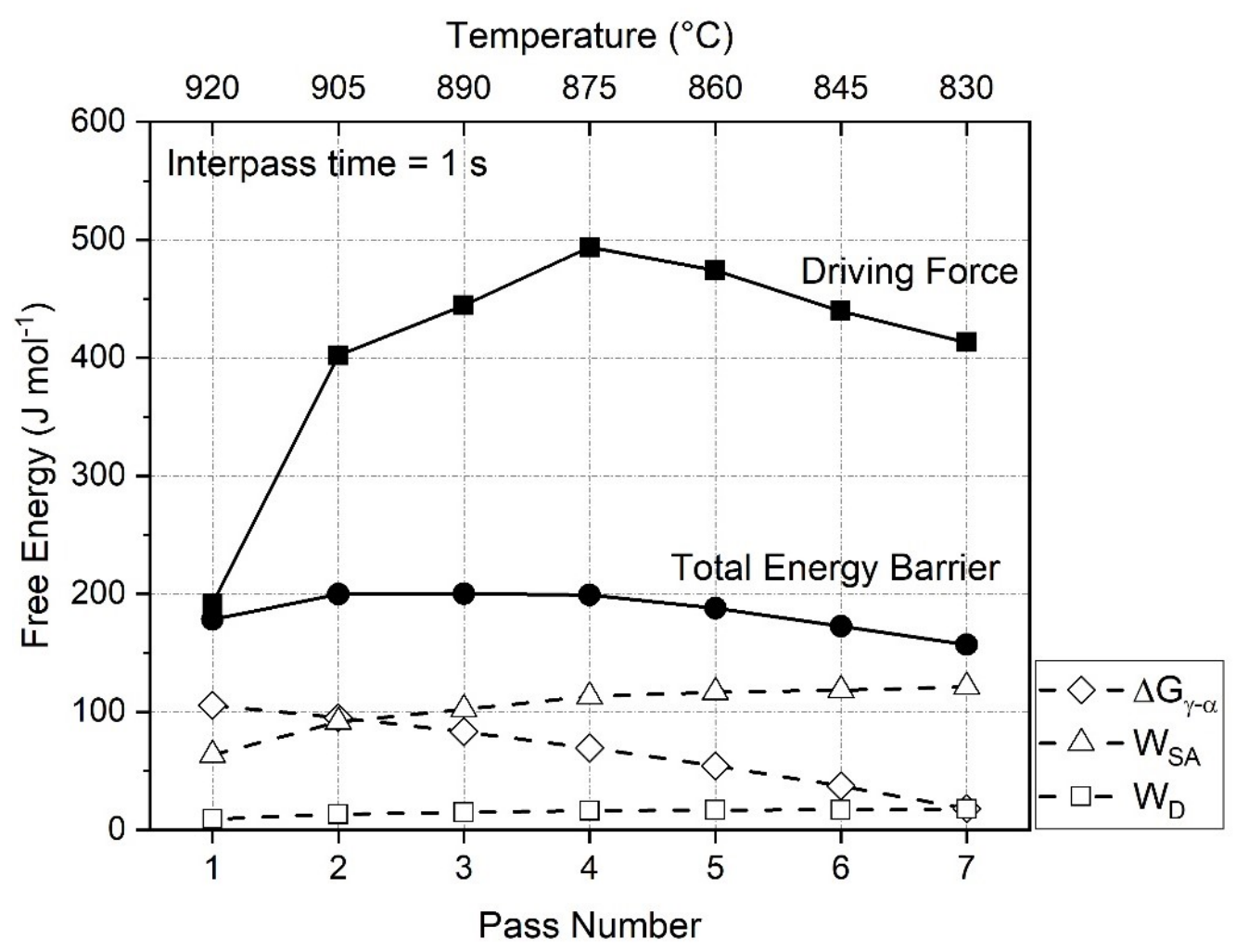

Figure 3.11: Driving force and total energy barrier obtained for each finishing pass with $1 \mathrm{~s}$ of interpass time. The total energy barrier is composed by the Gibbs free energy difference between austenite and ferrite $\left(\Delta \mathrm{G}_{\gamma-\alpha}\right)$, and the work due to shear accommodation $\left(\mathrm{W}_{\mathrm{SA}}\right)$ and dilatation $\left(\mathrm{W}_{\mathrm{D}}\right)$ that arise from the transformation.

\subsection{Conclusions}

The occurrence of DT above the $\mathrm{Ae}_{3}$ temperature of an API -X80 steel was investigated through torsion testing under continuous cooling conditions. Three different interpass times were investigated in this study. The following conclusions can be drawn: 
1. The increase in flow stress is less than expected for all interpass times. Also, the rate of increase of MFS is less. These observations indicate that austenite can transform dynamically into ferrite above the transformation temperature since ferrite is softer than austenite.

2. During longer interpass times, more ferrite transforms back into austenite through a diffusional mechanism, resulting in higher MFS values.

3. The critical strains for the onset of DT and DRX were determined by the double differentiation method. The first pass exhibited higher critical strains because the austenite grains are completely recrystallized due to the long holding times at high temperature after the roughing passes.

4. The volume fraction of dynamically formed and retained ferrite increases with the cumulative strain. The volume fraction of retained ferrite is lower for longer interpass times due to the reverse transformation during holding.

5. Analysis of the driving forces and energy barriers shows that it is thermodynamically possible for austenite to dynamically transform into ferrite above the $\mathrm{Ae}_{3}$ temperature. During the first pass, only the most favorably oriented austenite grains can transform dynamically.

\subsection{Acknowledgments}

The authors acknowledge with gratitude funding received from the Natural Sciences and Engineering Research Council of Canada (NSERC). B. G. is grateful to the Engineering Faculty for a McGill Engineering Doctoral Award (MEDA). 


\subsection{References}

[3.1] Y. Matsumara and H. Yada, "Evolution of ultrafine-grained ferrite in hot successive deformation”, Trans. Iron Steel Inst. Jpn., vol. 27, pp. 492-498, 1987.

[3.2] H. Yada, Y. Matsumara and T. Senuma, "A new thermomechanical heat treatment for grain refining in low carbon steels", in Proc. Int. Conf. Physical Metallurgy of Thermomech. Process. Steels Other Metals, THERMEC-88, 1988, pp. 200-207.

[3.3] H. Yada, C. M. Li and H. Yamagata, "Dynamic $\gamma \rightarrow \alpha$ transformation during hot deformation in iron-nickel-carbon alloys", ISIJ Int., vol. 40, pp. 200-206, 2000.

[3.4] Y. Chen and Q. A. Chen, "Dilatometric investigation on isothermal transformation after hot deformation", J. Iron Steel Res. Int., vol. 10, pp. 46 48, 2003.

[3.5] Z. Liu, D. Li, S. Lu and G. Qiao, “Thermal stability of high temperature deformation induced ferrite in low carbon steel”, ISIJ Int., vol. 47, pp. 289-293, 2007.

[3.6] X. Sun, H. Luo, H. Dong, Q. Liu and Y. Weng, "Microstructural evolution and kinetics for post-dynamic transformation in a plain low carbon steel”, ISIJ Int., vol. 48, pp. 994-1000, 2008. [3.7] V. Basabe and J. J. Jonas, “The ferrite transformation in hot deformed $0.036 \% \mathrm{Nb}$ austenite at temperatures above the Ae3", ISIJ Int., vol. 50, pp. 1185-1192, 2010.

[3.8] C. Ghosh, V. V. Basabe, J. J. Jonas, Y. M. Kim, I. H. Jung and S. Yue, "The dynamic transformation of deformed austenite at temperatures above the Ae3", Acta Mater., vol. 61, pp. 2348-2362, 2013.

[3.9] R. Grewal, C. Aranas Jr., K. Chadha, D. Shahriari, M. Jahazi and J. J. Jonas, "Formation of Widmanstätten ferrite at very high temperatures in the austenite phase field", Acta Mater., vol. 109, pp. 23-31, 2016.

[3.10] V. Basabe, J. J. Jonas and C. Ghosh, "Formation of Widmanstätten ferrite in a 0.036\% Nb low carbon steel at temperatures above the Ae3", Steel Res. Int., vol. 85, pp. 8-15, 2014. 
[3.11] C. Ghosh, C. Aranas Jr. and J. J. Jonas, "Dynamic transformation of deformed austenite at temperatures above the Ae3”, Prog. Mater. Sci., vol. 82, pp. 151-233, 2016.

[3.12] S. F. Rodrigues, C. Aranas Jr., T. Wang, and J. J. Jonas, "Dynamic transformation of an X70 steel under plate rollong conditions”, ISIJ Int., vol. 57, pp. 162-169, 2017.

[3.13] S. F. Rodrigues, C. Aranas Jr., F. Siciliano, and J. J. Jonas, "Dynamic transformation during the simulation of plate rolling in an X70 steel”, Steel Res. Int,, vol. 88, pp. 1-9, 2017.

[3.14] S. F. Rodrigues, C. Aranas Jr., and J. J. Jonas, "Dynamic transformation during the simulated plate rolling of a $0.09 \% \mathrm{Nb}$ steel”, ISIJ Int., vol. 57, pp. 1102-1111, 2017.

[3.15] S. F. Rodrigues, C. Aranas Jr., and J. J. Jonas, "Retransformation behaviour of dynamically transformed ferrite during the simulated plate rolling of a low $\mathrm{C}$ and an X70 $\mathrm{Nb}$ steel", ISIJ Int., vol. 57, pp. 929-936, 2017.

[3.16] C. W. Bale et al., "FactSage thermomechanical software and databases, 2010-2016", CALPHAD: Comput. Coupling Phase Diagrams Thermochem., vol. 54, pp. 35-53, 2016.

[3.17] C. A. Schneider, W. S. Rasband, K. W. Eliceiri, "NIH Image to ImageJ: 25 years of image analysis", Nat. Methods, vol. 9, pp. 671-675, 2012.

[3.18] S. L. Semiatin and J. J. Jonas, "Torsion testing to assess bulk workability" in Handbook of Workability and Process Design, G. E. Dieter, H. A. Kuhn and S. L. Semiatin, Eds., Materials Park, USA: ASM International, 2003, ch. 8, pp. 86-121.

[3.19] J. J. Jonas, "Modelling the length changes that take place during torsion testing", Int. J. Mech. Sci., vol. 35, pp. 1065-1077, 1993.

[3.20] E. I. Poliak and J. J. Jonas, “A one-parameter approach to determining the critical conditions for the initiation of dynamic recrystallization”, Acta Mater., vol. 44, pp. 127-136, 1996.

[3.21] C. Ghosh, V. V. Basabe and J. J. Jonas, "Determination of the critical strains for the initiation of dynamic transformation and dynamic recrystallization in four steels of increasing carbon contents", Steel Res. Int, vol. 84, pp. 490-494, 2013. 
[3.22] J. J. Jonas, F. Montheillet, L. S. Toth and C. Gosh, "Effects of varying twist and twist rate sensitivities on the interpretation of torsion testing data”, Mater. Sci. Eng., A, vol. 591, pp. 9-17, 2014.

[3.23] C. Aranas Jr. and J. J. Jonas, "Effect of Mn and Si on the dynamic transformation of austenite above the Ae3 temperature", Acta Mater., vol. 82, pp. 1-10, 2015.

[3.24] J. P. Schillé, Z. Guo, N. Saunders, and A. P. Miodownik, "Modeling Phase Transformations and Material Properties Critical to Processing Simulation of Steels", Mater. Manuf. Processes, vol. 26, pp. 137-143, 2011.

[3.25] X. Li, A. P. Miodownik, and N. Saunders, "Simultaneous calculation of mechanical properties and phase equilibria", J. Phase Equilib., vol. 22, pp. 247-253, 2001.

[3.26] C. Aranas Jr, T. Nguyen-Minh, R. Grewal, and J. J. Jonas, "Flow Softening-based Formation of Widmanstätten Ferrite in a $0.06 \% \mathrm{C}$ Steel Deformed Above the Ae $\mathrm{A}_{3}$, ISIJ Int., vol. 55, pp. 300-307, 2015.

[3.27] H. K. D. H. Bhadeshia, "Material factors" in Handbook of Residual Stress and Deformation of Steel, G. Totten, M. Howes, T. Inoue, Eds., Materials Park, USA: ASM International, 2002, pp. $3-10$.

[3.28] J. J. Jonas ad C. Ghosh, "Role of mechanical activation in the dynamic transformation of austenite”, Acta Mater., vol. 61, pp. 6125-6131, 2013. 


\section{Chapter 4: SuMmary}

The dynamic transformation of austenite into ferrite during simulated hot rolling was studied in an API-X80 steel. For this purpose, the hot rolling process was simulated through torsion tests. Seven finishing passes were applied under continuous cooling conditions, with an interval of $15^{\circ} \mathrm{C}$ between passes. The deformation passes were carried out over the temperature range of 920 to $830^{\circ} \mathrm{C}$, all of which are above the equilibrium transformation temperature $\mathrm{Ae}_{3}$. Three different interpass times were investigated: 1,8 and $20 \mathrm{~s}$. Samples were water quenched before and after the odd-numbered passes and were examined using optical and scanning electron microscopy. The following conclusions were drawn:

- Optical micrographs revealed the presence of DT ferrite under all conditions evaluated. The volume fraction of ferrite increases with cumulative strain and is lower for longer interpass times due to the reverse transformation that takes place during holding. The SEM analysis showed that the DT ferrite is nucleated primarily at the austenite grain boundaries, but it can also nucleate within the austenite grains.

- The increase in flow stress is less than expected for all interpass times, which is evidence for the formation of DT ferrite since ferrite is softer than austenite. As a result, the rate of increase of MFS with strain is also less than expected. For longer interpass times, the MFS values are higher because more austenite transforms back into austenite.

- The double differentiation method was employed to determine the critical strains for the initiation of DT and DRX. The critical strains for the first pass are higher than in the subsequent passes because the austenite grains are completely recrystallized. 
- The energy barriers for DT and the driving force were calculated by considering that the softening resulting from transformation provides the energy to overcome the barriers. The results indicate that the occurrence of DT during hot rolling is thermodynamically possible. 